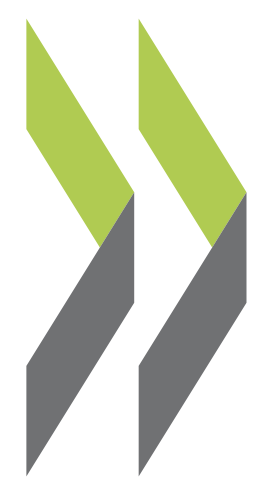

OECD Labour Market and Social Policy Occasional Papers No. 56

\title{
An Assessment of the Performance of the Japanese Health Care System
} Hyoung-Sun Jeong, Jeremy Hurst 
Organisation de Coopération et de Développement Economiques

Organisation for Economic Co-operation and Development

06-Dec-2001

DIRECTORATE FOR EDUCATION, EMPLOYMENT, LABOUR AND SOCIAL AFFAIRS

English text only EMPLOYMENT, LABOUR AND SOCIAL AFFAIRS COMMITTEE

LABOUR MARKET AND SOCIAL POLICY - OCCASIONAL PAPERS NO. 56

AN ASSESSMENT OF THE PERFORMANCE OF THE JAPANESE HEALTH CARE SYSTEM

Hyoung-Sun Jeong and Jeremy Hurst

JT00118112

Document complet disponible sur OLIS dans son format d'origine

Complete document available on OLIS in its original format 


\title{
DIRECTORATE FOR EDUCATION, EMPLOYMENT, LABOUR AND SOCIAL AFFAIRS
}

\section{OCCASIONAL PAPERS}

This series is designed to make available to a wider readership selected labour market and social policy studies prepared for use within the OECD. Authorship is usually collective, but principal writers are named. The papers are generally available only in their original language -- English or French -- with a summary in the other.

Comment on the series is welcome, and should be sent to the Directorate for Education, Employment, Labour and Social Affairs, 2, rue André-Pascal, 75775 PARIS CEDEX 16, France. Additional, limited copies are available on request.

The opinions expressed and arguments employed here are the responsibility of the author(s) and do not necessarily reflect those of the OECD

\author{
Applications for permission to reproduce or translate \\ all or part of this material should be made to: \\ Head of Publications Service \\ OECD \\ 2, rue André-Pascal \\ 75775 Paris, CEDEX 16 \\ France
}

Copyright OECD 2001 
DEELSA/ELSA/WD(2001)9

\section{ACKNOWLEDGEMENTS}

The authors of this paper wish to thank Odile Sallard, Peter Scherer and Séphane Jacobzone in the Directorate for Education, Employment, Labour and Social Affairs, and Yutaka Imai in the Economics Department for their valuable comments. 


\section{SUMMARY}

There is much interest in the Japanese health care system from the perspective of other OECD countries. The Japanese health care system appears to perform well. What explains this apparently good performance? This paper aims both to provide a description of how the Japanese health system works and an assessment of its performance in the context of an international comparison.

The Japanese health care system is characterised by public health insurance with mainly private providers. Japan has universal public health insurance with coverage of a comprehensive range of services and only modest cost sharing by patients. It has mainly private providers paid mainly by fee-for-service. The share of its population that is elderly is above the OECD average. Such a combination would usually be associated with high levels of health expenditure. Yet less is spent on health care in Japan than would be expected for an OECD country with its standard of living. Cost containment seems to have been achieved by a mix of controls.

With the exception of admission to hospital, the volume of health care is high - particularly in terms of consultations with doctors and the value of pharmaceutical consumption per capita. That is likely to be in part a response to the fee-for-service payment system. Physician numbers are relatively low compared with other OECD countries, which suggests that doctors offering ambulatory care are productive, at least in terms of volume of care.

It is difficult to judge the outcomes (including both responsiveness and health improvement) from the system. The evidence on the responsiveness of the system to consumers suggests that patients often wait some time to see a doctor at big hospitals and then receive only a short consultation and brief explanations. Although patients seem to be satisfied with the service they receive, that may be an indication of their low expectations rather than an indication that care is timely and of a high quality by international standards. To some extent, quality may be sacrificed at the expense of quantity. Evidence on health improvement - gains in health status strictly attributable to the health system - is scanty. Japanese health status is, in most respects, the highest observed among OECD countries but it is not clear to what extent this is due to the health system and to what extent due to other factors such as the Japanese culture, diet or social conditions. Scraps of evidence gathered for this study suggest that health improvement is indeed high in Japan.

In terms of equity, financing of health care seems to be mildly regressive - as in many other OECD countries. Access to health care, judging by geographical variations in need and in utilisation of services, appears to be quite equitable, although evidence is lacking on equity of access across income groups.

With a rapidly ageing population, reforms in recent years have focused on improving access to health and long term care services by the elderly and on shifting the balance of long term care away from hospitals towards nursing homes and domiciliary settings. These reforms seem to be a highly appropriate response to the challenge of ageing and are already showing signs of success, such as the beginning of a decline in length of stay in general hospitals.

This assessment confirms that there is much to interest other OECD countries in the Japanese health system. The system resembles those of Germany and France, yet, despite the handicap of an ageing population, there is at least a suggestion that it achieves higher health status than those countries and reasonable satisfaction among patients, with lower health expenditure and far fewer doctors per capita. In such respects it may offer bench marks to the rest of the OECD. 


\section{RÉSUMÉ}

Le système de santé du Japon suscite beaucoup d'intérêt de la part d'autres pays de l'OCDE. Le système de santé du Japon semble atteindre une performance remarquable. Quels sont les facteurs qui permettent d'expliquer cette dernière? Cet article vise à offrir une description de la façon dont le système de santé du Japon fonctionne et à évaluer sa performance exécution dans le contexte d'une comparaison internationale.

Le système de santé du Japon se caractérise par une assurance maladie publique et des offreurs de soins privés. La couverture maladie est universelle et offre une couverture large de services, avec seulement de modestes tickets modérateurs. Les offreurs privés sont payés principalement à l'acte. La part de sa population qui est âgée est au-dessus de la moyenne de l'OCDE. Une telle combinaison serait habituellement associée à des niveaux élevés de la dépense de santé. Pourtant le Japon dépense moins pour sa santé qu'il n'en serait attendu pour un pays de l'OCDE avec son niveau la vie. La retenue de coût semble avoir été réalisée par un mélange des commandes.

A l'exception de l'admission à l'hôpital, le volume de soins de santé est élevé - en particulier en termes de consultations avec des médecins et de valeur de consommation pharmaceutique per capita. Ceci est sans doute une réponse au système de paiement à l'acte. Le nombres de médecins est relativement bas comparés à d'autres pays de l'OCDE, ce qui suggère que les médecins offrant les soins ambulatoires sont productifs, au moins en termes de volume de soin.

Il est difficile de juger les résultats (en termes de réponse aux besoins et d'amélioration de la santé) du système. L'évidence sur la réponse du système aux consommateurs suggère que les patients attendent souvent un certain temps pour voir un médecin dans les grands hôpitaux, reçoivent ensuite une consultation courte et de brèves explications. Bien que des patients semblent être satisfaits du service qu'ils reçoivent, ceci peut être une indication de leurs basses espérances plutôt qu'une indication que le soin est délivré à temps et de haute qualité selon les normes internationales. Dans une certaine mesure, la qualité peut être sacrifiée aux dépens de la qualité. L'évidene sur l'amélioration de la santé - gains dans l'état de santé strictement attribuable au système de santé - est également mince. L'état de santé japonais est, à bien des égards, le plus haut parmi des pays de l'OCDE mais il n'est pas clair dans quelle mesure ceci est dû au système de santé et ou à d'autres facteurs tels que la culture japonaise, le régime ou les conditions sociales. Certains éléments suggèrent que l'amélioration de santé est notable au Japon.

En termes d'équité, le financement de la santé semble être modérément régressif - comme dans beaucoup d'autres pays de l'OCDE. L'accès à la santé, jugeant par des variations géographiques dans le besoin et de l'utilisation des services, semble être tout à fait équitable, bien que l'évidence manque au sujet d'autres dimensions de l'équité d'accès comme le revenu ou les catégories d'âge.

Avec un vieillissement rapide de la population, les réformes ces dernières années se sont concentrées sur l'amélioration de l'accès à la santé et aux soins à long terme pour les personnes âgées et sur le rééquilibrage de l'offre de soins dépendance, depuis les hôpitaux vers des maisons de repos et des services à domicile. Ces réformes semblent être une réponse fortement appropriée au défi du vieillissement et montrent déjà des signes de succès, tels que le début d'un déclin dans la longueur du séjour dans les hôpitaux généraux.

Cette évaluation confirme que le système de santé du Japon est peut être d'intérêt pour d'autres pays de l'OCDE. Le système ressemble à ceux de l'Allemagne et la France. Pourtant, en dépit du handicap que représente le vieillissement rapide de la population, les éléments suggèrent qu'il soit en mesure d'obtenir un état de santé plus élevé que ces pays et une satisfaction raisonnable des patients, avec des dépenses de santé inférieures et bien moins de médecins per capita. À quelques égards il peut offrir une référence pour le reste de l'OCDE. 


\section{TABLE OF CONTENTS}

SUMMARY

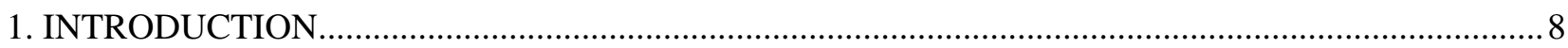

2. MAIN CHARACTERISTICS OF THE JAPANESE HEALTH CARE SYSTEM ................................. 9

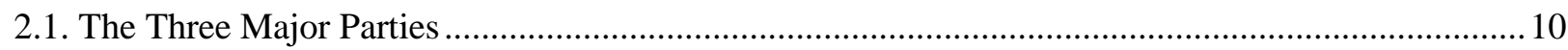

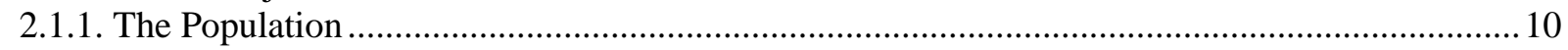

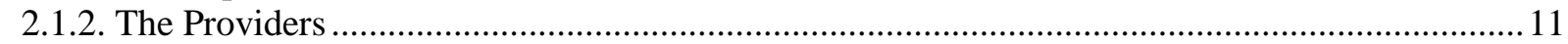

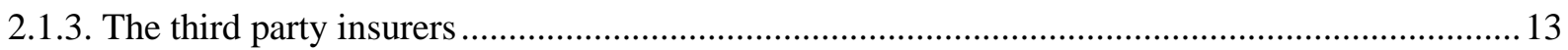

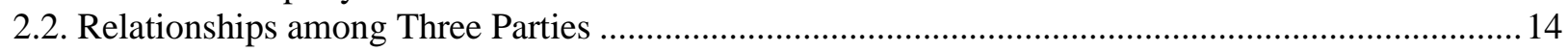

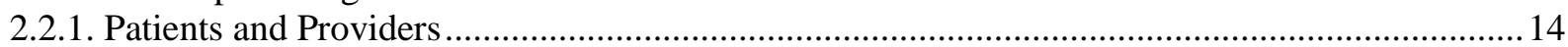

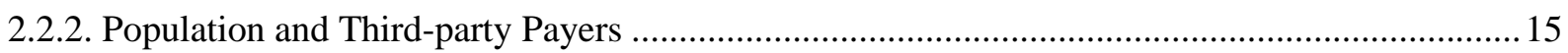

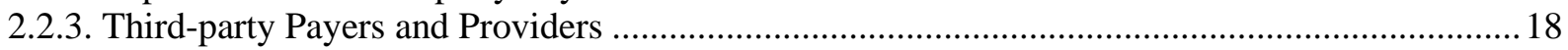

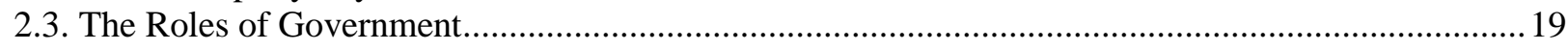

3. MONETARY AND REAL FLOWS IN THE JAPANESE HEALTH CARE SYSTEM .......................22

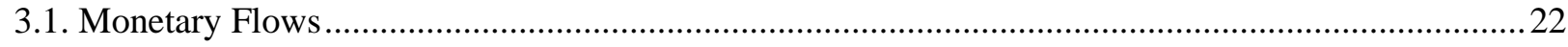

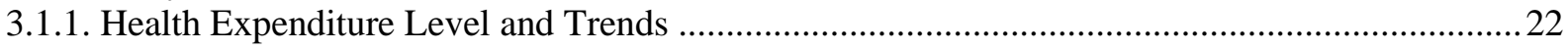

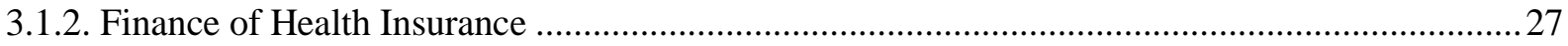

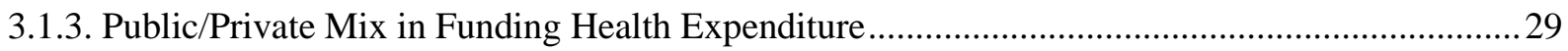

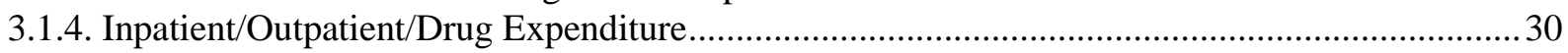

3.2. Real Flows

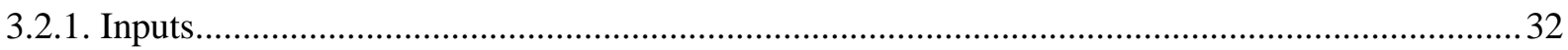

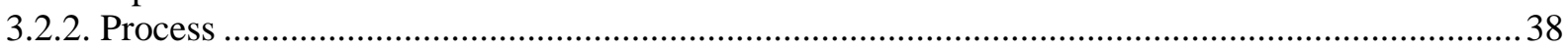

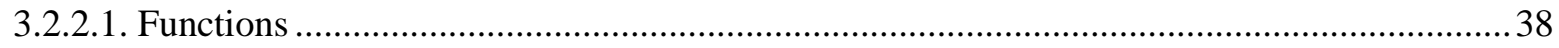

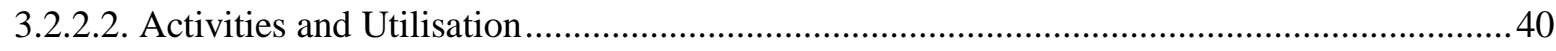

4. ASSESSMENT OF PERFORMANCE AND ITS DETERMINANTS .................................................4

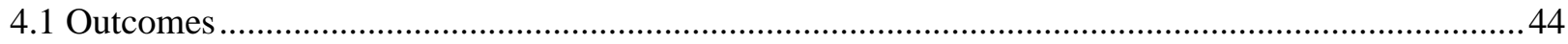

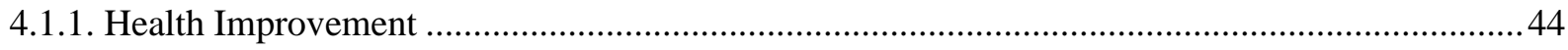

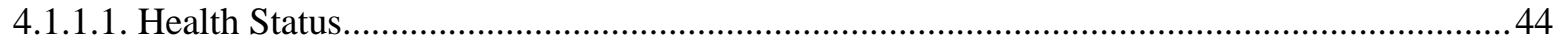

4.1.1.2. Health Outcomes Attributable to Health Care System..................................................... 47

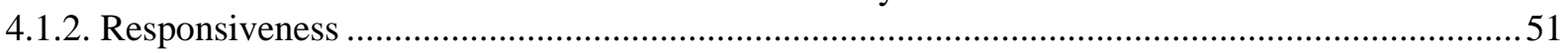

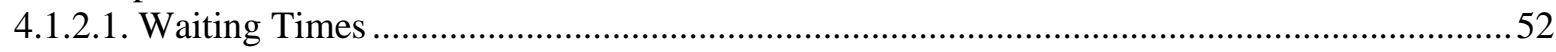

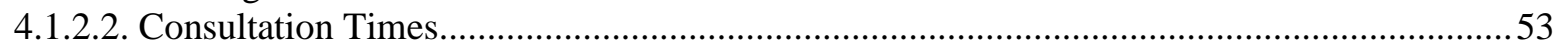

4.1.2.3. Doctor's Explanation and Medical Information for the Patient ..........................................54

4.1.2.4. Quality of 'Hotel' Care and Technology in Hospitals..........................................................55

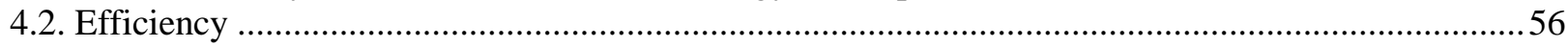

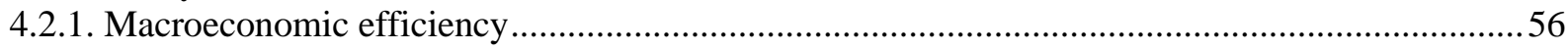

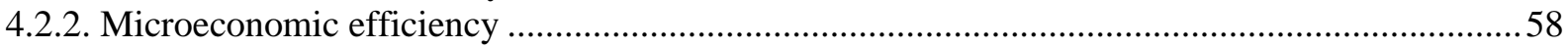




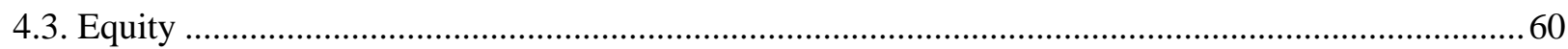

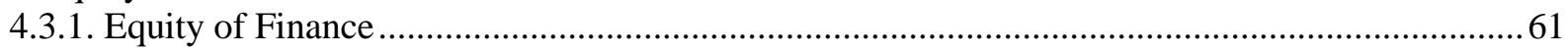

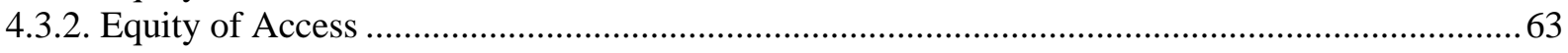

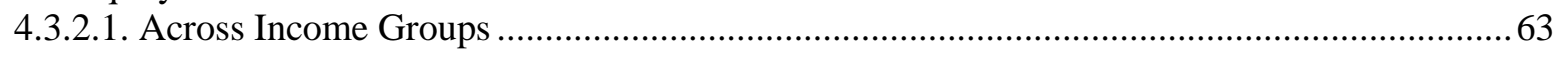

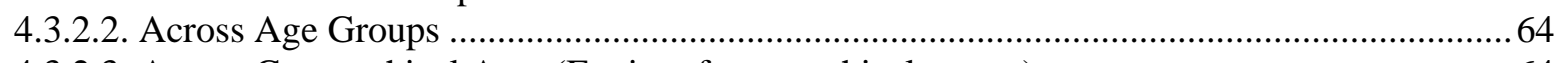

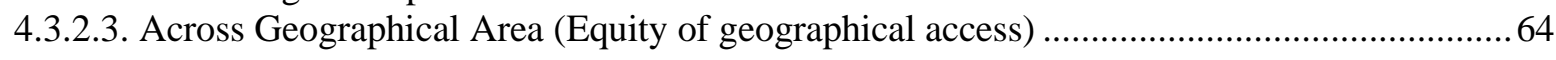

5. CONCLUSIONS AND SOME IDEAS ABOUT FUTURE REFORMS .............................................67

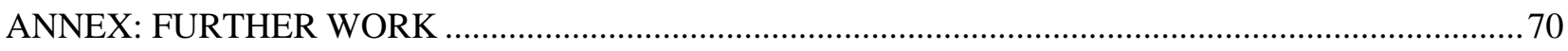

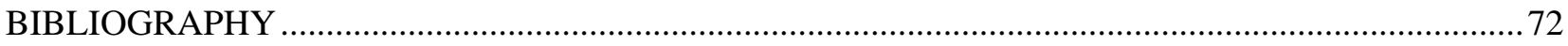

\section{Boxes}

Towards the separation between Prescribing and Dispensing of Drugs............................................... 15

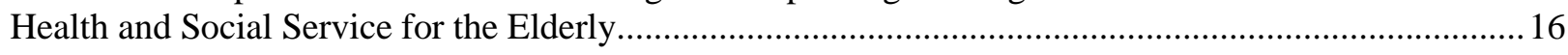

National Medical Expenditure and the Determinants of its Growth .....................................................24 


\section{NTRODUCTION}

1. There is much interest in the Japanese health care system from the perspective of other OECD countries. Japan has universal public health insurance with broad benefits and only modest cost sharing by patients. It has mainly private providers paid mainly by fee-for-service. The share of its population which is elderly is above the OECD average. Such a combination would usually be associated with high levels of health expenditure. Yet the share of health expenditure in Gross Domestic Product (GDP) in Japan was only $7.6 \%$ in 1998 - below the average (for 22 OECD countries) of $8.3 \%$. Moreover, on most measures Japan has the highest level of health status of any OECD country. Although there are, of course, other determinants of health status in Japan, such as standards of living, diet, and smoking habits, there is no obvious sign, here, that the health care system is ineffective - quite the opposite.

2. Hence, on the face of it, the Japanese health care system appears to perform remarkably well. Are there other, less well known aspects of performance, which might detract from such a preliminary assessment? What explains this apparently good performance?

3. This paper contains a detailed assessment of the Japanese health care system. It starts with a description of the characteristics of the system, which outlines the roles of the main actors in the system and the relationships between them. It continues with a chapter assembling evidence on the monetary and real flows through the system, with international comparisons. This is designed to examine two essentially economic characteristics of the system: i) the exchange of money for services; ii) the production 'function' which relates health care resources, through health care activity, to health status and patient satisfaction. That leads into a chapter that draws together an assessment of the overall performance of the system against efficiency and equity objectives and explores the determinants of performance. Here, an attempt is made to loop back to the description of the characteristics of the system - to show how the characteristics gave rise to the monetary and real flows which, in turn, give rise to the performance. Finally, there is an Annex containing suggestions about further work that might be done to evaluate the performance of the health care system in Japan.

4. This paper has been written mainly with the aim of obtaining a better understanding of the existing Japanese health system from the perspective of other OECD countries. It does not explore new and emerging challenges facing the system in Japan. Nor does it consider except briefly the case for major, long term reforms to the system. Further suggestions about future reforms to the Japanese health care system will be included in the forthcoming 2001 OECD Economic Survey of Japan. 
DEELSA/ELSA/WD(2001)9

\section{MAIN CHARACTERISTICS OF THE JAPANESE HEALTH CARE SYSTEM}

5. Modern health care in Japan started with the introduction of Western medicine after the Meiji Reform in 1867. Initially, most health care was provided privately. Public health care policies were initiated both to improve nutritional status for so-called "social defence" and to fight against acute communicable diseases ${ }^{1}$. In the decade after World War II, measures to prevent the spread of communicable disease became an urgent task because of massive outbreaks of infectious diseases in this period. Tuberculosis was brought under control with the help of streptomycin in the 1950s. Regular screening for Tuberculosis was expanded to all Japanese citizens, and BCG vaccinations were administered at public expense from the mid-1950s.

6. Public intervention on the demand side was centred upon public health insurance schemes. The first public health insurance scheme (EHI in section 2.1.3 The third party insurers) $)^{2}$ was introduced in enterprises with 10 employees or more in 1927 (the Health Insurance Act), and a regional health insurance scheme (NHI in section 2.1.3 The third party insurers $)^{3}$ was introduced to the self-employed on a voluntary basis in 1938 (the National Health Insurance Act). With the rapid economic growth in the 1950s, public health insurance coverage in population was extended to include the whole population by $1961^{4}$. The enlargement of the coverage in benefits continued in the 1960s and 1970s. In 1973, those aged 70 or over were exempted from payment for health services by the revision of the Elderly Welfare Act, and a cap was set on co-payments of all the Japanese. In 1983, the Health Service System for the Elderly (HSSE in Box 2) introduced moderate co-payments by the elderly and a system of transfers to correct the imbalances caused by the different share of elderly people between health insurers. In 1986, coverage was extended to intermediate nursing facilities for the elderly. In the 1990s, the main focus was on preparing the ground for the introduction of the Long-term Care Insurance System that started in April 2000. That extended insurance coverage for nursing homes and the supporting services for home care, and, for the first time, required contributions by the elderly themselves.

7. A variety of policy measures including minimum criteria of medical facilities were taken to rationalise the supply side in the Medical Service Act of 1948, which was subsequently amended four times. The first revision in 1985 introduced annual medical planning by each prefecture. The revisions in 1992, 1997 and 2000 were intended to reinforce the functional differentiation among medical institutions. In a separate process, the Health Service System for the Elderly introduced certain improvements in provision of health services for the elderly in the Elderly Health Act of 1982. In a revision of this Act, domiciliary nursing care support in the form of home-visit provided by nursing stations started in 1992 .

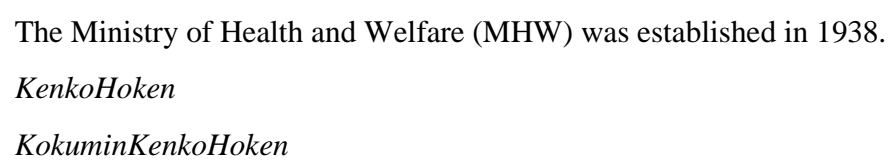

The Ministry of Health and Welfare (MHW) was established in 1938.

KenkoHoken

KokuminKenkoHoken

4. The number of those not covered by 1956, mainly the self-employed and farmers, was about 30 million. Coverage was gradually extended under a four-year expansion plan, with full coverage being achieved by 1961 . 


\subsection{The Three Major Parties}

8. Japan's health care system is characterised by private ownership on the supply side and mainly public finance on the demand side. It is mainly private providers that supply health services, although forprofit enterprises are prohibited from running hospitals. Purchasing of health services for the entire population is directly or indirectly under the control of the statutory and compulsory health insurance, and the insurers operate fairly passively under rules set by the government.

9. The following description of the Japanese health care system is organised around the three main actors in the system - the population/patients; the providers; and the 'third party' insurers - and the relationships between them. In terms of the models set out in OECD (1992), Japan's health care system is a "public contract model" where the (third party) health insurers are public and they have contractual relations with the private providers. Co-payments are quite modest, that is, patients pay very little "out-ofpocket" for health services. Chart 1 shows, in a simplified form, some of the main features of the organisation and financing of health care in Japan. Service flows are shown as broken lines and financial flows as solid lines.

Chart 1. Japanese health care system, early 2000

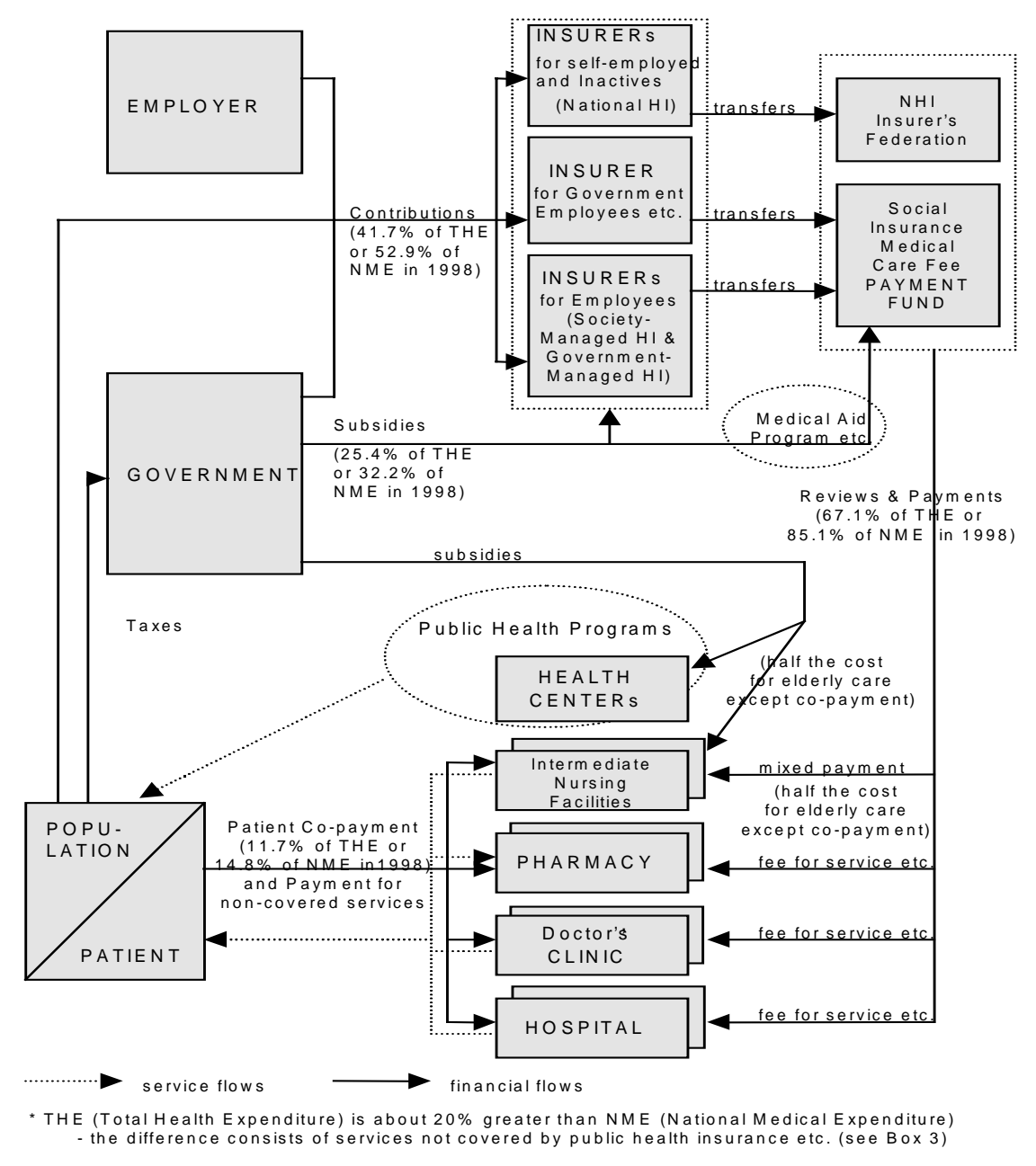




\subsubsection{The Population}

10. At the bottom left of Chart 1 is the population, the whole of which is covered by public health insurance. People pay for health care broadly in four ways: by health insurance contributions that constitute the largest source; by patient co-payments for the insured health services; by taxes that finance various public health programs and subsidies to health insurers; and by the out-of-pocket payments (mainly for non-covered health services and drugs). ${ }^{5}$

\subsubsection{The Providers}

11. At the bottom right of the diagram are the providers of health services, which are shown as multiple in the Chart 1 since there is usually a certain degree of competition within and, to some extent, between these groups of providers. They include: hospitals, many of which are private but not-for-profit in that they cannot distribute any financial surplus ${ }^{6}$; doctor's clinics ${ }^{7}$ that are usually managed by private feefor-service doctors in independent practice; health centres (641 managed by prefectures and 1909 managed by municipalities in 1999); and pharmacies $\left(42,412\right.$ in 1997) ${ }^{8}$. As shown in Table 1, all hospitals except mental and tuberculosis hospitals are classified as general hospitals. General hospitals can own beds earmarked for long-term care ${ }^{9}$ and some general hospitals are treated as special function hospitals for advanced medical care. Some geriatric hospitals ${ }^{10}$ were included among general hospitals. More than $70 \%$ of beds are found in private hospitals, which represent $80 \%$ of total hospitals in number. The top managers of hospitals are mandatorily required to have medical qualifications. The majority of hospital-based doctors are salaried employees. Hospitals are virtually all closed in the sense that doctors in doctor's clinics cannot treat their patients in hospitals. The relationship between doctor's clinics and hospitals is partly complementary and partly competitive. Both offer ambulatory care. A fifth of the doctor's clinics have beds, although the number of beds per doctor's clinic is as small as 12 on average. Some doctor's clinics are equipped with advanced diagnostic machines for investigating more complicated cases.

\footnotetext{
5 The shares of contributions, co-payments and taxes in the National Medical Expense (KokuminIryohi which excludes out-ofpocket payments for non-covered health services and drugs) were $52.9 \%, 14.9 \%$ and $32.2 \%$ in 1998, respectively. (see section 3.1.2. Finance of Health Insurance)

6 These are called IryoHojin, literally meaning 'medical legal person' or 'medical legal entity'.

7 Shinryozyo. A doctor's clinic is defined as a medical facility with less than 20 inpatient beds.

8 Certain other providers such as dentists and oriental medicine institutions have been omitted from the chart.

9 RyoyogataByoshogun

10. This classification disappeared under the revision of Medical Service Act in 2000.
} 
Table 1: Hospitals, doctor's clinics and intermediate nursing facilities in Japan, 1999

(According to type of facilities)

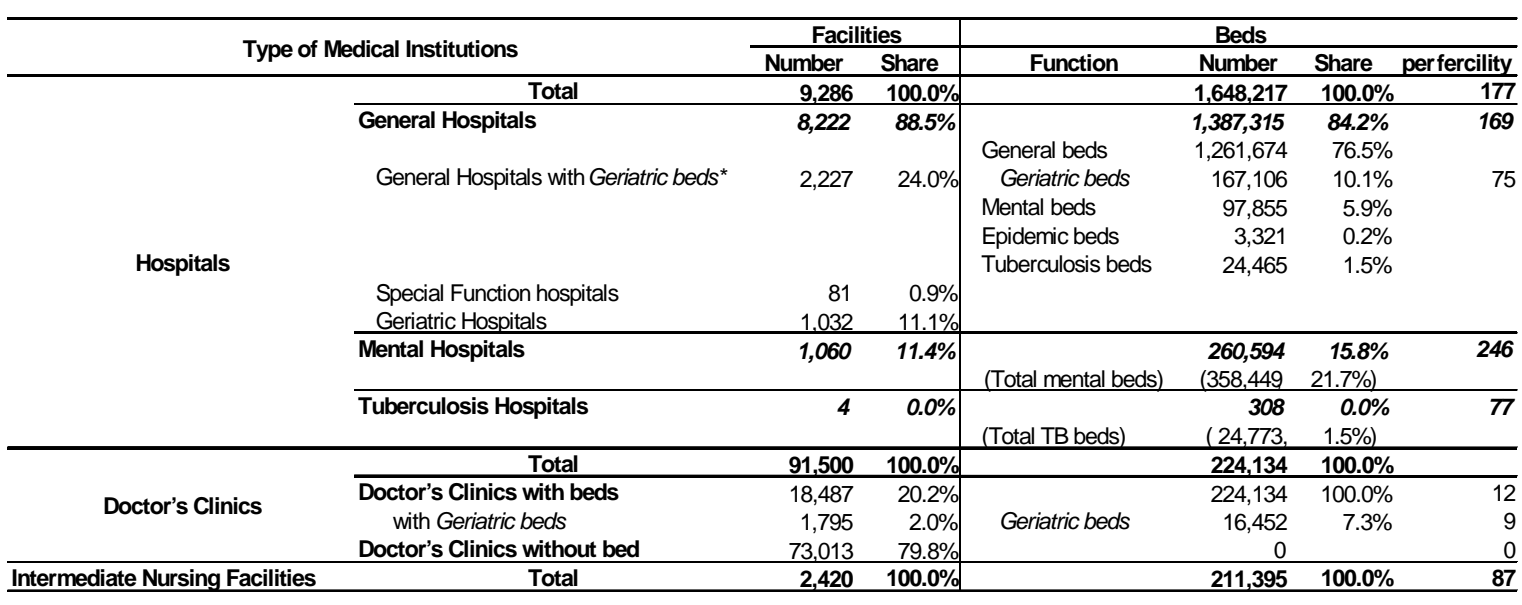

Source: Survey of Medical Institutions 1999

Survey on Intermediate Nursing Facilities 1999

* Geriatric beds indicate beds earmarked for long-term care( RoyyogataByoshogun)

${ }^{*}$ Changes in hospital and bed types by the revision of Medical Service Act at the end of the year 2000 are not reflected.

(According to ownership)

\begin{tabular}{|c|c|c|c|c|c|c|}
\hline $\begin{array}{l}\text { Type of Medical } \\
\text { Institutions }\end{array}$ & Ownership & Facilities & Share & Beds & Share & $\begin{array}{c}\text { Beds per } \\
\text { facility }\end{array}$ \\
\hline \multirow{10}{*}{ Hospitals } & Total & 9,286 & $100.0 \%$ & $1,648,217$ & $100.0 \%$ & 178 \\
\hline & Public & 1,869 & $20.1 \%$ & 541,783 & $32.9 \%$ & 290 \\
\hline & Central Government & 370 & $4.0 \%$ & 148,663 & $9.0 \%$ & 402 \\
\hline & Local Government or other Public & 1,368 & $14.7 \%$ & 354,577 & $21.5 \%$ & 259 \\
\hline & (Local Government) & $(1071$ & $11.5 \%$ & 253,391 & $15.4 \%$ & 237) \\
\hline & Social Insurance & 131 & $1.4 \%$ & 38543 & $2.3 \%$ & 294 \\
\hline & Private & 7,417 & $79.9 \%$ & $1,106,434$ & $67.1 \%$ & 149 \\
\hline & Iryo Hojin (Medical Legal Person) & 5,299 & $57.1 \%$ & 783,081 & $47.5 \%$ & 148 \\
\hline & Individual & 1,281 & $13.8 \%$ & 112,916 & $6.9 \%$ & 88 \\
\hline & Other Hojin (Other Legal Person) & 837 & $9.0 \%$ & 210,437 & $12.8 \%$ & 251 \\
\hline \multirow{9}{*}{ Doctor's Clinics } & Total & 91,500 & $100.0 \%$ & 224,134 & $100.0 \%$ & 12 \\
\hline & Public & 5,650 & $6.1 \%$ & 6,489 & $2.9 \%$ & \\
\hline & Central Government & 578 & $0.6 \%$ & 2,347 & $1.0 \%$ & 10 \\
\hline & Local Government or other Public & 4,224 & $4.6 \%$ & 4,104 & $1.8 \%$ & 10 \\
\hline & Social Insurance & 848 & $0.9 \%$ & 38 & $0.0 \%$ & 6 \\
\hline & Private & 85,850 & $93.8 \%$ & 217,645 & $97.1 \%$ & \\
\hline & Iryo Hojin (Medical Legal Person) & 22,680 & $24.8 \%$ & 94,989 & $42.4 \%$ & 14 \\
\hline & Individual & 53,973 & $59.0 \%$ & 120,392 & $53.7 \%$ & 11 \\
\hline & Other Hojin (Other Legal Person) & 9,197 & $10.1 \%$ & 2,264 & $1.0 \%$ & 11 \\
\hline \multirow{6}{*}{$\begin{array}{c}\text { Intermediate Nursing } \\
\text { Facilities }\end{array}$} & Total & 2,420 & $100.0 \%$ & 211,395 & $100.0 \%$ & 87 \\
\hline & Local Governments & 129 & $5.3 \%$ & 9,369 & $4.4 \%$ & 73 \\
\hline & Social Insurance etc. & 46 & $1.9 \%$ & 3,984 & $1.9 \%$ & 87 \\
\hline & Medical Legal Person & 1,780 & $73.6 \%$ & 155,923 & $73.8 \%$ & 88 \\
\hline & Social Welfare Legal Person & 380 & $15.7 \%$ & 34,389 & $16.3 \%$ & 90 \\
\hline & Others & 85 & $3.5 \%$ & 7,730 & $3.7 \%$ & 91 \\
\hline
\end{tabular}

Source: Survey of Medical Institutions 1999

Survey on Intermediate Nursing Facilities 1999

* Some figures are minutely changed on the basis of recent data provided by the Japanese government.

12. Apart from hospitals, there are intermediate nursing facilities ${ }^{11}$, which provide both nursing home and medical care for the aged population (see Table 1). There is also domiciliary support in the form of home-visit nursing cares provided by nursing stations (3,619 in 1999). In addition, special nursing

$11 \quad$ RojinHokenShisetsu, literally meaning health service facilities for the elderly 
homes $^{12}$ (4,214 in 1999) provide long-term care services for the aged that are eligible for social welfare services (see Box 2 in section 2.2.2. Population and Third-party Payers).

13. There is considerable self-regulation by professionals and providers. However, clinical guidelines remain underdeveloped because Japanese medical education is apprenticeship-oriented and idiosyncratic from one medical school to another. The networks of local hospitals affiliated to university clinical departments, where doctors do their graduate work, determine clinical practice rather than the networks of specialised colleagues across the nation (Campbell and Ikegami, 1998). Lacking standardisation makes "evidence-based medicine" difficult. The Japanese Council for Quality Health Care (JCQHC) $)^{13}$ was established in 1995 as an independent agency in order to evaluate the functions performed by hospitals. Participation by the hospitals is voluntary. The JCQHC has tried to focus on the process aspects of medical services as well as the structural aspects. It can issue a certificate of approval for a hospital that has been assessed as playing an appropriate role in the community and as achieving a certain quality of medical services. Transparency in the results is debatable. Hospitals can only say they went through such an evaluation and whether they passed or not. As of August 2001, 511 hospitals (about 6\% of total hospitals) had acquired the certificate.

\subsubsection{The third party insurers}

14. At the top of Chart 1 are the third party insurers, which collect contributions from both the population and employers, and pay the providers directly for services delivered. Health insurers are not shown here as multiple since there is little or no competition among them even though they are very numerous. Most of them are the quasi-autonomous, non-government bodies charged with operating the compulsory national health insurance scheme. However, they are to some degree regulated by both central and local governments in their carrying out of what is essentially a public function.

15. Japan's health insurance system is a complex arrangement born of its historical background (Ministry of Health, Labour and Welfare, 1999 a). There exist over five thousand health insurers, which can be classified broadly into three categories (see Chart 2). Firstly, National Health Insurance (hereafter, $N H I$ ) covers $36 \%$ of the population, mainly the inactive (including self-employed) and the elderly. Insurers are both local governments (hereafter, NHI municipalities) and occupation-based societies (hereafter, NHI societies). Secondly, Employees Health Insurance (EHI) covers employees. This is divided into two types: the Government-Managed Health Insurance (GMHI), managed by the Ministry of Health, Labour and Welfare $(M H L W)^{14}$, which covers employees of small and medium-sized enterprises $(30 \%$ of the population) and the Society-Managed Health Insurance (SMHI), which covers employees of large companies (26\% of the population). Thirdly, there are health insurers for those with special occupations, including civil servants and private school employees. The society for seamen is, however, managed by the $M H L W$.

\footnotetext{
TokubetsuYogoRojinHomu, literally meaning special long-term care elderly homes NihonIryoKinoHyokaKiko

14 This new Ministry, MHLW, was formed on 1 January 2001, incorporating the former ministries of Health and Welfare and of Labour (MHW and MOL).
} 


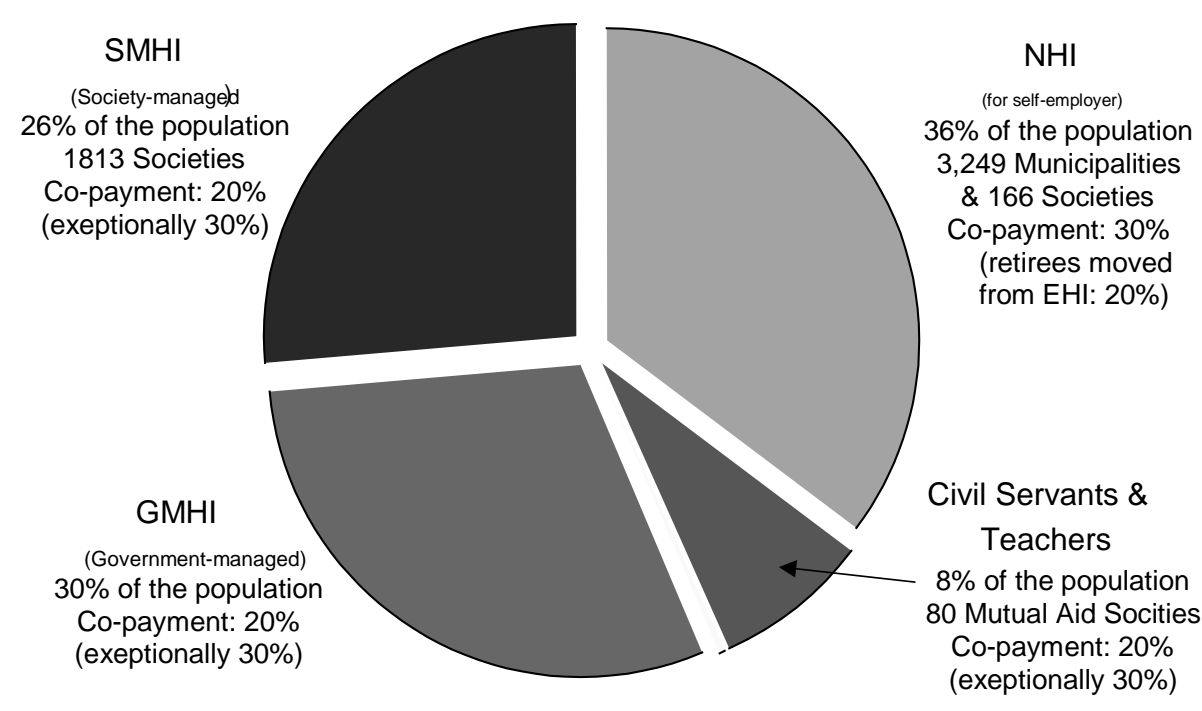

Source: Ministry of Health, Labour and Welfare, Trends in Insurance and Pension, etc.

16. The role of private health insurance is currently quite marginal, although most private insurance companies do provide medical insurance of cash benefits and their share in private health expenditure is on the increase.

\subsection{Relationships among Three Parties}

\subsubsection{Patients and Providers}

17. The relationship between patients and providers is characterised by freedom of the patient in the choice of provider and freedom of the doctor in the choice of location and prescription. The same principle is applied to the selection by the patient between doctor and pharmacist to obtain drugs (see Box 1). The patient who seeks primary medical care can choose to consult any general practitioner or specialist in a clinic. However, there exist some restrictions levied on the service providers (see section 2.3. The roles of Government).

18. It could not be said that the Japanese have their own family doctors (in the sense of doctors with whom they are registered), even though they may consult the same doctor regularly ${ }^{15}$. There is no gatekeeper system, and specialist doctors are not differentiated from General practitioners (GPs). Virtually all doctors in the clinics, GPs or specialists, try to deal with all the problems of every patient who visits. The medical speciality system is not based on as clear a division of labour as exists in some Western countries. This is related to the Japanese medical education described in section 2.1.2. The Providers. For other health personnel, too, the professional division of labour is not very clear. Nurses cannot earn professionally recognised credits for specialisation, nor is there any formal process of accreditation for

15 According to the Survey on Patient's Behaviour and Satisfaction 1999 (MHWL), $63.1 \%$ of the out-patients and $62.9 \%$ of the inpatients replied that they have their own Kakaritsukei, which means the frequently-visited [or familiar] doctor. 
medical social workers or medical record librarians. There are no professional schools for hospital administration. Hospitals are managed jointly by physicians and a small, clearly subordinate administrative staff, all of whom get only on-the-job training.

19. It is mainly between patients and service providers that the volume of health care consumption is determined, leaving little room for direct control by the health insurers as the third party. Patients have a degree of financial incentive to economise since they make co-payments, as determined by the health insurance Fee Schedule (see next section 2.2.2. Population and Third-party Payers). As for the providers, they have the incentive to see as many patients as they can manage and to give each patient as much treatment as possible. This is because they are paid mainly by fee-for-service and can send bills to the health insurers without legal limit on the frequency or duration of consultation, provided they are considered necessary. Moreover, doctors can both prescribe and dispense drugs (see Box 1). Such an arrangement is unusual in OECD countries (except in areas with low population density) and is believed to be one of the reasons that Japan has one of the highest level of pharmaceutical expenditure per capita among OECD countries (see section 3.1.4. Inpatient/Outpatient/Drug Expenditure).

\section{Box 1. Towards the separation between Prescribing and Dispensing of Drugs}

It is usual in Japan for ambulatory patients to come out of doctor's offices with drugs dispensed by the doctor. Most of the hospitals and doctor's clinics have their own dispensary rooms, and doctor's assistants, such as nurses or quasinurses, under the doctor's orders, provide drugs. This practice is thought to have evolved from traditional Oriental Medicine where there has been no clear distinction between doctors and pharmacists.

The government has used various methods for discouraging dispensing by doctors. In particular, it has gradually reduced the margin above the wholesale price of drugs, which has lowered the incentive for doctors to dispense (see section 2.2.3. Third-party Payers and Providers). Also, the fee for writing a prescription to an outside pharmacy was increased dramatically from previous $¥ 60$ to $¥ 500$ in 1974 and again to $¥ 760$ in 1994 . Furthermore, the government introduced in 1997 additional co-payments by outpatients for drugs dispensed directly by doctors, varying according to the kinds of drugs.

The government's attempts at role separation between doctors and pharmacists (Iyakubungyou) have had some positive results in increasing the share of drugs dispensed by pharmacies. However, the ratio of prescription orders to ambulatory patient consultations (the so-called ratio of Iyakubungyo) was still $39.5 \%$ in 2000 . That means that almost three fifths of ambulatory patients still receive drugs directly from doctors. Moreover, there is no clear indication that consumption on drugs by the Japanese has been lowered in the meantime (see section 3.1.4. Inpatient/Outpatient/Drug Expenditure).

\subsubsection{Population and Third-party Payers}

20. The entire population is covered by statutory and compulsory health insurance. A small group of very poor people is assisted by the Medical Aid program (see section 2.3. The roles of Government). In addition, employers pay for a separate work-related accident scheme for their employees. Enrolment in the health insurance scheme is automatic with little choice of coverage for either consumers or insurers. All adults are enrolled with one of thousands of health insurers, depending on where he/she works $(E H I)$ or where he/she lives $(N H I)$. Children are enrolled automatically with the insurer of their parent or parents. The care of the elderly is financed either by the Health Service System for the Elderly or by the Long-term Care Insurance (see Box 2).

21. The contributions of employees are calculated in proportion to their monthly wages. The maximum was $¥ 980$ thousand in case of the GMHI, about 3.4 times their average wage in 1998 . Employees pay half or less of the total contribution, and employers pay the rest (44:56 in case of the 
$S M H I$ ). Health insurers of the $S M H I$ are free to vary the contribution rates of their members, though they tend to follow a tacit guideline given by changes in the contribution rate in the GMHI (8.5\% of the salary in 1998), which the government decides. Contribution rates ranged widely around the average $(8.46 \%$ in 1997) among different insurers of the SMHI (see section 4.3.1. Equity of Finance). Some tax relief is given on the contributions. For the self-employed and inactives, assets as well as income are taken into account when contributions are assessed.

22. All health insurers are required by law to offer a basic package of benefits (medical consultation; supply of drugs and other materials; medical treatment, surgery and other services; home care treatment and nursing; hospitalisation and nursing at medical institutions). As shown in Chart 2, the patient's copayment rate in $E H I$ is currently $20 \%$, whereas that in $N H I$ is $30 \%$. Retirees under 70 , who quit $E H I$ and chose to belong to $N H I$, continue to face a $20 \%$ co-payment rate, more favourably than other individuals in NHI. Differences also exist between the enrolees and their dependants. Dependants under EHI unfavourably face a $30 \%$ co-payment rate for outpatient services, as opposed to $20 \%$ for enrolees. Copayment rates apply in the same way to most health services including hospital care. There is a ceiling for co-payments in a given month, which is currently $¥ 63,600$ ( $¥ 35,400$ for those with low income and $¥ 121,800$ for those with high income) plus $1 \%$ of the health care cost above it. Thus, the patient's burden is capped at a rather low level. The elderly under the Health Service System for the Elderly paid a fixed consultation fee and a fixed hospitalisation fee until $10 \%$ co-payment rate subject to monthly maxima was introduced at the beginning of 2001. Their effective co-payment rate was only $7.3 \%$ in 1999 (6.6\% excluding the government subsidy for drugs). The elderly now make contribution to Long-term Care Insurance out of their pensions (see Box 2).

23. Each insurer is also able to offer additional benefits under the collective scheme. Most of the extra benefits are provided in kind and in the form of reimbursement of the patient's co-payment. There are also cash benefits in the form of injury and sickness allowances, maternity allowances, delivery expenses and funeral expenses. Patients make a separate and additional payment for meals, $¥ 780$ a day in the case of standard meals, on the grounds that meals must be paid for outside the hospital.

\section{Box 2. Health and Social Services for the Elderly}

The financing and provision of health and social services for the elderly has played an important part in the development of Japanese health policy. That is because Japan is facing the most rapid ageing of the population of any OECD country and use of health services by the elderly is much higher, on average, than that of younger people (see Table 4 in Box 3).

\section{Health Service System for the Elderly}

Before the introduction of Long-term Care Insurance in 2000, long-term care support for the elderly ${ }^{16}$ were provided through two schemes: welfare service programs and the Health Service System for the Elderly (hereafter, HSSE). The HSSE started in 1983 to cover comprehensive health services including long-term health care in hospitals, and was extended in 1986 to intermediate nursing facilities. The aim of introducing coverage in intermediate nursing facilities was to reduce the build-up of long-term patients in general hospitals. The HSSE is composed of two main institutions. One is so-called RojinIryo (Elderly medical services), whose most characteristic feature is the co-finance scheme, a transfer scheme designed to correct the imbalances in the payments to providers experienced by the various health insurers due to their differing proportions of elderly members. The Scheme applies to all people aged 70 or more and people aged 65-69 with severe disability (hereafter, the elderly). The other is so-called HokenJigyo (Health services), which consists of the direct or contracted provision for people aged 40 or more of various health programs. It includes the provision of health handbooks, health education, health counselling, health check-ups, functional training and home-visit guidance.

16 Kaigo services 
HSSE is financed by taxes, health insurance contributions and co-payments. Until a $10 \%$ co-payment rate with monthly caps (ranging from $¥ 3,000$ to $¥ 5,000$ for consultation fee and from 15,000 to $¥ 37,200$ for hospitalisation fee) was introduced at the beginning of 2001, the co-payments were a fixed consultation fee of $¥ 530$ per visit (free for those with low income), a fixed hospitalisation fee of $¥ 1200$ per day ( $¥ 500$ for those with low income) and a fixed intermediate nursing facility fee of around $¥ 60$ thousand per month. The remaining expenditure ${ }^{17}$ is shared between insurers, the central government and local governments in the ratio of 7:2:1. ${ }^{18}$ In the case of the health insurer's share, under the co-finance scheme, each health insurer contributes to a central Payment Fund as if it had the overall average ratio of the elderly. The overall average ratio was $11.3 \%$ in 1999 . The actual ratios of the elderly to total insurees covered by each insurance scheme were $23.3 \%$ in the case of NHI, 5.6\% in the case of GMHI and $2.9 \%$ in the case of $S M H I$, on average.

\section{Long-term Care Insurance}

As a result of the continual ageing of the population, the increasing participation rate of women and the down-scaling of family support, there has been a growing necessity for society to support long-term care. The number of people requiring long-term care is expected to rise more than twofold between 1997 and 2025. Insufficient welfare services, however, together with the incentive to hospitalise the elderly in need of long-term care, have given rise to the problem of "social hospitalisation". The Long-term Care Insurance scheme (hereafter LTCI) ${ }^{19}$ was started in April 2000 with the aims of introducing improved insurance coverage for home care and extending such coverage for the first time to nursing homes and further reducing the dependency of the elderly on beds in hospitals. LTCI incorporated both the previous social or welfare services and the long-term care services under the HSSE.

The insured of the LTCI are divided into two categories: Type 1 (citizens of 65 or older) and Type 2 (citizens between 40-64). The insured of Type 1 can receive long-term care services when their needs for long-term care are certified by the Certification Committee on the basis of opinions by their care managing doctors, who play an important gatekeeper role in this case by assessing their needs for long-term care. The insured of Type 2 can receive care only when their needs are caused by 15 specific diseases such as pre-senile dementia, cerebrovascular disease etc.

Long-term care support for the elderly covered by the LTCI is composed of two broad categories according to where the service receiver stays; at-home services, including various home-support services, home nursing services by nursing stations, day-centre care, and care at short stay facilities; and at-institution services provided by special nursing homes, intermediate nursing facilities, and geriatric beds in hospitals (see section 2.1.2. The Providers). Some of these services - services by nursing stations, intermediate nursing facilities and geriatric beds - were originally covered by the HSSE.

Payments under the LTCI are made directly to providers in the form of a lump sum according to the assessed need. The benefits are financed by taxes, LTCI contributions and co-payments. The elderly are required to bear $10 \%$ of the cost as co-payments and to pay for meals additionally (a cap is set on the co-payments for the elderly with low incomes). Insurers, the central government and local governments share the rest of the expenditure in the ratio of $2: 1: 1{ }^{20}$ For the first time, the elderly themselves (Type 1) have been required to make contributions which are collected in the form of a deduction from their pensions (varying according to the income level) ${ }^{21}$. Younger insurees (Type 2) are required to make a new contribution of about $1 \%$ of income in addition to their health insurance contributions.

17 Health expenditure for the elderly other than co-payments accounted for $34.1 \%$ of the total health insurance expenditure, or the $N M E$ explained in Box 3, in 1998. It is expected to grow 54\% in 2525.

18 There are exceptions. Governments pays half of the cost (in the ratio of 3:2:1) for health care services by intermediate nursing facilities, nursing stations etc.

19 KaigoHoken or Kaigo Insurance. Kaigo signifies "assistance and nursing" or support for the elderly. This terminology started to be used in the Elderly Welfare Act in 1963.

20. The final share of the central government is a little more than that ratio since it subsidise health insurers additionally.

${ }^{21}$. Pensioners who receive annual pension with $¥ 180,000$ or more pay Type 1 contributions. They amount about $70 \%$ of the elderly. 
Chart 3: Transition in sources of finance for services for the elderly

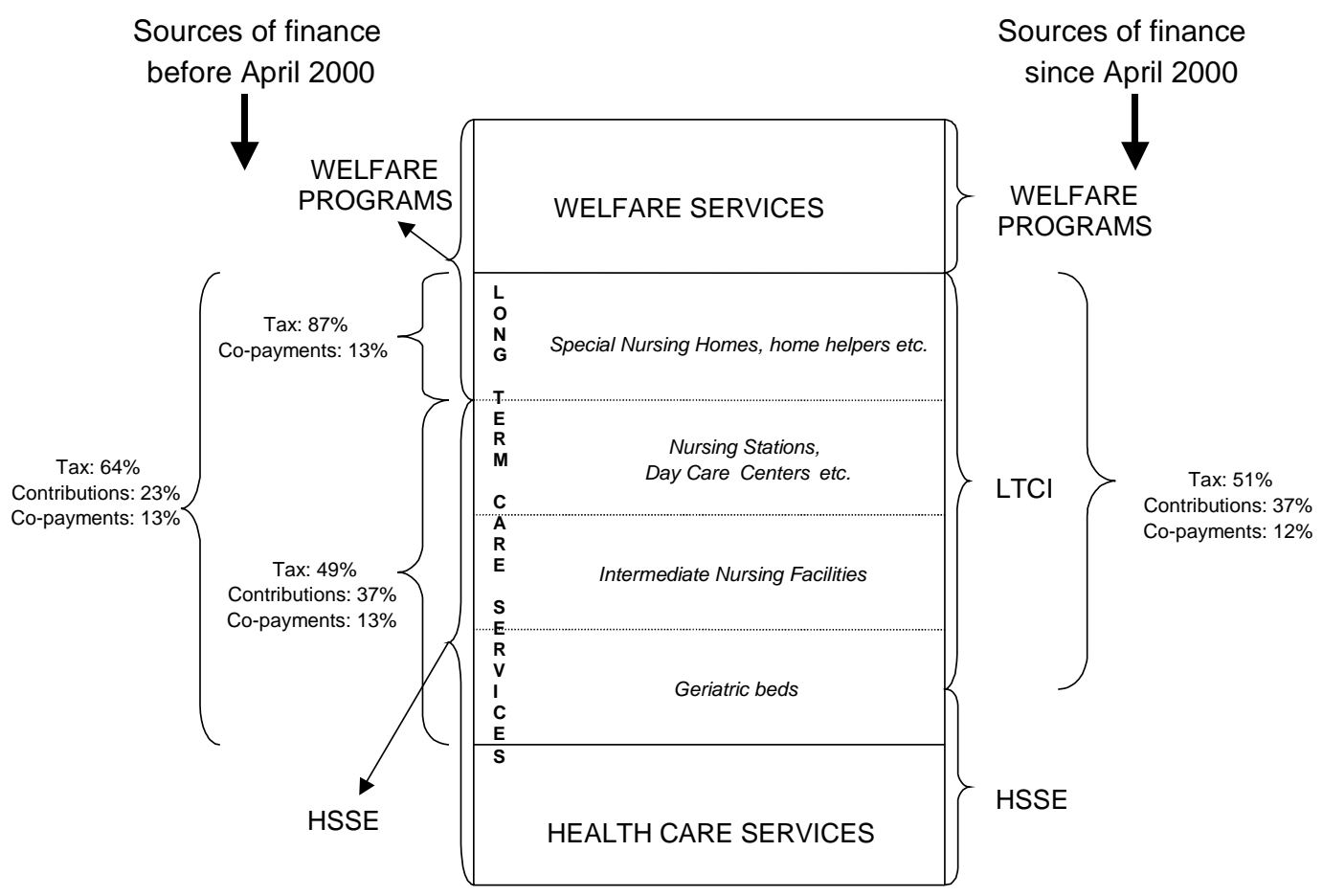

Source: Budget in fiscal year 2000

HSSE: HEALTH SERVICE SYSTEM FOR THE ELDERLY (Health Insurance), LTCI: LONG-TERM CARE INSURANCE

Chart 3 shows from where money flows into LTCI for long-term care support for the elderly. The share of tax (or government budget) is estimated to account for $51 \%$ (central government $29 \%$, local governments $22 \%$ ) of the total expenditure for LTCI in the fiscal year 2000, the share of LTCI contributions 37\% (Type 1: 15\%, Type 2: 22\%), and the share of co-payments $12 \%$. Some of the former tax burden has been shifted onto insurance by the introduction of the new contribution by the elderly.

\subsubsection{Third-party Payers and Providers}

24. Even though Japan's health care system can be categorised as a "public contract model", contracts between the insurer and the health service providers are rather minimal in the sense that the insurers operate fairly passively under rules set by the central government. In addition, the Prefecture governors, who operate mainly under policies set by the central government, designate, almost unilaterally, the providers eligible for treating patients under the health insurance scheme. The relationship between the insurers and the providers is in this respect overridden by a relationship between the government and the providers. ${ }^{22}$

25. Service providers are paid by the health insurers for that part of medical costs not borne by the patient. Payments to providers are mainly on a fee-for-service basis ${ }^{23}$. The Fee Schedule is published in the

22. It has been said that health care policies in Japan have been formed and developed under conflict and co-ordination between the former Ministry of Health and Welfare and the Japanese Medical Association. (Campbell and Ikegami, 1998)

23. An inclusive per diem payment that bundles hospitalisation, drugs and laboratory tests was introduced as an option for chronic inpatient care in 1993. This had a dramatic effect. According to a study of one geriatric hospital, after the adoption of the inclusive per diem the spending on drugs was cut by two thirds and on laboratory tests by 90 per cent. A DRG-based fee scheme has been tested for acute inpatients as a pilot study since 1998. Here, medical costs for inpatients include both 
form of a ministerial notification under the Health Insurance Act. Revision of the Fee Schedule is made in negotiations between providers and insurers at the Central Social Insurance Medical Council (CSIMC) ${ }^{24}$. The Schedule is composed broadly of two parts: the sections fixing a fee for each service category such as consultation, medication, injection, treatment, surgery and medical check-up, on the one hand, and the other sections like hospitalisation, nursing, etc., on the other. Home care services were incorporated in detail into the Fee Schedule in 1994. No direct compensation is made for capital investment costs, which are regarded as already being reflected in the service items of the Fee Schedule. The Fee Schedule applies to all patients, regardless of which health insurance scheme they belong to. There is usually no clear differentiation of fees between providers in each service category - for example, the fee for a consultation will usually be the same whether it is given by clinic doctors or hospitals and by public or private hospitals with exceptions for some consultations and treatments. "Labour services" are seen as underemunerated compared with prices of "medical goods" despite attempts to raise the former compared with the latter in recent years.

26. A positive drug list with 13 thousand pharmaceuticals currently is operated as part of the Fee Schedule. While the wholesale prices are decided by their manufacturers, the insurance prices are set by the government. Until the early 1990s, the reimbursement prices were determined by the " $90 \%$ bulk line" method, that is, at the price at or below which $90 \%$ of the supply of the drug could be bought in the market. In 1992, the Ministry introduced a new method of setting the reimbursement price based on a weighted average wholesale prices together with a reasonable margin. The margin (or R-zone) has been reduced substantially, from $15 \%$ in 1992 , to $13 \%$ in $1994,11 \%$ in $1996,10 \%$ in 1998 and further to $2 \%$ in 2000 , with the aim to make drugs relatively less attractive than before as a source of income for doctors (see section 3.1.4. Inpatient/outpatient/drug expenditure). The introduction of a "reference pricing system" where the drug with the lowest price is used to set the reimbursement price among a group of substitute drugs was under debate until recently.

27. The health insurers have no control over the location of doctors and little direct control over the volume of their medical services. However, they do monitor some of each provider's bills and feed back the results to the reimbursement process in the hope that this will discourage the doctor's tendency to overprescribe. The Social Insurance Medical Fee Payment Fund ${ }^{25}$ is engaged in screening the bills submitted monthly by the providers including the particulars of medical services performed, on behalf of health insurers. For this work, the Payment Fund takes advice from appropriate medical specialists. The bills are forwarded to the health insurers together with the Payment Fund's judgement about the appropriateness of the doctor's level of services. Necessary measures are taken to redress inappropriate prescriptions. Overmedication or dishonest claims are sanctioned.

\subsection{The Roles of Government}

28. Governments in Japan play at least three significant roles in relation to the health care system: a regulatory role, an insurer role and, on a small scale, a provider role.

fixed prices for the part of DRG and fees for services like surgery, anaesthesia etc. This pilot study involves 183 DRGs at 11 national and insurer's hospitals, and the results will be evaluated in 2003. DRGs are difficult to develop in Japan given the wide variation in clinical practices, but this pilot study prepares grounds for future applications of DRG-based payment. (Forthcoming Economic Surveys Japan 2001)

24. The CSIMC (Chuikyo) is composed of representatives of three groups; the insurers and the insured, the providers including doctors, dentists and pharmacists; and representatives of public interests. However, the $M H L W$ takes the initiative in each revision process, as described in section 2.3. The Roles of Government. 
29. Japan's health care system possesses the diversity of a private market, but is to a degree supervised by the government. The government's regulatory roles range from overall system building and planning to micro level regulations. Although each level of government has its own responsibilities, the Ministry of Health, Labour and Welfare $(M H L W)$, in particular, takes the lead in system building for the central government. The central government sets a legal framework for the health care system. Both the Health Insurance Act (enacted in 1922) and the National Health Insurance Act (enacted in 1938) serve to set a legal framework for the demand side, and the Medical Service Act (enacted in 1948) and the Community Health Act (enacted in 1994) set a framework for the supply side. Major reforms of the health care system have been introduced via amendments to those acts.

30. In terms of the demand side of health care, the government regulates public health insurance. In particular, it exercises strong negotiating power in the biennial revision of the Fee Schedule. The MHLW takes the initiative in each revision process at the Central Social Insurance Medical Council (CSIMC) and can influence the result of fee revision. This influence over price is sometimes linked to influence over volume in that the revision of the fee for each service can be aimed at discouraging excessive use of a particular service and at favouring low-technology primary care.

31. In terms of the supply side of health care, the government has considerable influence upon the supply of private provision of some services. Local governments undertake planning for the construction of new hospitals and beds and for the acquisition of medical equipment. Prefecture governors are obliged to draw up regional medical care plans under the first revision of the Medical Service Act, 1985. Each plan sets a certain "norm" for beds in their own area. When "the number of current beds" exceeds the "norm", additional hospitals and beds are not covered for health insurance. Also, the central government has formulated and revised the Plan for Health and Medical Care for Remote Areas nine times since 1956 to tackle the shortage of necessary medical services in remote areas.

32. Regulations in terms of the supply side include planning and in part controlling the number of students entering medical school ${ }^{26}$. This has had the effect of restraining the number of doctors in Japan compared with many other OECD counties. Qualifications as medical doctors are mandatory for top managers of hospitals, and for-profit enterprises are prohibited from running hospitals, as explained in section 2.1.2. The providers. There are also legal requirements for minimum bedroom space and about medical and nursing staff/bed ratio. In addition, disseminating information on medical service providers, such as advertising by doctors or hospitals, is broadly restricted, though such restrictions have been eased gradually. Patients are restricted to a considerable degree in obtaining information either from their medical bills or from their medical records.

33. The central and local governments themselves play a role as third-party insurers. Central government manages the GMHI and the society for seamen, and local governments manage the NHI. The $G M H I$ is composed of enterprises that are too small to organise their own insurance societies for their employees. In relation to the regulatory role of the government, the change in contribution rates in the $G M H I$ works as a tacit guideline to the rate of increase in contribution rates of the other insurers.

34. In addition, the central government, together with local governments, provides the Medical Aid program for the very poor who would otherwise have difficulty in affording their co-payments in the health insurance. This program is provided as one of the Public Assistance benefits enacted under the Public Assistance Act in $1950 .^{27}$ The number of Medical Aid recipients was 0.8 million in 1999, $0.6 \%$ of the

\footnotetext{
26 There is full control of entry to national medical schools, but control of entrants is indirect in the case of private medical schools and local medical schools.

27 That means that this program had existed even before the introduction of universal health insurance in 1961.
} 
whole population or $80 \%$ of the total Public Assistance recipients. The benefits of the program are seldom different from those of Health Insurance.

35. The central and local governments provide health services through their own hospitals ${ }^{28}$. As shown in Table 1, both central and local governments, in particular, own $18.7 \%$ of total hospitals in number, whose beds account for $30.5 \%$ of the total beds. These health services are reimbursed according to the insurance Fee Schedule in the same way as health services supplied by private hospitals. The national hospitals focus more on implementing the so-called 'policy-based medical services' such as innovative advanced medical care for cancer, circulatory diseases etc., treating special diseases like AIDS, leprosy, tuberculosis, etc., preparing for the provision of medical activities in emergency situation, and so on. They also carry out teaching and research. For example, the pilot testing for the DRG-based fee scheme has been carried out mainly in national hospitals.

36. Local governments, assisted by the central government, are also involved in the provision of public health services in their region, through Prefecture Health Centres and Municipal Health Centres. Activities by these Health Centres include the prevention of communicable and venereal diseases, the collection and reporting of both epidemiological and administrative information including health statistics, nutrition and hygiene activities, and the provision of health services for some mothers, children and the elderly.

28 However, following "The Basic Plan on the Reduction of National Administrative Organisations and Improvement of Efficiency" (1999), these national hospitals are planned to transfer to the hands of 'independent administrative legal persons' by 2004 . 


\section{MONETARY AND REAL FLOWS IN THE JAPANESE HEALTH CARE SYSTEM}

37. This chapter assembles the evidence available for assessing the performance of the Japanese health system. It begins with supplying evidence on the monetary flows through the system including the level and growth of health expenditure and the sources of finance. It continues by supplying evidence on the real flows that are purchased by those flows of health expenditure. These real flows are viewed as a productive process: inputs lead to activity that leads to outcomes including health improvement and responsiveness (patient 'satisfaction' or patient 'experience'). Based on this evidence, an assessment will be made of the overall performance of the Japanese health system in the next chapter.

\subsection{Monetary Flows}

38. There is mounting pressure on health care systems to improve their performance. For this, it is necessary to intensify the search for improvements in value for money. The fact that the Japanese health system is associated with high health status and yet appears to spend less than expected as a share of Japan's GDP makes it an important system to explore from the perspective of other OECD countries.

\subsubsection{Health Expenditure Level and Trends}

39. According to OECD Health Data, total health expenditure (hereafter, THE) in Japan was $7.6 \%$ of its gross domestic product (GDP) in $1998^{29}$ (Table 2). That was less than both the G7 average of $8.9 \%$ and the OECD average of $7.9 \%$. Per capita health expenditure was 1,822 US\$ PPPs in 1998 (or 1,795 US\$ PPPs in OECD Health Data 2001), which is higher than the OECD average of 1,701 US\$ PPPs, but much less than the G7 average of 2,192 US\$ PPPs.

29. In the case of Japan, there are slight differences in figures for health expenditure in 1998 between OECD Health Data 2000 and OECD Health Data 2001. The latter is a new trial for the health expenditure following the System of Health Account by the OECD (OECD, 2000). For example, the THE share in 1998 in OECD Health Data 2001 was $7.4 \%, 0.2 \%$ less than it was in OECD Health Data 2000. This paper uses existing figures throughout since the new estimation methods have not yet been applied to earlier years. 
Table 2: Health expenditure as a percent of Gross Domestic Product, 1970-1998

\begin{tabular}{|c|c|c|c|c|c|}
\hline Year* & 1970 & 1980 & 1990 & 1998 & $\begin{array}{l}\text { 1998, Per capita } \\
\text { US\$ PPP }\end{array}$ \\
\hline Australia & 5.7 & 7.0 & 7.9 & 8.6 & 2085 \\
\hline Austria & 5.3 & 7.6 & 7.1 & 8.0 & 1894 \\
\hline Belgium & 4.0 & 6.4 & 7.4 & 8.6 & 2050 \\
\hline Canada & 7.0 & 7.1 & 9.0 & 9.3 & 2360 \\
\hline Czech Republic & & 3.8 & 5.0 & 7.1 & 937 \\
\hline Denmark & 8.0 & 9.1 & 8.5 & 8.3 & 2132 \\
\hline Finland & 5.6 & 6.4 & 7.9 & 6.9 & 1510 \\
\hline France & 5.7 & 7.4 & 8.6 & 9.4 & 2043 \\
\hline Germany & 6.3 & 8.8 & 8.7 & 10.3 & 2361 \\
\hline Greece & 5.6 & 6.5 & 7.5 & 8.4 & 1198 \\
\hline Hungary & & & & 6.8 & 717 \\
\hline Iceland & 4.9 & 6.1 & 7.9 & 8.4 & 2113 \\
\hline Ireland & 5.1 & 8.4 & 6.7 & 6.8 & 1534 \\
\hline Italy & 5.1 & 7.0 & 8.1 & 8.2 & 1824 \\
\hline Japan ** & 4.6 & 6.5 & 6.1 & 7.6 & 1822 \\
\hline Korea & & & 4.8 & 5.1 & 740 \\
\hline Luxembourg & 3.5 & 5.9 & 6.1 & 6.0 & 2246 \\
\hline Mexico & & & 4.4 & 5.3 & 419 \\
\hline Netherlands & 7.2 & 8.0 & 8.5 & 8.7 & 2150 \\
\hline New Zealand & 5.2 & 6.0 & 7.0 & 8.1 & 1440 \\
\hline Norway & 4.4 & 7.0 & 7.8 & 8.6 & 2244 \\
\hline Poland & & & 5.3 & 6.4 & 524 \\
\hline Portugal & 2.7 & 5.6 & 6.2 & 7.7 & 1203 \\
\hline Spain & 3.6 & 5.4 & 6.6 & 7.0 & 1194 \\
\hline Sweden & 6.9 & 9.1 & 8.5 & 7.9 & 1732 \\
\hline Switzerland & 5.4 & 7.3 & 8.3 & 10.4 & 2853 \\
\hline Turkey & 2.4 & 3.3 & 3.6 & 4.8 & 316 \\
\hline United Kingdom & 4.5 & 5.6 & 6.0 & 6.8 & 1510 \\
\hline United States & 6.9 & 8.7 & 11.9 & 12.9 & 4165 \\
\hline G-7 average & 5.5 & 7.1 & 7.8 & 8.9 & 2192 \\
\hline 20 -country average $e^{\star \star \star}$ & 5.3 & 6.9 & 7.6 & 8.3 & 1990 \\
\hline $29-$ country average $\mathrm{e}^{\star \star \star \star}$ & & & 7.2 & 7.9 & 1701 \\
\hline \multicolumn{6}{|c|}{$\begin{array}{l}{ }^{*} \text { Note that } 1970 \text { data for Australia and Denmark refer to } 1971,1970 \text { data for the Netherlands } \\
\text { refer to } 1972 \text {. }\end{array}$} \\
\hline \multicolumn{6}{|c|}{$\begin{array}{l}\text { ** } 1998 \text { data for Japan refers to } 1998 \text { data in OECD Health Data } 2000 \text { for the reason } \\
\text { explained in the main text (footnote 29). }\end{array}$} \\
\hline \multicolumn{6}{|c|}{$\begin{array}{l}\text { *** } 20 \text {-country average is for only those } 20 \text { countries that have a relatively complete set of data } \\
\text { for the years } 1970-1998 \text { and have not reported any major breaks in their series. There are } \\
\text { suggestions of breaks in the expenditure series for Belgium, Portugal and Sweden. The } \\
\text { average includes interpolated data for } 1970 \text { from Australia, Denmark, and the Netherlands. }\end{array}$} \\
\hline
\end{tabular}

40. As shown in Chart 4, the health expenditure share of GDP (hereafter, THE share) rose in the 1970s, fell slightly in the 1980s and rose again in the 1990s. Chart 4 shows particularly how the changes in THE share were related to changes in its two components: real health expenditure per capita and real GDP per capita. The average growth rate of real GDP per capita was almost the same in both 1970s and 1980s (3.3\% in 1970s and 3.5\% in 1980s), but the average growth of real health expenditure per capita was much faster in the first of these decades (7.1\% in 1970s and $2.7 \%$ in 1980s). In contrast, the average growth rate of real GDP per capita declined rapidly between 1980s and 1990s (3.5\% in 1980s and $1.1 \%$ in 1990s), whereas the average growth rate of real health expenditure per capita increased $(2.7 \%$ in $1980 \mathrm{~s}$ and $4.0 \%$ in 1990s). In other words, it was more a low THE change than the GDP change which brought about the decrease of the THE share in the 1980s, whereas it was more a low GDP change than THE change which brought about the increase of the THE share in 1990s. 


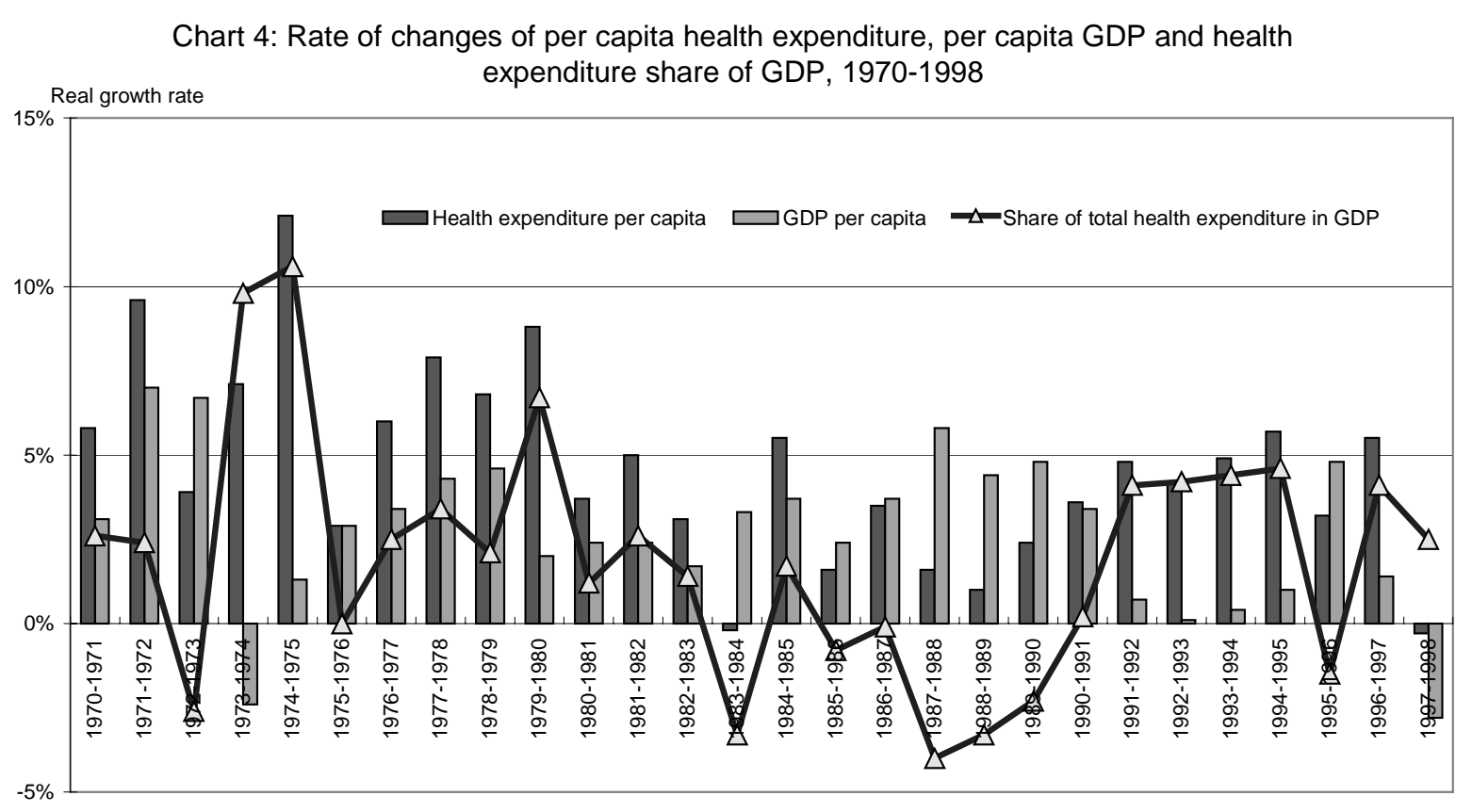

Source: Calculated based on OECD Health Data 2001

41. THE had started to grow at an explosive rate after free access to health care was offered to the elderly in 1973. In reaction to the resulting growth in financial burden both on the public treasury and on the health insurers, the government instituted a series of cost-control reforms in the 1980s. The reimbursement prices in the Fee Schedule were held down over this period. Co-payments by the elderly were reintroduced in 1983. The enrolees in the EHI also became subject to $10 \%$ of co-payments in 1984 . Co-payments by the elderly were augmented again in 1986. These reforms were successful in tempering the speed of spending growth, which levelled off rapidly in the 1980s. However, owing to the economic slump in the 1990s, the financial position of health insurers as well as the government deteriorated again. Consequently, the insurance Fee Schedule including the reimbursement prices of drugs continued to be tightly controlled. The co-payment rate of the EHI enrolees and the co-payment amount of the elderly were augmented in 1997 with the aim again of containing the growth of health expenditure as well as relieving the deficit in public health insurance.

\section{Box 3. National Medical Expenditure and the Determinants of its Growth}

Caution is required when referring to terms like "Total Health Expenditure" and "National Medical Expenditure" in the case of Japan. This is because OECD's Total Health Expenditure (THE) is often translated into "KokuminIryohi", which means "national medical expenditure" in a word-by-word translation, although there is a big difference in definition between the two. Japanese National Medical Expenditure (KokuminIryohi, hereafter NME) is the total medical payment, including the patient co-payment, for services covered by the health insurance scheme. In contrast, the THE includes not only payments for items covered by the health insurance but also expenditure for the items not covered such as OTC (over-the-counter) drugs, some dentistry, amenity beds, individual health check-up etc. In other words, the NME is a subset of THE. The difference between OECD's THE and Japan's NME amounts to more than $20 \%$ each year (Table 3). The Ministry has estimated the latter each year for almost 50 years, using it as the main criterion to control health care prices, particularly since the early 1980s. 
DEELSA/ELSA/WD(2001)9

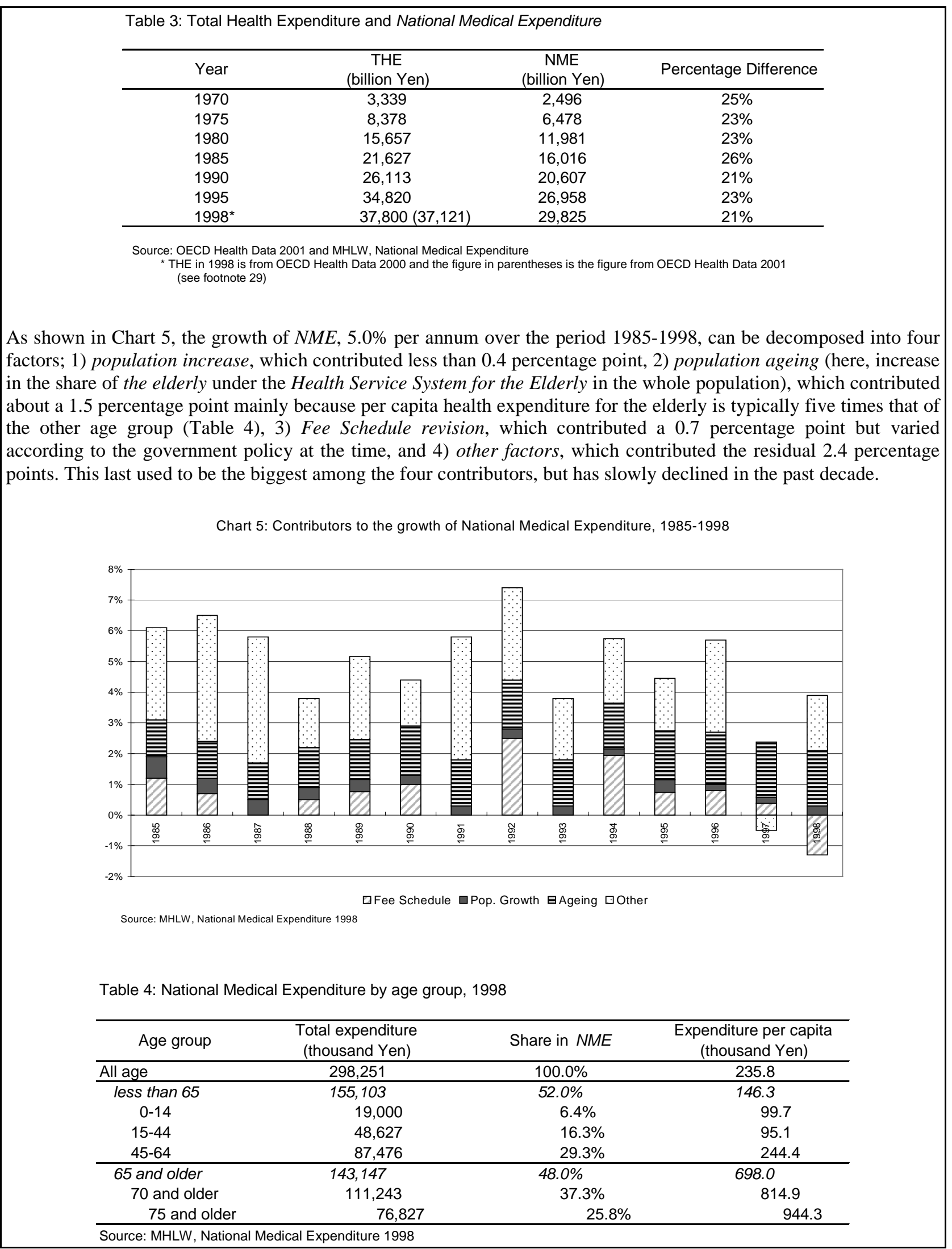


The 'other factors' corresponds closely to what is called the 'natural increase" ${ }^{30}$ in the volume and intensity of health care, which is taken into account in setting the Fee Schedule. Before 1981, fees were raised approximately in proportion to the rise of national income per capita less an ageing factor. In addition, doctors' incomes benefited from the 'natural increase'. After 1981, the government modified its negotiating stance with the aim of allowing fees to rise only at the rate of rise of national income per capita less the rate of the 'natural increase' as well as an ageing factor. In effect, this removed an element of double counting for volume increases from the revision of the Fee Schedule. Analysis of the trends in three components of per capita health expenditure (Chart 6), i.e. a) cases per capita ${ }^{31}$, b) days per case and c) cost per day, is helpful for understanding these "other" factors. Change in c) cost per day can be divided again into; c1) price change, which coincide with the Fee Schedule Revision, and c2) volume/intensity change, which includes a myriad of effect such as quality improvement and technological advance. Hence, other factors are composed of a) cases per capita, b) days per case and c2) volume/intensity change in cost per day.

Chart 6: The role of "other factors" in the growth of National Medical Expenditure, 1985-98

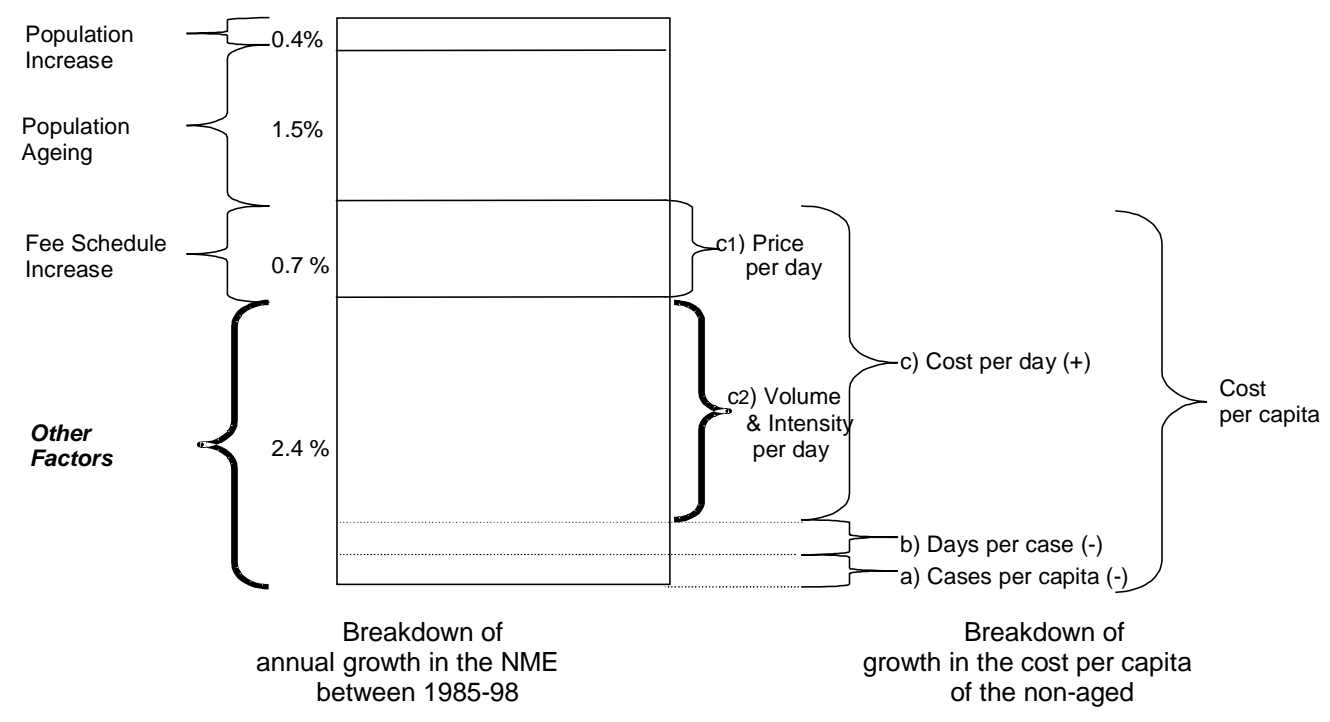

Source: MOHLW, National Medical Expenditure 1998, and MOHLW, Trends in Insurance and Pension (1999) a, etc.

The determinants of the growth in other factors can be explored by looking at the case of Government Managed Health Insurance (GMHI), although it may not be typical of the insured population as a whole. In the case of GMHI, a) inpatient cases per capita have been on the decrease ${ }^{32}$ for the last three decades even though the rate of decline has been attenuated since the mid-1980s, whereas a) outpatient cases per capita have remained almost constant in the same period. b) Days per case decreased until the mid-1980s, and have stayed almost unchanged thereafter. In contrast, c) cost per day showed an increasing trend over the last three decades except in 1997, when cases per capita and days per case shrank as well. In all, the increase of health expenditure has been due more to the rise in c) cost per day. Increase in cost per day has been caused mainly by $\mathrm{c}_{2}$ ) volume/intensity increase, considering a minor $\left.\mathrm{c}_{1}\right)$ price increase, or Fee Schedule revision, as shown above. In other words, c2) volume/intensity change in cost per day, or intensification of medical services reflecting technology advance etc., was the main contributor to the growth of medical expenditure.

\footnotetext{
$30 \quad$ Shizenzo

31 ZyushinRitsu

32 This does not square with the increase in the admission rate of the entire Japanese population (see section 3.2.2.2. Activities and Utilisation). However, the breakdown of growth in the cost per capita in Chart 6 shows the cases for the insured (affiliates) except both the dependants and the elderly people who are covered through the Health Service System for the Elderly. As such, the population factors like population increase and population ageing, out of the four contributors to the growth of $N M E$, are already excluded from the start.
} 


\subsubsection{Finance of Health Insurance}

42. Chart 7 shows from where money flows into the health insurance scheme. The share of insurance contributions accounted for 52.9\% (employer 22.7\%, insured 30.2\%) of $N M E$ in 1998, the share of tax (or government budget) $32.2 \%$ (central government $24.4 \%$, local governments $7.8 \%$ ), and the share of copayments $14.9 \%$. The share of contributions has not significantly changed for the last 40 years. The share of tax increased until the early 1980s, slightly declined in the mid-80s, and then stayed almost unchanged. The share of co-payments, which was $30.0 \%$ in 1960, decreased until 1982, when the share was $10.5 \%$, and then slightly increased or stayed at the same level of $11-12 \%$ over a decade. However, the share increased to $13.7 \%$ in 1997 and again to $14.9 \%$ in 1998, as a result of higher co-payments by the EHI insured and the elderly in $1997^{33}$ (see section 3.1.1. Health Expenditure Level and Trends).

Chart 7: Trends in sources of finance for National Medical Expenditure, 1960-1998

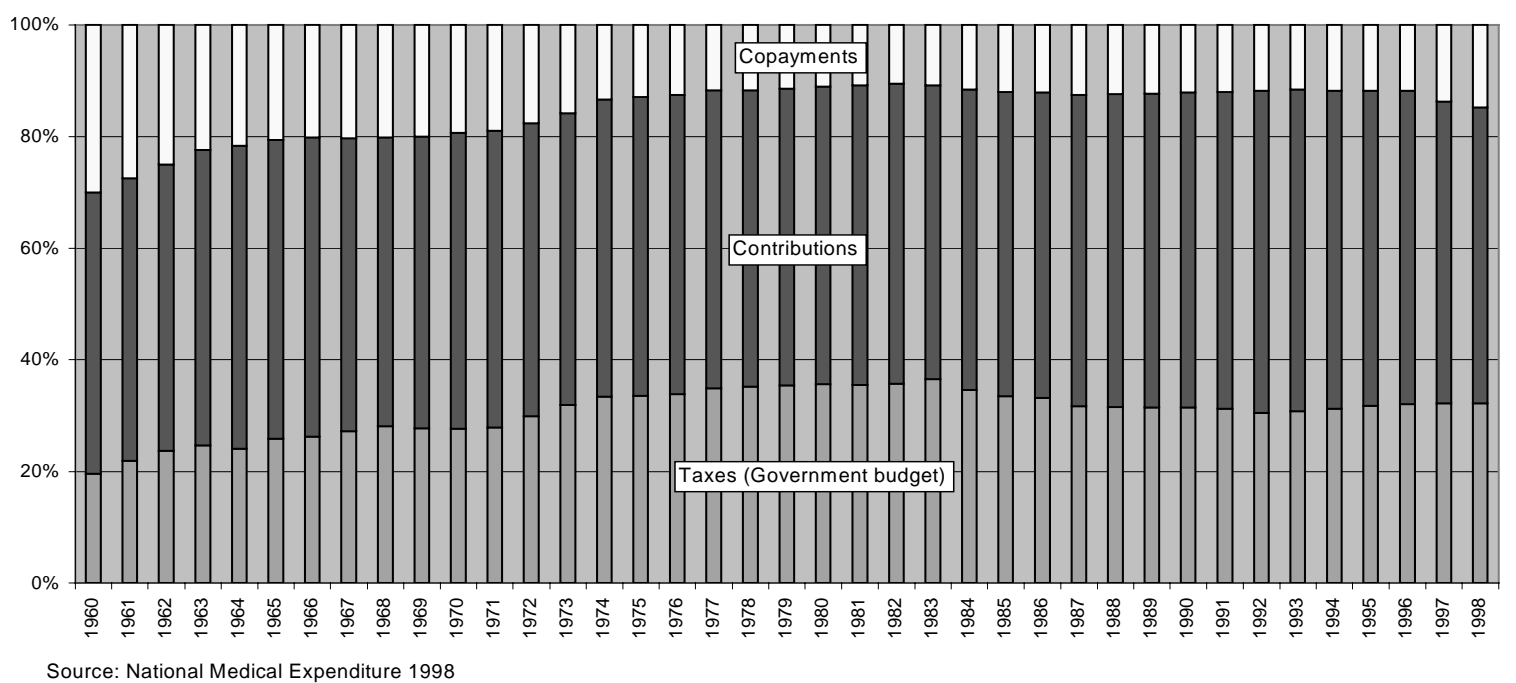

33. The share of co-payments in the Health Expenditure for the Elderly was increased from the previous $5 \%$ level to $7.2 \%$ in 1998 , but declined again to $6.5 \%$ in 1999 owing to the exemption of co-payments for drug by the elderly in July 1999. For reference, the average level of co-payment share by the non-elderly in the NME was around $19 \%$ in 1999. 
43. Japan's health insurance scheme as a whole is experiencing a serious financing problem. Recently, expenditure on insurance benefits has increased more rapidly than revenue from insurance contributions. The result has been a deficit (Table 5). NHI municipalities recorded a $1.8 \%$ deficit of their total expenditure in 1999, even after a subsidy from the government budget and a considerable transfer from the cross-subsidisation scheme. About $60 \%$ of the NHI municipalities were in deficit, which is due partly to the high proportion of low-income and elderly contributors in NHI. GMHI has run a deficit every year since 1993, which reached approximately $4.4 \%$ of its total expenditure in 1999. The surplus accumulated in previous years is expected to run out in 2002. In the case of SMHI, societies recorded a $3.3 \%$ deficit of their total expenditure in 1999. About $70 \%$ of societies have gone into deficit in 1999. The deficit of both GMHI and SMHI societies is due largely to their contribution to the Health Service System for the Elderly, through the co-finance scheme between insurers (see Box 1).

Table 5: Deficits in health insurance schemes

\begin{tabular}{|c|c|c|c|c|c|c|}
\hline & Year & 1995 & 1996 & 1997 & 1998 & 1999 \\
\hline \multirow{4}{*}{$\mathrm{NHI}$} & Revenue (A) & 5,771 & 6,049 & 6,217 & 6,294 & 6,685 \\
\hline & Expenditure (B) & 5,880 & 6,164 & 6,247 & 6,396 & 6,805 \\
\hline & Difference $(A-B)$ & -109 & -115 & -29 & -102 & -121 \\
\hline & Difference/Revenue & $-1.9 \%$ & $-1.9 \%$ & $-0.5 \%$ & $-1.6 \%$ & $-1.8 \%$ \\
\hline \multirow{4}{*}{ GMHI } & Revenue $(A)$ & 6,608 & 6,751 & 6,926 & 6,981 & 6,909 \\
\hline & Expenditure (B) & 6,887 & 7,170 & 7,021 & 6,977 & 7,225 \\
\hline & Difference (A-B) & -278 & -419 & -95 & 3 & -316 \\
\hline & Difference/Revenue & $-4.0 \%$ & $-5.8 \%$ & $-1.4 \%$ & $0.0 \%$ & $-4.4 \%$ \\
\hline \multirow{4}{*}{ SMHI } & Revenue (A) & 5,506 & 5,626 & 5,925 & 5,958 & 5,874 \\
\hline & Expenditure (B) & 5,629 & 5,823 & 5,927 & 5,918 & 6,078 \\
\hline & Difference $(A-B)$ & -122 & -198 & -2 & 41 & -203 \\
\hline & Difference/Revenue & $-2.2 \%$ & $-3.4 \%$ & $0.0 \%$ & $0.7 \%$ & $-3.3 \%$ \\
\hline
\end{tabular}

Source: Ministry of Health, Labour and Welfare 


\subsubsection{Public/Private Mix in Funding Health Expenditure}

44. The share of public funding for health care $^{34}$ in THE (hereafter, the public funding share) in Japan was $78.5 \%$ in 1998 , a little over the OECD average of $75.2 \%$ for 21 countries for which there is complete data for all the years in Table $6^{35}$. The Japanese public funding share has increased for the last three decades, staying quite close to the OECD average throughout that period. Table 6 indicates that some countries with a high public funding share have moved towards a lower public funding share, whereas countries with a low public funding share have moved towards a higher public funding share. (Countries like France and Germany have stayed close to the average.) In the case of Japan, the increase in the public funding share had been led by decreasing co-payments until the mid-1970s, but the increase thereafter has been due more to increasing government expenditure on public health (Chart 7).

Table 6: Public funding as a percent of health expenditure, 1970-1998

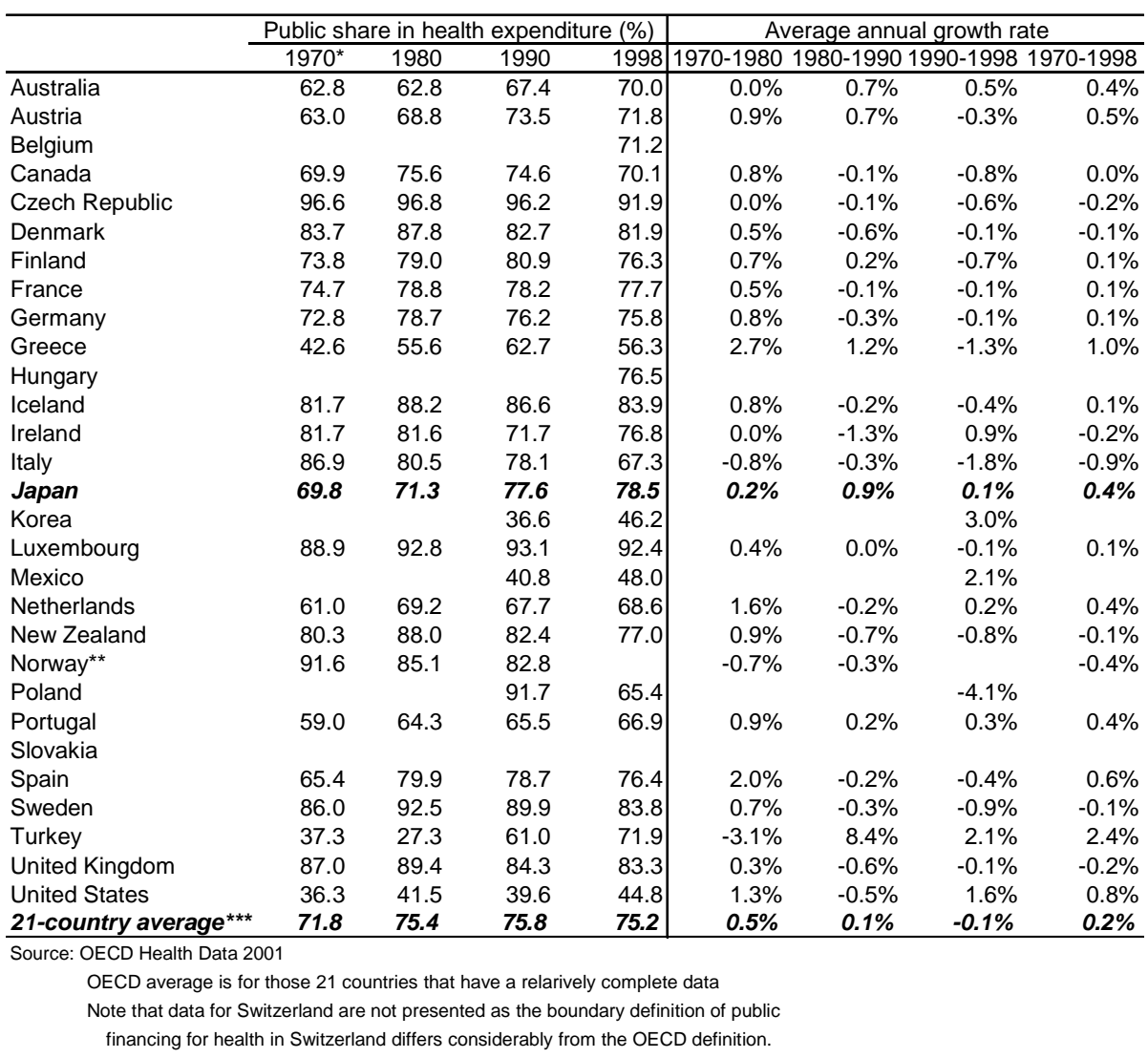

34 According to OECD Health Data, public funding for health care is the "compulsory funding typically by a mix of central, state and local taxes, and by contributions to social security schemes'.

35. This comparatively high public funding share is noteworthy in terms of a low health expenditure in Japan for two reasons: the government's incentive to contain costs and the broad field for its monopsony power (see section 4.2.1. Macroeconomic Efficiency). First, Japanese governments have tried to contain health expenditure because the bulk of the health expenditure falls on the public purse and there is increasing popularity of tax-cuts. A health price increase in the revision of the Fee Schedule would bring about a corresponding increase in government subsidy by the general budget. Second, the probability of success in cost-containment policies is rather high because the field where Japanese public sector's monopsony power of setting the prices in the Fee Schedule works is relatively broad (JEONG, 1994). 


\subsubsection{Inpatient/Outpatient/Drug Expenditure}

45. Table 7 suggests that Japan has an unusual mix of health expenditure by type of service, compared with thirteen other OECD countries for which data are available. In 1998, it had the fourth lowest inpatient share of THE (37.6\%), a higher-than-average outpatient (or ambulatory) share (32.8\%) and the second or third highest drug share $(16.8 \%)$ among 14 countries $^{36}$. These three shares coincide, respectively, with a low admission rate, a high consultation rate (see section on 3.2.2.2. Activities and Utilisation) and a lack of separation between prescribing and dispensing (see below). The outpatient share in Japan, however, has declined fast for the last two decades, while the OECD average has remained almost unchanged in the same period.

Table 7: Health expenditure according to type of service, \% of Total Health Expenditures

\begin{tabular}{|c|c|c|c|c|c|c|c|c|c|}
\hline \multirow{2}{*}{ Country } & \multicolumn{3}{|c|}{ Inpatient Care } & \multicolumn{3}{|c|}{ Outpatient Care } & \multicolumn{3}{|c|}{ Drugs } \\
\hline & 1980 & 1990 & 1998 & 1980 & 1990 & 1998 & 1980 & 1990 & 1998 \\
\hline Australia & 51.0 & 45.9 & 43.3 & 22.3 & 21.9 & 22.0 & 7.9 & 8.9 & 11.4 \\
\hline Belgium & 33.1 & 32.8 & 34.6 & 39.2 & 39.8 & 34.0 & 17.4 & 15.5 & \\
\hline Canada & 53.8 & 49.0 & 43.1 & 25.1 & 26.0 & 26.5 & 8.5 & 11.4 & 15.0 \\
\hline Denmark & 61.6 & 56.7 & 54.3 & 22.3 & 22.2 & 23.8 & 6.0 & 7.5 & 9.2 \\
\hline Finland & 46.3 & 44.7 & 41.1 & 25.0 & 31.4 & 30.6 & 10.7 & 9.4 & 14.6 \\
\hline France & 48.2 & 46.0 & 44.6 & 25.2 & 23.6 & 23.0 & 15.9 & 20.0 & 21.9 \\
\hline Germany & 33.2 & 34.7 & 34.0 & 33.4 & 30.4 & 28.9 & 13.4 & 14.3 & 12.7 \\
\hline Iceland & 59.1 & 54.9 & 55.1 & 16.9 & 22.9 & 22.9 & 15.9 & 15.7 & 15.5 \\
\hline Italy & 46.7 & 45.3 & 44.5 & 27.5 & 29.1 & 27.7 & 13.7 & 18.3 & 17.5 \\
\hline Japan & 30.9 & 33.0 & $37.6(29.8)^{*}$ & 44.6 & 43.9 & $32.8(39.6)$ & $19.5^{\star \star}$ & 21.4 & $16.8(20.0)$ \\
\hline Luxembourg & 31.3 & 26.4 & 30.7 & 49.5 & 49.3 & 49.9 & 14.5 & 14.9 & 12.3 \\
\hline Netherlands & 55.5 & 50.5 & 52.8 & 21.4 & 24.4 & 20.2 & 7.4 & 9.1 & 10.8 \\
\hline Switzerland & 39.9 & 49.5 & 50.3 & 42.6 & 39.5 & 40.1 & 8.9 & 8.2 & 7.6 \\
\hline United States & 49.6 & 44.9 & 41.3 & 27.2 & 31.1 & 32.5 & 9.1 & 9.2 & 10.1 \\
\hline Average & 45.7 & 43.9 & 43.8 & 30.2 & 31.1 & 29.4 & 11.5 & 13.1 & 13.2 \\
\hline \multicolumn{10}{|c|}{ Source: OECD Health Data 2001} \\
\hline \multicolumn{10}{|c|}{ NOTE: Nearest available data to 1980,1990 and 1998 were used for some countries } \\
\hline \multicolumn{10}{|c|}{$\begin{array}{l}{ }^{*} \text { Figures in parenthesis are shares in 1997. These figures are shown since there is a break in estimation method between } 1998 \\
\text { and previous years in Japanese health expenditure data. This break has brought Japanese data closer in line with OECD Health } \\
\text { Data standards. }\end{array}$} \\
\hline 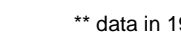 & & & & & & & & & \\
\hline
\end{tabular}

46. Chart 8-1 shows that drug expenditure $e^{37}$ per capita in Japan was the fourth highest among the 25 countries for which data is available. Looking at trends over time, drug expenditure per capita in real terms (i.e. adjusted for changes in the GDP deflator) has increased continuously for decades. The increase in real terms can be divided into a) (relative drug) price and b) volume increases. Price increases (a) have been

36 There appears to exist differences in the mix of Japanese health expenditure by type of services between Table 7 and National Medical Expenditure (NME), of which in-patient expenditure including in-patient drugs and meals was $41.0 \%$, ambulatory care expenditure $41.4 \%$ and expenditure at pharmacy $6.7 \%$. Main difference here lies in the different classification such as where drugs prescribed by doctors belong (see footnote 37 ). In terms of expenditure by disease group, circulatory diseases accounted for $23.2 \%$ of general health care expenditure (IppanshinryoIryohi: a subset of NME which includes health care expenditure in both hospitals and doctor's clinics but excludes expenditure at dental clinics, pharmacies, etc.). Malignant neoplasm accounts for $10.8 \%$ of general health care expenditure, digestive disease for $8.1 \%$, respiratory diseases for $8.0 \%$, and musculo-skeletal diseases for $7.8 \%$.

37 According to OECD definition, drug expenditure covers expenditure on prescription medicines and self-medication, often referred to as over-the-counter (OTC) products. It also includes pharmacists' remuneration when the latter is separate from the price of medicines. Drugs consumed in inpatient wards of hospitals are excluded. Japanese drug expenditure in the OECD Health Data follows this definition by covering expenditures on pharmaceutical goods delivered in outpatient department of hospitals and by doctors in doctor's clinics as well as prescription medicines and self-medication delivered in pharmacies. These figures are calculated, by multiplying the total expenditure of each department (from National Medical Expenditure estimates) by the "drug share" (the share of the fees for "medications" and "injections" to the total fees). It also includes pharmacists' remuneration. 
successfully controlled. Linking them with the actual retail prices surveyed by the government has long lowered the reimbursement prices, particularly of old drugs, which are normally falling ${ }^{38}$. Although most pharmaceutical companies have managed to counteract price controls on older drugs by continuously introducing marginally improved "new drugs", for which higher prices could be charged, overall drug prices have been kept low. The high level of increase in drug expenditure is due to volume increases (b). As shown in Chart 8-2, out of the 3.8\% real annual growth rate in per capita drug expenditure between 1984 and 1997, the part due to increase in the (relative drug) price was only 0.1 percentage points. Government's policy to reduce the difference between purchasing and reimbursing prices of drugs does not seem to have succeeded in achieving its main aim of reducing doctor's incentive to over-prescription. As has been indicated above (see Box 1 in section 2.2.1. Patients and Providers), the lack of separation between prescribing and dispensing of drugs in Japan, i.e. the current policy whereby doctors are legally permitted to dispense drugs rather broadly, may offer part of the explanation.

Chart 8-1: Drug expenditure per capita (US\$PPP), 1999

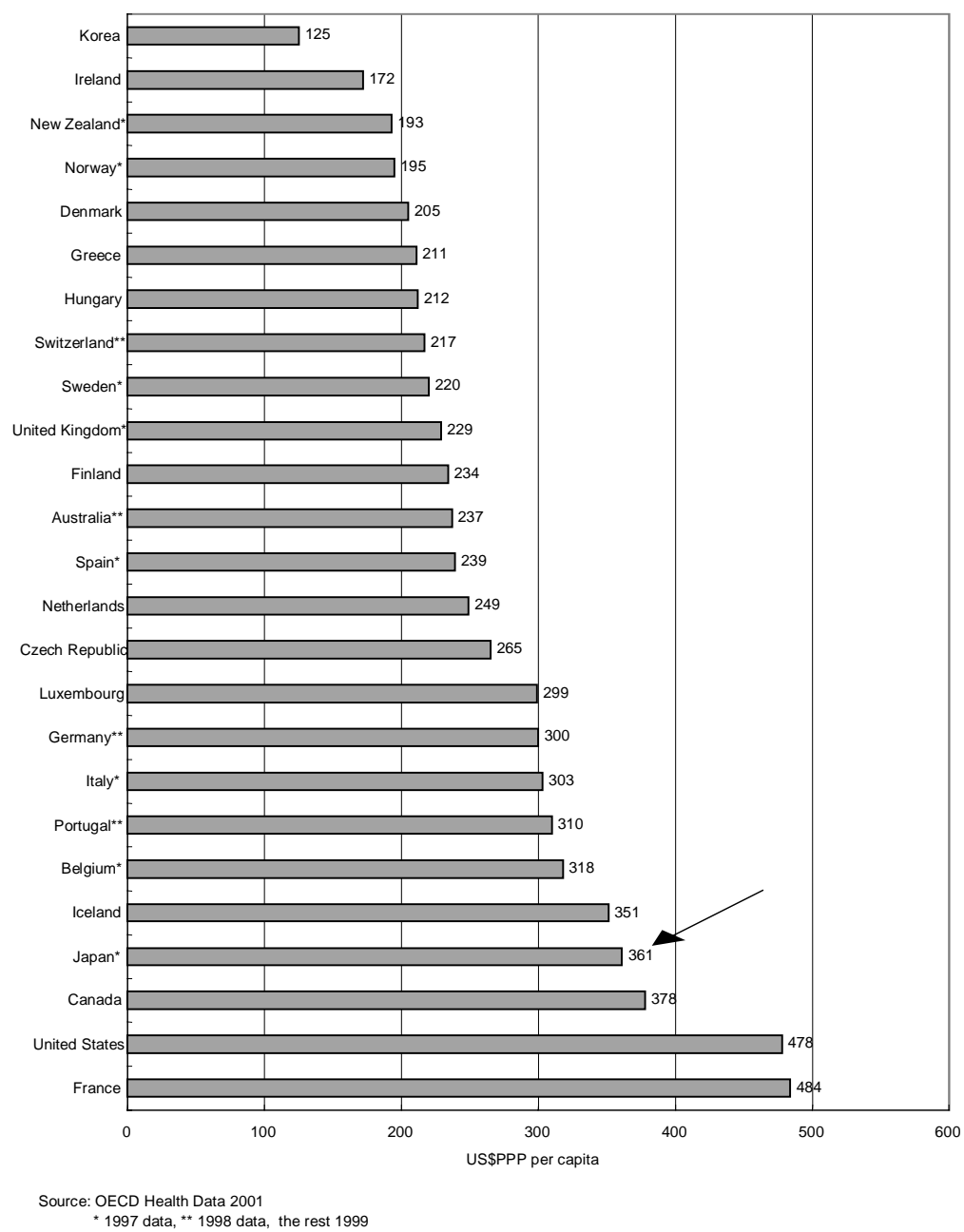

38. On-site inspections of drug wholesalers, in addition to the periodic national questionnaire survey of the price paid by the providers, have been carried out to check the actual retail price of popular pharmaceuticals since the 1981 Fee Schedule revision. 


\section{DEELSA/ELSA/WD(2001)9}

\section{Chart 8-2: Volume and price increase in the real growth of drug expenditure per capita Japanese,}

1984-1997

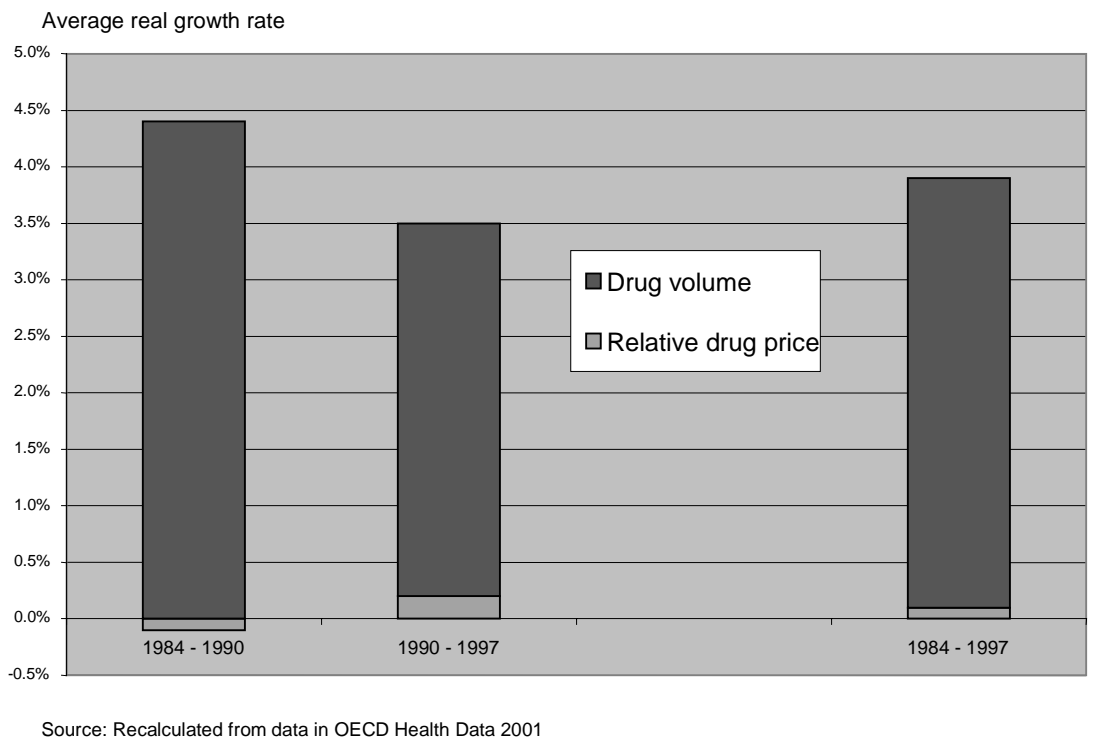

\subsection{Real Flows}

\subsubsection{Inputs}

47. As shown in Chart 9, the number of practising doctors per 1000 population in Japan was 1.9 in $1998^{39}$. This is among the lowest in the OECD, whose average was 2.9. Only Japan and the $\mathrm{UK}^{40}$ had less than 2.0 practising doctors per 1000 population in the OECD, putting aside some relatively low-income countries. Among OECD countries, the increase in the number of doctors was slowest in Japan with an average annual growth rate of $1.7 \%$ between 1960 and 1998, compared with the OECD average growth rate of $2.6 \%$. The Japanese government has followed a policy of constraining the growth of doctors on the expectation that supply could exceed need. An official report submitted to the Ministry estimated that the doctors needed per 1000 population in 2020 would be 2.37 , while the doctors supplied would be 2.43 as long as the graduation rate of medical students continued at its current rate ${ }^{41}$. The policy is, therefore, to try to reduce entrants to medical school by $10 \%$ before 2020 , when the population of the aged is expected to peak.

39 The number of Japanese doctors per 1000 population is a little more than this. The OECD figure is the number of active doctors. In 1996, 96.2\% of existing doctors were reported to work in medical facilities.

40 In the case of the UK, with 1.7 doctors per 1000 population in 1998, the current government considers that there is now a shortage of doctors. The UK is planning an unparalleled increase of doctors by training 7,500 more consultants and 2,000 more GPs between now and 2004. (The NHS Plan, www.nhs.uk/nhsplan/)

41 The report of the Review Committee on Supply and Demand of Doctors (1998) expects an oversupply of doctors from 2017 and the oversupply would amount to about 6,000 doctors in 2020. Here, factors considered to influence the supply of doctors were the number of entrants to medical schools, the success rate in the examination for the licence of medical doctor, and the activity rate of aged doctors and female doctors; whereas, factors considered to influence the demand of doctors were the change of population structure, the number of inpatients and outpatients, the trend of the aged who need care, the rate of consultation with doctors, the demand for doctors in university hospitals and in emergency care, the number of doctors under the internship in teaching hospitals and the number of doctors in the non-clinical field. 
Chart 9: Practising doctors* per 1000 population
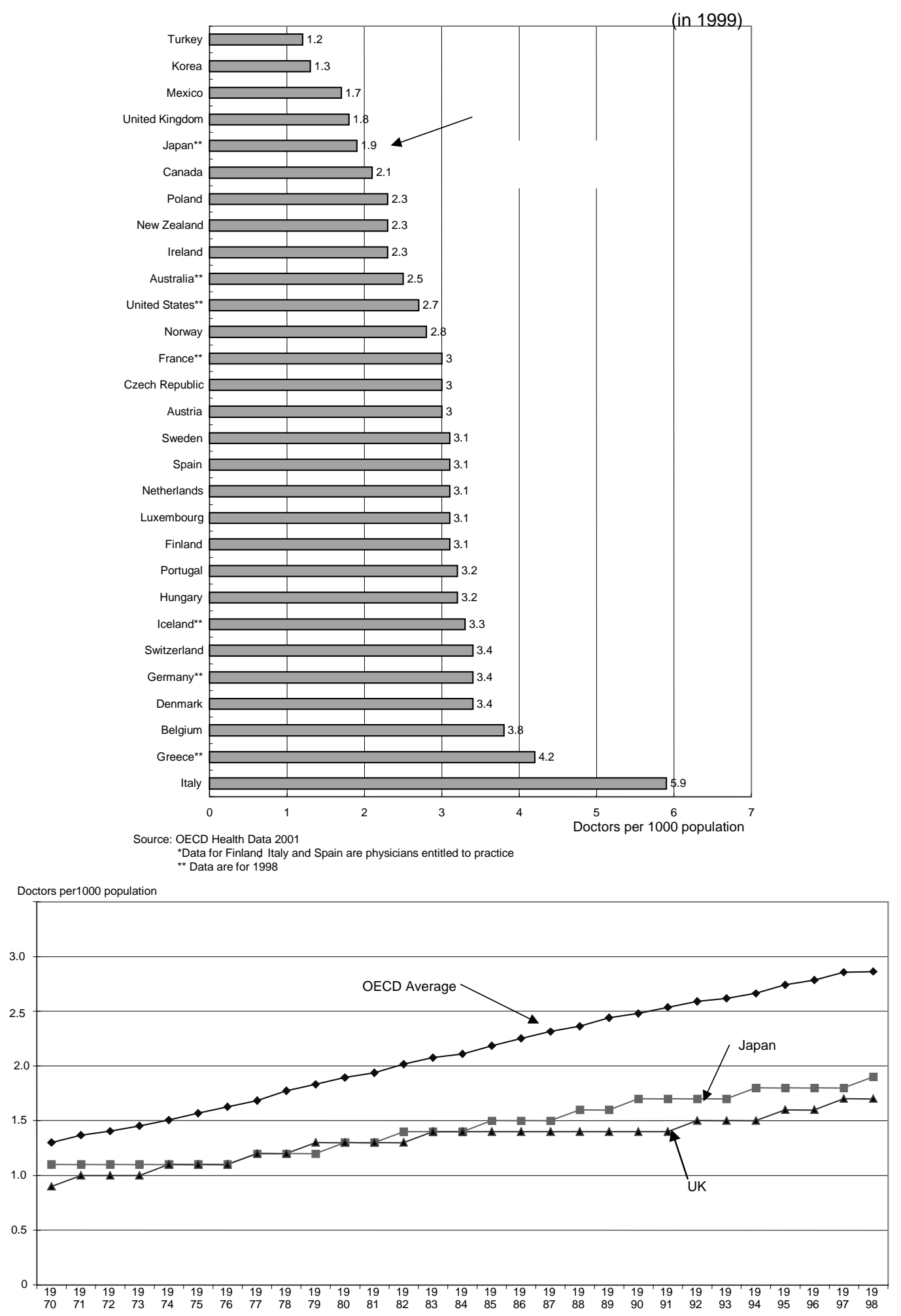

Source: OECD Health Data 2001 
48. The number of practising pharmacists ${ }^{42}$ per 1000 population was $1.0 \mathrm{in} 1998$. It is of interest that this is much over the OECD average of 0.7, despite the fact that doctors as well as pharmacists dispense in Japan. The number of practising pharmacists per doctor, at 0.53 in the late $1990 \mathrm{~s}$, was also the highest among OECD countries, whose average was 0.26.

Table 8: Practicing pharmacists both per 1000 population and per doctor, late 1990s

\begin{tabular}{lcc}
\hline \multicolumn{1}{c}{ Country } & $\begin{array}{c}\text { Pharmacists per } 1000 \\
\text { population }\end{array}$ & Pharmacists per docor \\
\hline Australia & 0.6 & 0.24 \\
Austria & 0.5 & 0.17 \\
Belgium & 1.4 & 0.40 \\
Canada & 0.6 & 0.29 \\
Czech Rep. & 0.4 & 0.13 \\
Denmark & 0.5 & 0.15 \\
Finland & 1.4 & 0.48 \\
France & 1.1 & 0.37 \\
Germany & 0.6 & 0.18 \\
Greece & 0.8 & 0.20 \\
Hungary & 0.5 & 0.16 \\
Iceland & 1.2 & 0.36 \\
Ireland & 0.8 & 0.35 \\
Japan & $\mathbf{1 . 0}$ & $\mathbf{0 . 5 3}$ \\
Luxembourg & 0.7 & 0.23 \\
Netherlands & 0.2 & 0.06 \\
New Zealand & 0.6 & 0.29 \\
Norway & 0.4 & 0.14 \\
Poland & 0.5 & 0.22 \\
Portugal & 0.8 & 0.25 \\
Spain & 0.7 & 0.23 \\
Sweden & 0.6 & 0.19 \\
Turkey & 0.3 & 0.25 \\
U.K. & 0.6 & 0.38 \\
USA & 0.7 & 0.27 \\
\hline Average & $\mathbf{0 . 7}$ & \\
Source: OECD Health Data 2001 & & \\
& &
\end{tabular}

49. The number of practising certified nurses ${ }^{43}$ per 1000 population in Japan was 7.8 in 1998 . This is a little over the OECD average of 7.3. Nurse numbers increased by 3.5\% per annum in Japan between 1960 and late 1990s. The OECD average growth rate was $2.2 \%$ during the same period. Japan suffered from a scarcity of nurses until the 1980s, and efforts made to resolve that problem brought about the fast increase of nurses in the 1990s.

42 According to the OECD definition, number of pharmacists self-employed or employed by others. The data should exclude full-time salaried pharmacists working in hospitals and in pharmaceutical manufacturing corporations as well as pharmacists working abroad. But, as a matter of fact, many countries' figures, including those for Japan, include salaried pharmacists working in research, industry and administration as well as hospital. (OECD Health Data 2001)

43 According to the OECD definition, actively practising certified/registered nurses employed in public and private hospitals, clinics and other health facilities. (OECD Health Data 2001) 
Table 9: Trends in number of practising certified nurses per 1000 population, 1960-1999

\begin{tabular}{|c|c|c|c|c|c|c|}
\hline \multirow{2}{*}{ Country } & \multicolumn{5}{|c|}{ Nurses per 1000 population } & \multirow{2}{*}{$\begin{array}{c}\text { Annual growth rate } \\
1980 \text { - late } 1990 \text { s }\end{array}$} \\
\hline & 1960 & 1970 & 1980 & 1990 & late 1990s & \\
\hline Australia & 6.1 & 4.3 & 7.1 & 8.5 & 8.1 & $0.8 \%$ \\
\hline Austria & 2.5 & 3.4 & 5.4 & 7.2 & 9.0 & $2.7 \%$ \\
\hline Canada & & 4.9 & 6.3 & 8.1 & 7.5 & $0.9 \%$ \\
\hline Czech Republic & & & 6.7 & 8.1 & 8.2 & $1.1 \%$ \\
\hline Denmark & & & 5.1 & 6.8 & 7.3 & $1.9 \%$ \\
\hline Finland & 2.6 & 6.0 & 8.3 & 10.2 & 14.4 & $2.9 \%$ \\
\hline France & & 3.0 & 4.6 & 5.4 & 6.0 & $1.6 \%$ \\
\hline Germany & 1.7 & 2.4 & 6.2 & 8.9 & 9.6 & $2.5 \%$ \\
\hline Greece & & 1.8 & 2.4 & 3.4 & 3.6 & $2.4 \%$ \\
\hline Hungary & 1.7 & 2.7 & 3.7 & 4.5 & 5.0 & $1.6 \%$ \\
\hline Iceland & 2.4 & 4.9 & 9.6 & 13.3 & 13.8 & $2.2 \%$ \\
\hline Italy & 1.1 & 2.1 & 4.1 & 4.7 & 4.6 & $0.6 \%$ \\
\hline Japan & 2.0 & 2.6 & 4.2 & 6.0 & 7.8 & $3.5 \%$ \\
\hline Mexico & & & 0.3 & 0.7 & 1.2 & $7.6 \%$ \\
\hline New Zealand & & & 6.1 & 9.3 & 9.6 & $2.4 \%$ \\
\hline Norway & & & 9.3 & 13.2 & 14.9 & $3.0 \%$ \\
\hline Poland & 2.1 & 3.0 & 4.4 & 5.5 & 5.1 & $0.8 \%$ \\
\hline Portugal & 0.7 & 1.5 & 2.3 & 2.8 & 3.8 & $2.8 \%$ \\
\hline Spain & 0.9 & 0.8 & 3.3 & 4.1 & 3.6 & $0.5 \%$ \\
\hline Sweden & 3.1 & 4.3 & 7.0 & 9.2 & 10.2 & $2.5 \%$ \\
\hline Turkey & & 0.2 & 0.6 & 0.8 & 1.1 & $3.2 \%$ \\
\hline United Kingdom & 3.5 & 3.9 & 4.3 & 5.2 & 4.5 & $0.2 \%$ \\
\hline United States & 2.9 & 3.7 & 5.6 & 7.2 & 8.3 & $2.2 \%$ \\
\hline Average & & & 5.1 & 6.7 & 7.3 & $2.2 \%$ \\
\hline
\end{tabular}

Source: OECD Health Data 2001

*1960,1970, 1980 and 1990: data of the nearest year for a few countries

50. The number of beds in inpatient care facilities per 1000 population was 16.5 in 1998, more than twice the OECD average of 6.9 (Chart 10). Bed numbers in Japan were almost at the average OECD level until the 1960s, but have grown rapidly compared with the average since then. However, this comparison is debatable since not all countries report bed data according to the OECD definition ${ }^{44}$.

Chart 10: Trends in number of beds in inpatient care facilities per 1000 population, 1960-1998

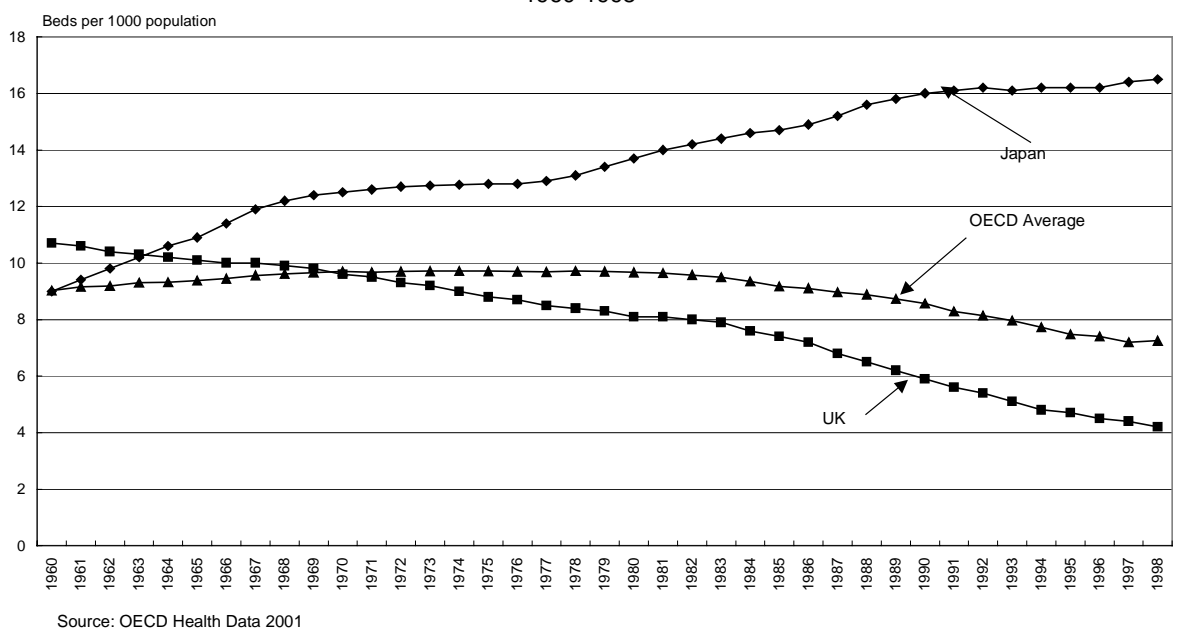

44 The recommended OECD definition is: beds accommodating patients in hospitals, in other nursing and residential care facilities or in establishments that are classified according to their focus of care under ambulatory care facilities but perform in-patient care as a secondary activity. In the case of Japan, data on "inpatient care beds" are reported by adding "beds in intermediate nursing facilities" based on the Survey of Health Services Facilities for the Aged to "all beds in all types of hospitals and doctor's clinics" based on the Survey of Medical Institutions. 
51. According to the Survey on Medical Institutions 1999, beds per 1000 population in the case of Japanese "general beds ${ }^{45}$ in general hospitals" (hereafter general beds I) were 10.0 in 1998 (Chart 11). This figure excludes not only the beds in dental, mental, epidemic and tuberculosis hospital and the beds in doctor's clinics but also the beds functioning as mental and tuberculosis bed in general hospitals. This still includes beds in geriatric hospitals and geriatric beds in general hospitals (see Table 1). General beds I less beds in geriatric hospitals and geriatric beds in general hospitals (hereafter general beds II) were 7.9 in 1998, still around twice the OECD average for beds in acute care hospital ${ }^{46}$ of 4.0 beds. However, the definitions may differ here. The growth of beds in Japan until 1980s was in contrast to the general tendency to reduce hospital beds in other OECD countries over this period, but Japanese general beds have decreased since 1990. The increase of beds in inpatient care facilities together with the decrease of general beds over this period suggests that recent reforms to shift the balance of long term care away from hospitals towards nursing homes have begun to have an effect.

52. Japanese general beds include some beds that are, in effect, used for long term care. Many of these might be classified as nursing home beds in other countries. The high number of long-term care beds in hospitals reflects what is sometimes referred to as "social hospitalisation". Part of the reason for "social hospitalisation" is that patients have faced a much lower price for long term care in hospitals than they would have faced for such care in their own homes or in private elderly homes ${ }^{47}$. That is because health insurance cover was not available for significant levels of home care or for nursing home care except intermediate nursing facilities prior to the introduction of Long-term Care Insurance. Only patients eligible for welfare could utilise special nursing homes with a low payment of around $¥ 40$ thousand per month. As a consequence, there has been little growth in private nursing homes.

IppanByosho

46 According to the OECD definition, beds accommodating patients where the principal clinical intent is to do one or more of the following: to manage labour (obstetric), to cure illness or provide definitive treatment of injury, to perform surgery, to relieve symptoms of illness or injury (excluding palliative care), to reduce severity of illness or injury, to protect against exacerbation and/or complication of an illness and/or injury which could threaten life or normal functions, and to perform diagnostic or therapeutic procedures. (OECD Health Data 2001)

47. Inpatients in geriatric hospitals or in geriatric beds of hospitals paid around $¥ 55$ thousand (¥36 thousand for institutionalisation plus $¥ 23$ thousand for meals) per month. The full (uninsured) cost of private nursing home care would have been at least $¥ 300$ thousand per month, considering that the intermediate nursing facilities received about $¥ 243$ to $¥ 289$ thousand from both governments and health insurers, in addition to $¥ 60$ thousand per month from their residents. (Ministry of Health, Labour and Welfare, 1999 a, p.179, and 1998, p.223) 
DEELSA/ELSA/WD(2001)9

Chart 11: Number of beds per 1000 population in acute care hospitals
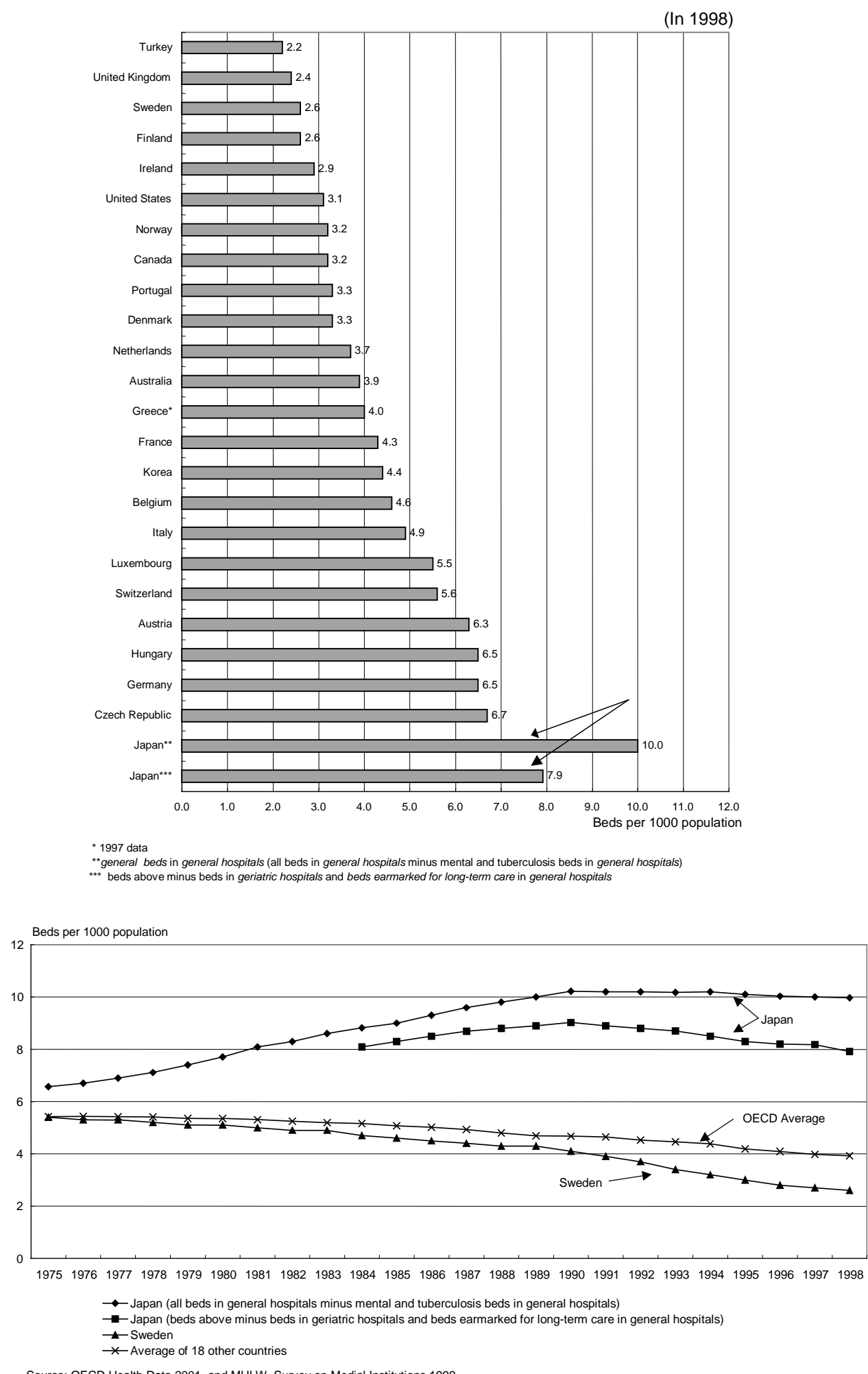

Source: OECD Health Data 2001, and MHLW, Survey on Medial Institutions 1999 


\subsubsection{Process}

\subsubsection{Functions}

53. Japanese hospitals offer a different mix of services from those in many OECD countries. They overlap both into primary ambulatory care and into long-term care. Firstly, hospitals are not clearly differentiated from doctor's clinics. According to Patient's Survey 1999 (MHLW), 37.5\% of total ambulatory care patients were visitors to hospitals in 1999 (Chart 12). The recent increase in the number of ambulatory care patients has been led by the rapid growth in the number of outpatients in hospitals. Hospitals maintain large outpatient departments from which they admit many of their inpatients. More than $90 \%$ of the visits to their outpatient department are made without a referral (Table 10). Hence, both doctor's clinics and hospitals compete for ambulatory patients who are free to choose the facility they want, presumably the one they see as being most convenient or having the best quality.

\section{Chart 12 . Share of ambulatory care patients} in doctor's clinics and hospitals

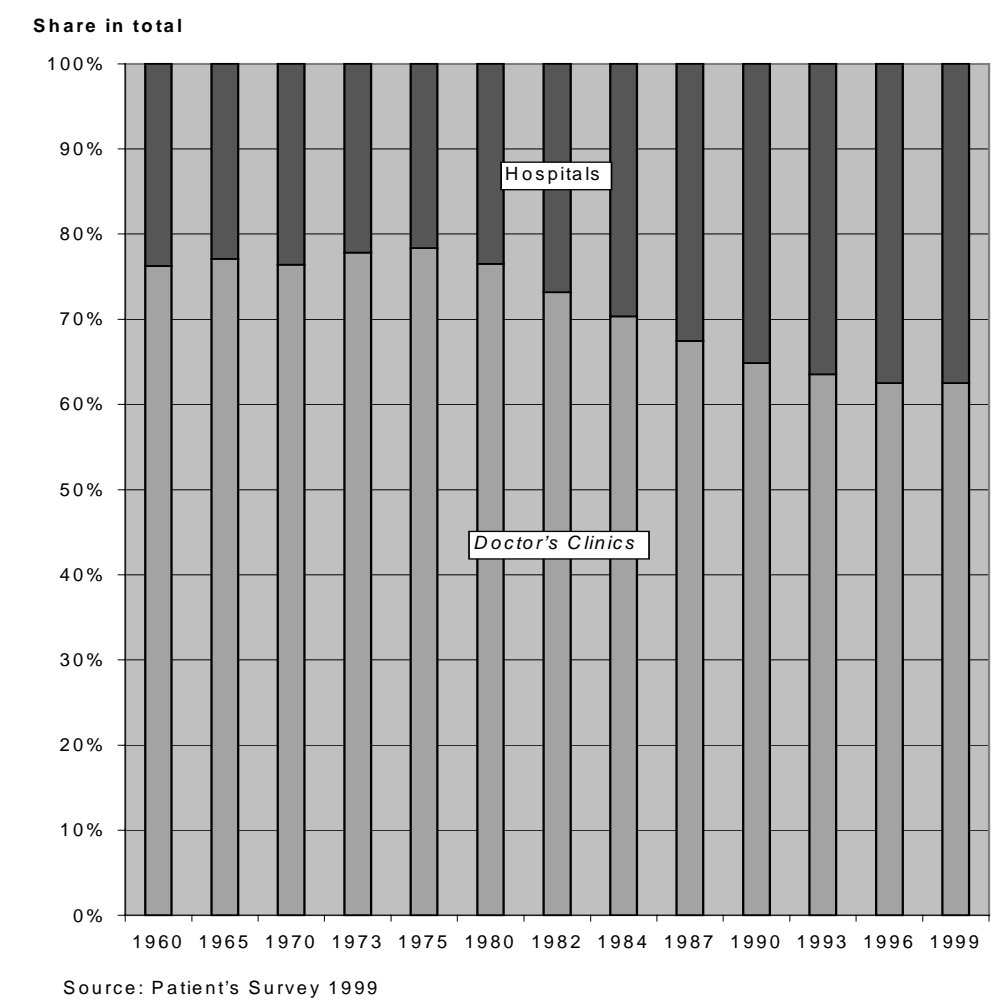

Table 10: Patients referred to hospitals

\begin{tabular}{lccccccc}
\hline & Referred patients & \multicolumn{5}{c}{ Referred from where (\% in tatal referred patients) } \\
\cline { 3 - 7 } & (\% in the surveyed) & Total & Hospital & Doctor's clinic & Dental clinic & Nursing home & the Others \\
\hline Inpatient & $41.8 \%$ & $100.0 \%$ & $57.1 \%$ & $18.0 \%$ & $0.1 \%$ & $5.2 \%$ & $19.5 \%$ \\
Outpatient & $9.6 \%$ & $100.0 \%$ & $38.4 \%$ & $33.1 \%$ & $1.4 \%$ & $0.8 \%$ & $26.4 \%$ \\
\hline
\end{tabular}

Source: Patient's Survey 1999 
54. The public and university hospitals have been made more and more attractive to ordinary patients seeking routine outpatient care. Hospitals have every incentive to deliver primary care since it is the most profitable type of treatment (Campbell and Ikegami, 1998). Paying all providers not so different fees for a given consultation or treatment does not encourage functional differentiation ${ }^{48}$. The result may be a misallocation of medical resources. This system sometimes leads to duplication of equipment and to repetition of diagnostic tests by different providers. In addition, the uniform fee-schedule has had the effect of deterring providers from supplying high technology procedures, by making these procedures relatively unprofitable. However, since the hospital doctors do not have their own private offices or clinics, they do not have incentives to induce their patients to take up private medical care as can be found in some other countries such as France.

55. Secondly, as has been mentioned above, some beds in general hospitals have taken on the longterm care function. Many hospital inpatients are elderly people receiving custodial care. According to the Patient's Survey, more than half of hospital inpatients were aged 65 or more. This differentiates Japan from most of the other OECD countries, where the elderly in need of care normally stay in nursing or residential homes $^{49}$. In 1984, the government split off geriatric hospitals that are legally hospitals but actually function in some part as nursing homes. All hospitals with at least $60 \%$ of its inpatients aged 65 or more, and not meeting the standards for nurse staffing ratios, were automatically given that title and became subject to more "bundling" in the fees paid for their services. The number of geriatric hospitals was 1,032, $12.6 \%$ of general hospitals in 1999. Geriatric beds earmarked for long-term care in general hospitals also became subject to "bundling" in the 1990s. Geriatric beds in general hospitals amounted to 167 thousand beds (13\% of general beds) in 2,227 hospitals (27\% of general hospitals) in 1999 (see Table 1).

48 It could rather be said that this single Fee Schedule resulted from little functional differentiation. The present fee schedule ultimately derives from the fee-for-service payments used by office-based doctors when social insurance was first introduced in 1927. The fees set initially on the basis of the then customary charges to the office-based doctors were extended to hospital practice, when doctor's offices developed into hospitals.

49 The difference in the types of institution between Japan and other western countries is noteworthy. "Institutionalisation rate" (Nyushoritsu) of the elderly, often cited in the international comparison as well, appears to be erroneously low in Japan, as it includes only the admission in the special nursing homes (TokubetsuYogoRojinhom), not the admission in intermediate nursing facilities (RojinHokenShisetsu). 


\subsubsection{Activities and Utilisation}

\section{Doctor's Activities}

56. The number of doctor consultations per capita per year (hereafter, the consultation rate) in Japan was 16.0 in 1996 (Chart 13). This is the second highest among OECD countries, whose average was 6.9, although the consultation rate in Japan has increased at a slower pace than in the majority of OECD countries. Except for Japan, only Hungary and the Czech Republic have a consultation rate greater than 10 in the OECD area. This high consultation rate shows Japanese people's strong appetite not only for ambulatory care but also for drugs in the sense that doctors dispense as well as prescribe drugs in Japan.

Chart 13: Doctor consultations per capita
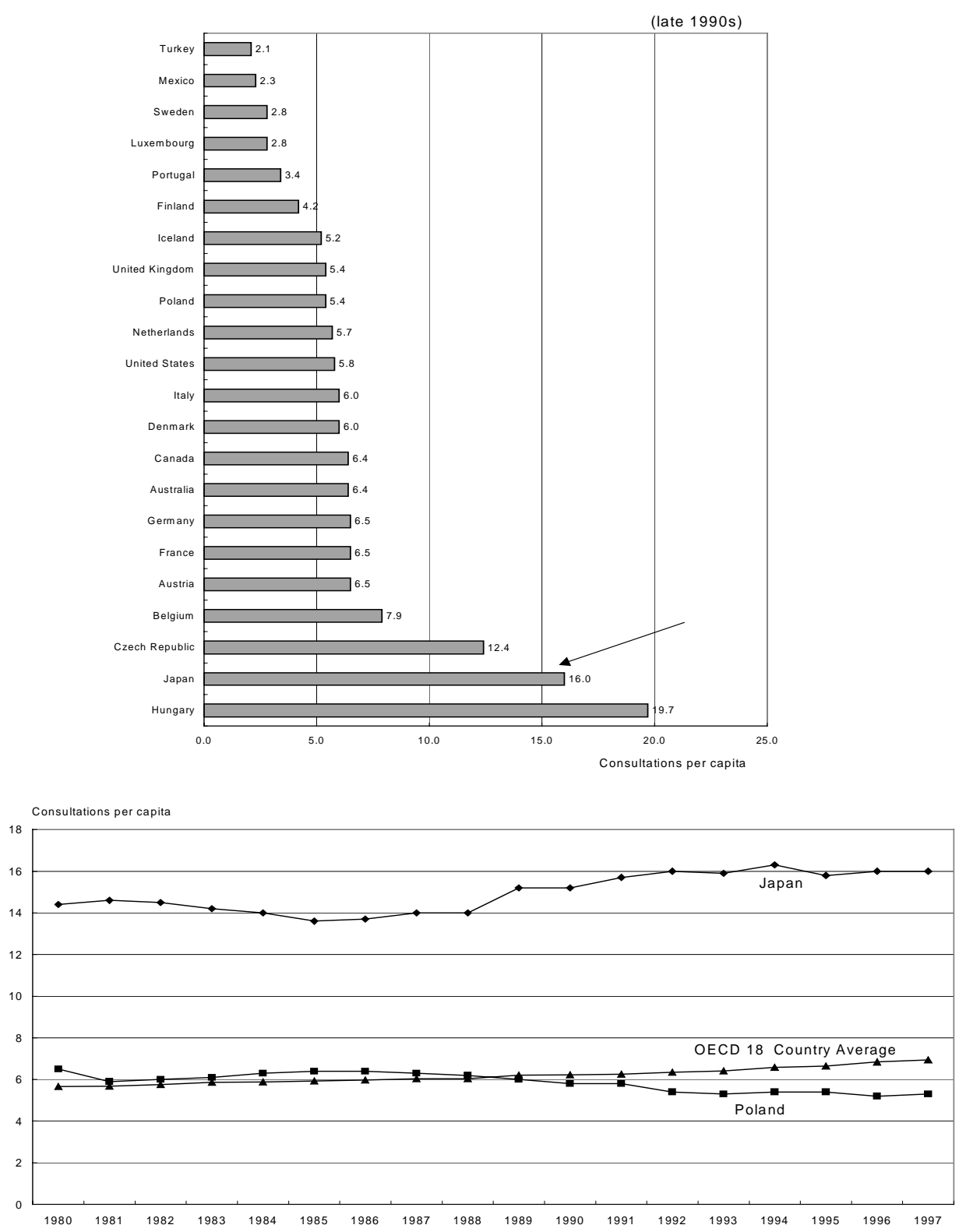

Source: OECD Health Data 2001 


\section{Bed Utilisation ${ }^{50}$}

57. Japanese patient days ${ }^{51}$ per capita in general beds I (3.0 days) or are much higher than the OECD average of bed days ${ }^{52}$ per capita in acute care hospitals (1.1 days). The main factors affecting bed days are average length of stay and admission rates.

58. The average length of stay (ALOS) of 30.8 days in general beds $I$ and the ALOS of 27.2 days in general beds II in 1999 were in contrast with the OECD average of 7.5 days in acute care hospital beds (Chart 14). The long ALOS in Japanese general beds is due largely to "social hospitalisation" (see section 3.2.1. Inputs). Also, the abundant supply of hospital beds, which had been built by the $1980 \mathrm{~s}$, gave hospitals an incentive to fill these beds (Jeong, 1995). Finally, the typical acute inpatient may be more severely ill than in other countries, given the low overall admission rate.

59. The ALOS in Japanese general beds of general hospital was at its peak in the early 1980s and then reduced. The reforms associated with the Health Service System for the Elderly, when intermediate nursing facilities started to be built, are likely to have played a part in bringing about the gradual reduction in length of stay. Also, Japanese hospitals may have begun to adopt earlier discharge practices for acutely ill patients, like hospitals in other OECD countries.

50. There are difficulties in comparing bed utilisation (bed days, length of stay and admissions) across OECD countries because of variations in the reporting of different types of hospital and nursing home activity to OECD Health Data. Japanese data on "inpatient care beds" are including "beds in intermediate nursing facilities" as well as "all beds in all types of hospitals and doctor's clinics". However, data on utilisation of inpatient care beds are those only of the latter. Moreover, Japanese acute care beds and their utilisation are not reported in OECD Health Data because of the lack of a Japanese equivalent for "acute care". However, general hospitals in Japan are hospitals that were built to treat acute cares as their main function, as were acute care hospitals in other OECD countries. The difference between the two lies in how far they are fulfilling their original function.

51. Here, a patient day is a day in which the patient stays overnight in hospital. Only days of admission are counted, but days of discharge are not counted (MHWL, Hospital Report 1999).

52. According to the OECD definition, a bed day is a day during which a person is confined to a bed and in which the patient stays overnight in a hospital. Day cases (patients admitted for a medical procedure or surgery in the morning and released before the evening) are excluded (OECD Health Data 2001). 


\section{DEELSA/ELSA/WD(2001)9}

Chart 14: Average Length of Stay in beds of acute care hospital

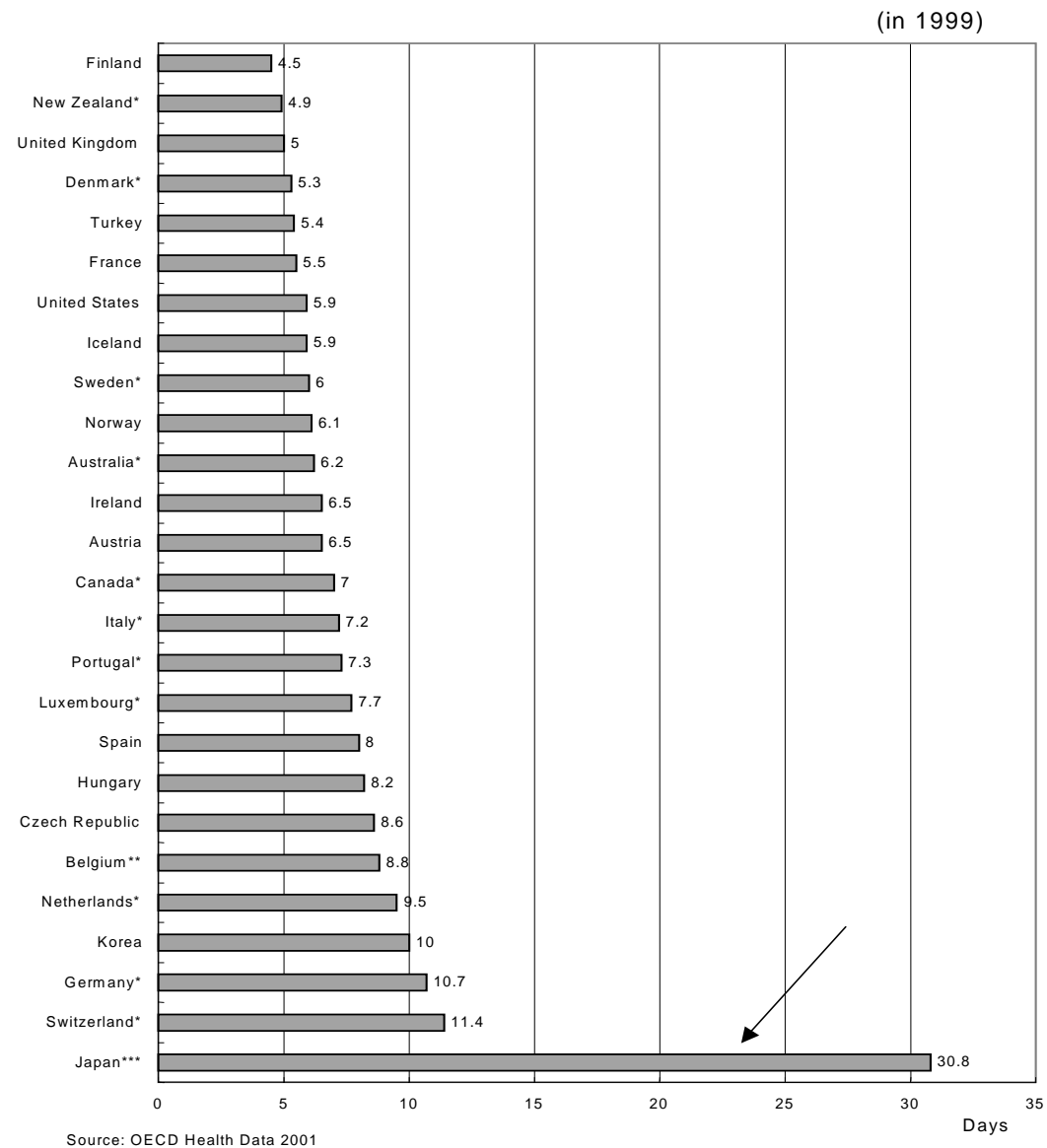

Source: OECD Health Data 2001

" 1998 data, ** 1997 data

from Hospital Report 1999

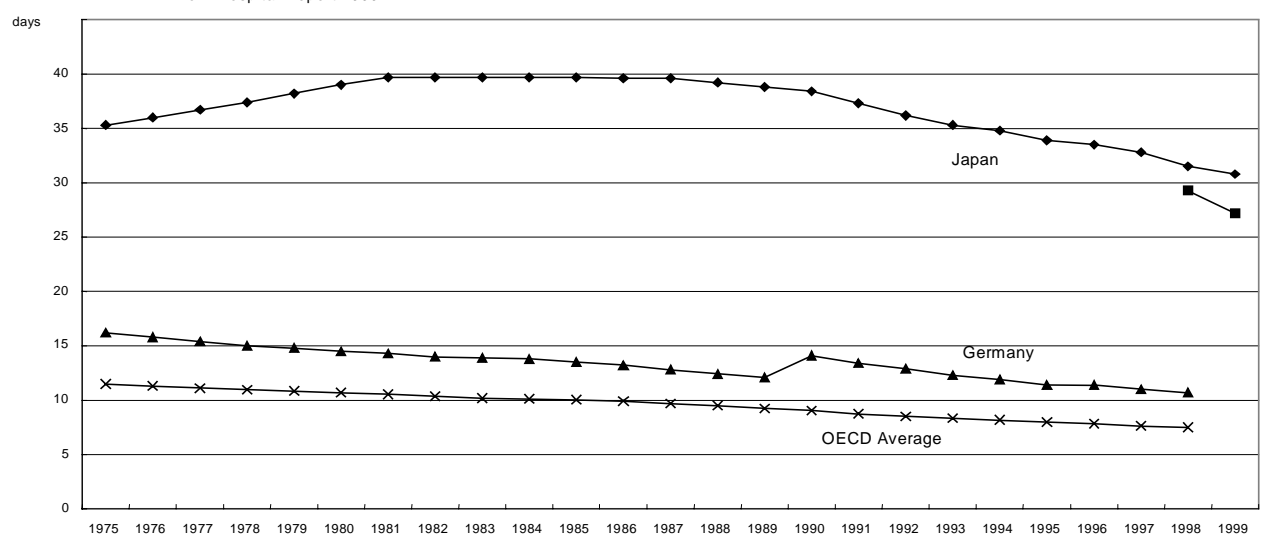

--Japan (all beds in general hospitals minus mental and tuberculosis beds in general hospitals)
- Japan (beds above minus beds earmarked for long-term care in general hospitals) \#-Average of 19 other countries

Source: OECD Health Data 2001

Japanese figure indicates ALOS in general beds of general hospitals from Hospital Report 1999 
60. Admissions to general beds per 1000 population in Japan were 98.1 in 1999, while the OECD average of admissions to acute care hospitals per 1000 population was 161.0 (Chart 15). This low admission rate may have been affected by Japanese people's long stays in hospitals, but it may also be due partly to the their aversion to invasive surgery. However, Japan experienced the largest growth among OECD countries in the admission rate over the past two decades.

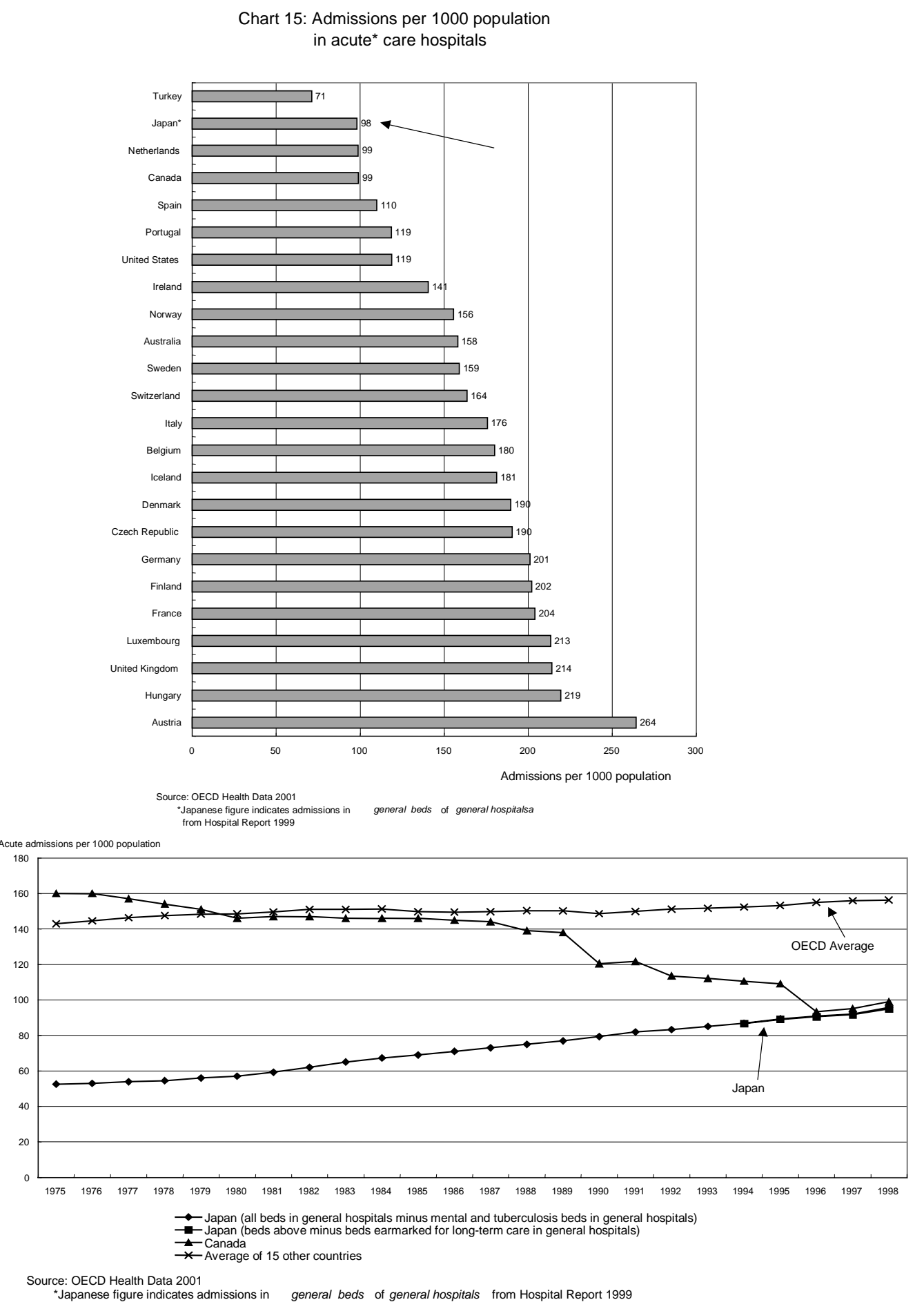




\section{ASSESSMENT OF PERFORMANCE AND ITS DETERMINANTS}

61. The OECD put forward some ideas about a common set of objectives for health care systems in 1992 (OECD, 1992). More recently, the WHO put forward somewhat similar proposals and has devoted its World Health Report 2000 to reporting estimates of the performance of the health care systems of its 191 Member countries against its proposed objectives (WHO, 2000). This assessment uses a framework derived from these ideas, set out in Table 11. It focuses on both the level and distribution of the three variables: health outcomes, responsiveness to consumers and health expenditure; and is designed to facilitate an assessment of both the efficiency (macro and micro) and the equity (fairness of distribution of health, fairness of access and fairness of finance) of any health system. This section will follow that framework. It will also explore some of the apparent determinants of the performance of the health system in Japan.

Table 11: Assessment framework

\begin{tabular}{|c|c|c|}
\hline Objectives & Average level & Distribution \\
\hline A. Health improvement/outcomes (+) & $\mathbf{V}$ * & V \\
\hline B. Responsiveness and access (+) & $\mathbf{V}$ & V \\
\hline \multirow[t]{2}{*}{ C. Financial contribution/health expenditure (-) } & V & $\mathbf{V}$ \\
\hline & Efficiency ** & Equity \\
\hline \multicolumn{3}{|l|}{ Source: OECD, DEELSA/ELSA/WP1(2000) } \\
\hline \multicolumn{3}{|l|}{ Adapted from Murray, C.J.S. and Frenk, J. (2000) } \\
\hline \multicolumn{3}{|c|}{ * This checking (v) signifies that data are collected to address the corresponding items. } \\
\hline \multicolumn{3}{|c|}{$\begin{array}{l}\text { ** Macroeconomic efficiency can be defined as whether health expenditure is at the desired level compared with other } \\
\text { goods and services. Microeconomic efficiency can be defined as the ratio of a weighted sum of health improvement and } \\
\text { responsiveness to health expenditure }[(\mathrm{a} A+\mathrm{bB}) / \mathrm{C} \text {, where } \mathrm{a} \text { and } \mathrm{b} \text { are weights on } \mathrm{A} \text { (average level of health Improvement } \\
\text { and } \mathrm{B} \text { (average level of responsiveness), respectively, and } \mathrm{C} \text { is average level of health expenditure]. }\end{array}$} \\
\hline
\end{tabular}

\subsection{Outcomes}

\subsubsection{Health Improvement}

\subsubsection{Health Status}

62. Japanese people enjoy excellent health status, judging by mortality data (Chart 16). The life expectancy at birth, 84.0 years for females and 77.2 years for males in 1998, is the highest in the world and is still on an increasing trend. The life expectancy in Japan was almost at the average OECD level until the early 1960s, but has grown more rapidly than in other OECD countries during the last four decades(Chart 17). The differential in life expectancy average between Japanese males and females has been widening for the last four decades, whereas the differential between males and females in the case of OECD average has slightly shrunk since 1980s. The number of potential years of life lost (PYLL) under age 70 per 100000 , at 2,182 for females and 3,996 for males, is also the lowest in the OECD area except for males in Sweden. 
DEELSA/ELSA/WD(2001)9

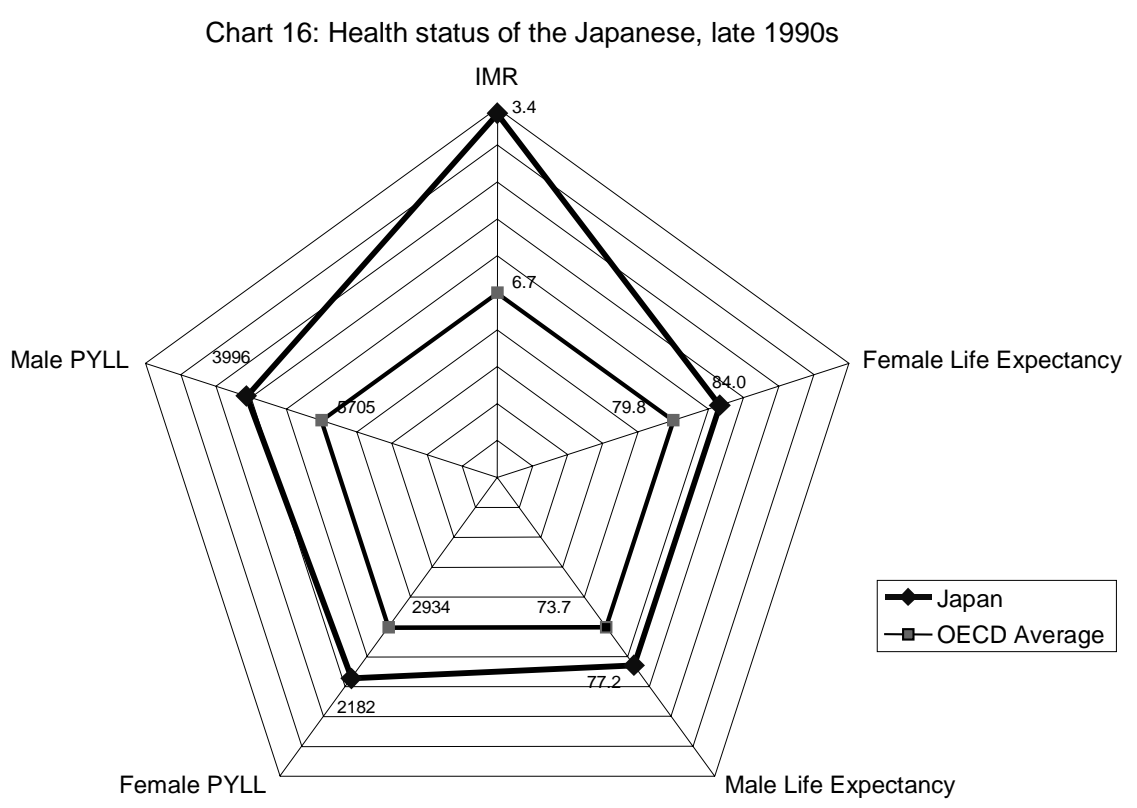

Source: OECD Health Data 2001

Chart 17: Trends in life expectancy at birth, 1960-1998

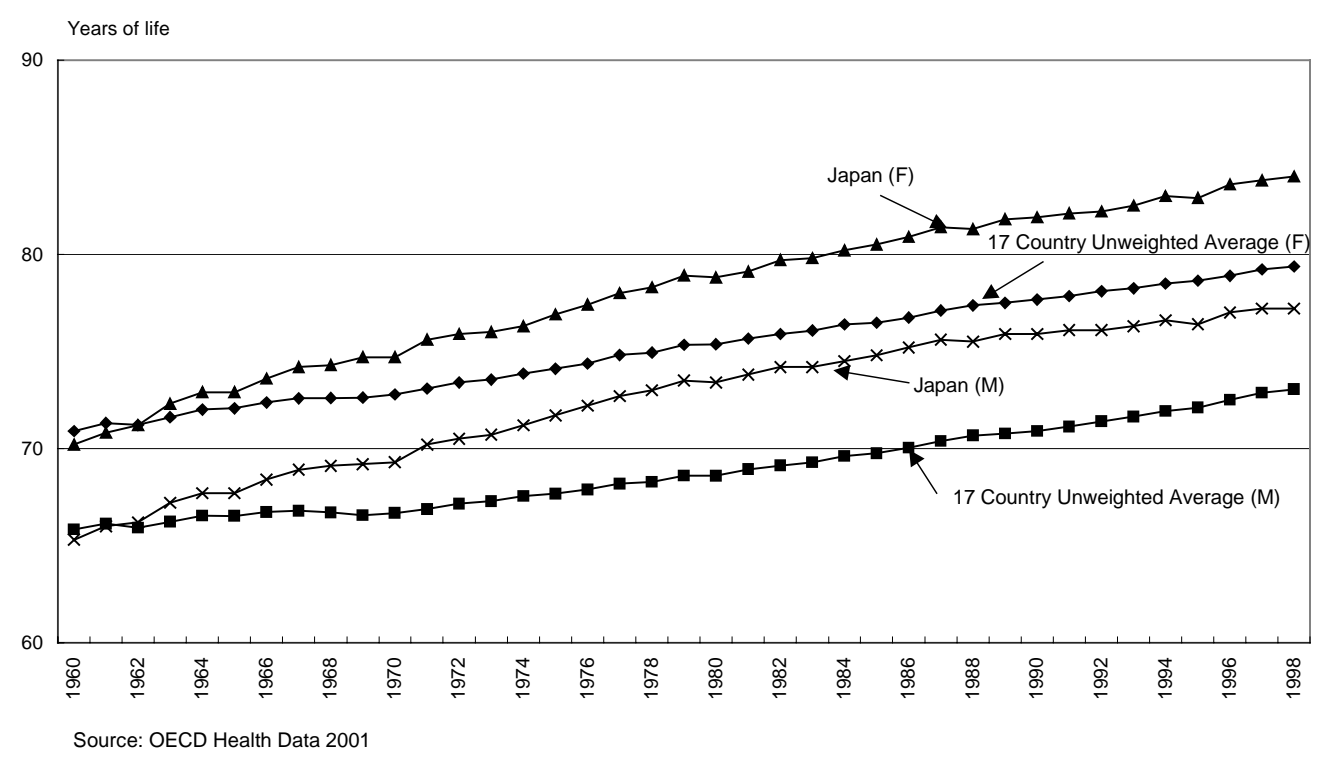


63. In contrast, the level of self-reported "good health" status is one of the lowest recorded among OECD countries. Less than half of the Japanese perceived his/her health as "good", while over $90 \%$ of the Canadian and the U.S. population reported themselves as being in good health (Chart 18). The reasons why Japanese people rate their health less positively than people in other OECD countries are not clear, but the low score is likely to be due partly to linguistic, survey design or cultural differences ${ }^{53}$. Many Japanese chose the neutral category "fair" in responding to the question. If one looks only at the negative side of responses to self-rated health (bad/very bad) the variation between Japan and other western countries narrows down (Table 12). On the whole, it seems better to rely on objective mortality data than on subjective survey data for evidence on comparative health status in Japan.

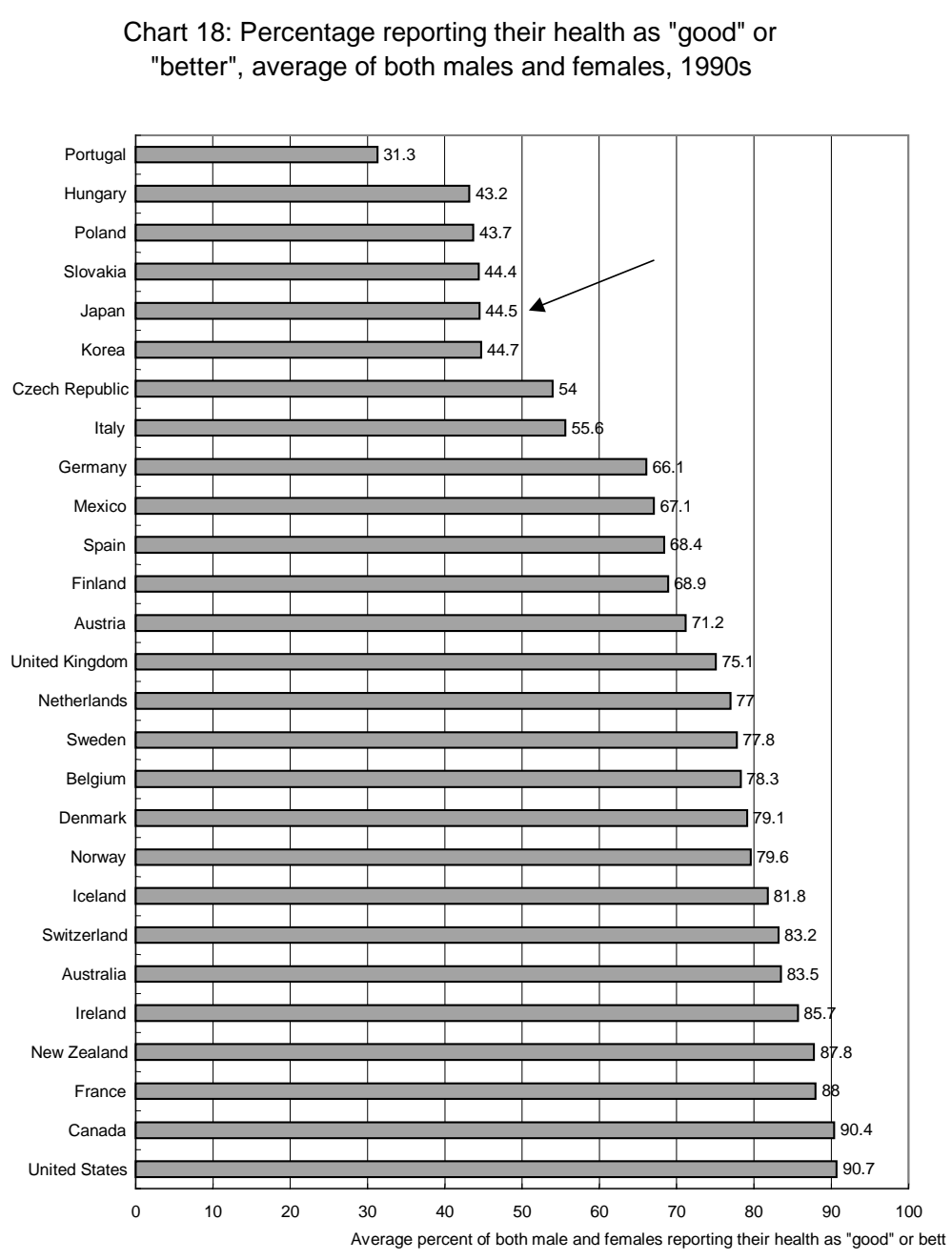

Source: OECD Health Data 2001

53 OECD [DEELSA/ELSA/WP1(2000)3/ANN1] suggests that there are three types of limitations in using self-rated general health data for international comparisons; variations in survey instruments across countries, translation barriers and reporting biases. 
DEELSA/ELSA/WD(2001)9

Table 12. Percentage of population aged 15 or more rating their health to be "good/very good", "fair" or "bad/very bad"

\begin{tabular}{lccc}
\hline \multicolumn{1}{c}{ Country } & Good/Very good & Fair & Bad/very bad \\
\hline Korea & 44 & 37 & 19 \\
Japan & $\mathbf{4 2}$ & $\mathbf{4 6}$ & $\mathbf{1 2}$ \\
Netherlands & 78 & 13 & 9 \\
Norway & 79 & 13 & 8 \\
Denmark & 79 & 15 & 6 \\
Australia & 83 & 13 & 4 \\
Ireland & 86 & 12 & 2 \\
U.S. & 91 & 7 & 2 \\
Canada & 91 & 7 & 2 \\
\hline
\end{tabular}

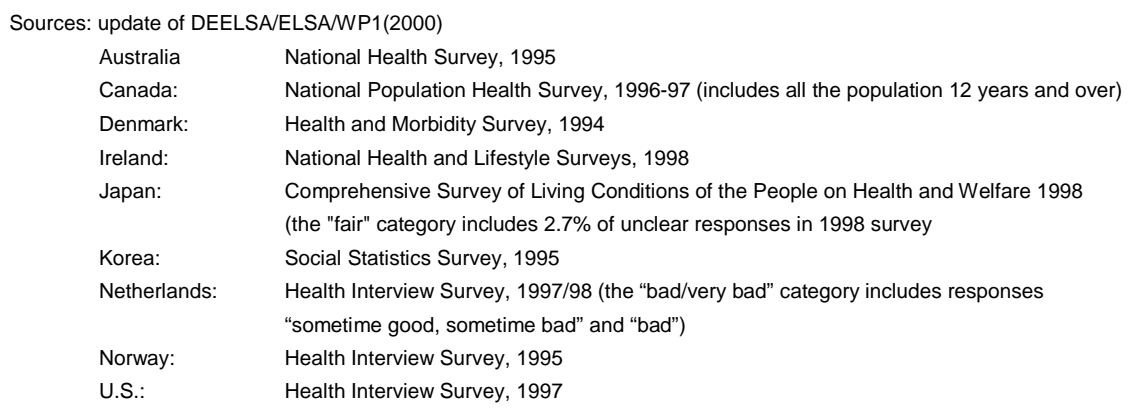

\subsubsection{Health Improvement Attributable to Health Care System}

64. Although the Japanese people enjoy excellent health status, it is difficult to ascertain to what extent this is due to the performance of the Japanese health care system. Other determinants of health status such as income, education and environmental factors explain an important proportion of the intercountry differences in health status. It is hard to isolate the impact of health care. Work done at the OECD, which has explored the impact of both medical and non-medical determinants of mortality across OECD countries, suggests that Japanese mortality rates are much lower than would be expected after allowing for all the determinants for which we have measures ${ }^{54}$. That leaves open the question as to whether the explanation for the unexpectedly low mortality in Japan is due to the high volume and, perhaps, high effectiveness of medical care in Japan or is due to lifestyle, social, environmental and genetic factors which have not yet been measured. Genetic causes seem to be unlikely because Japanese people who have migrated to both South America and United States have eventually taken up the disease patterns of their host population (Tsugane, 1992).

54. Or, Z.(2000) used as the determinants of PYLL under 70 years health expenditure per capita, share of public financing, $\mathrm{NO}_{\mathrm{x}}$ emissions, alcohol use, tobacco consumption, butter consumption, sugar consumption, GDP per capita and share of white collar worker. 
65. There is some circumstantial evidence that is consistent with the hypothesis that high health status in Japan is due in part to the high volume and, perhaps, high effectiveness of health care. Firstly, the infant mortality rate in Japan at 3.4 deaths per 1000 live births in 1999 was almost half the OECD average of 6.7 deaths and similar to that of Northern European countries, which have traditionally low infant mortality rates (Chart 19). The rate has decreased rapidly over the last half century, especially during the 1960 s, when public health insurance coverage in population was extended to include the whole population. On the other hand, the low birthweight rate ${ }^{55}$ in Japan, at 8.1 low birthweight infants in 100 live births in 1998, is now among the highest among OECD countries (Table 13). Japan belonged to the countries with a low low birthweight rate until 1980, but the rate has increased more rapidly than the OECD average since then. The low infant mortality rate in spite of the high low birthweight rate suggests that in at least one respect the Japanese health care system is effective in producing health outcome. This conclusion is based upon research which suggests that infant mortality is significantly affected by health care (Elola et. al., 1995; Grubaugh et. al., 1994) while the low birthweight is more affected presumably by non-medical determinants of health (Epstein, 1995; Eddy, 1998).

Chart 19: Infant mortality in OECD countries, 1999

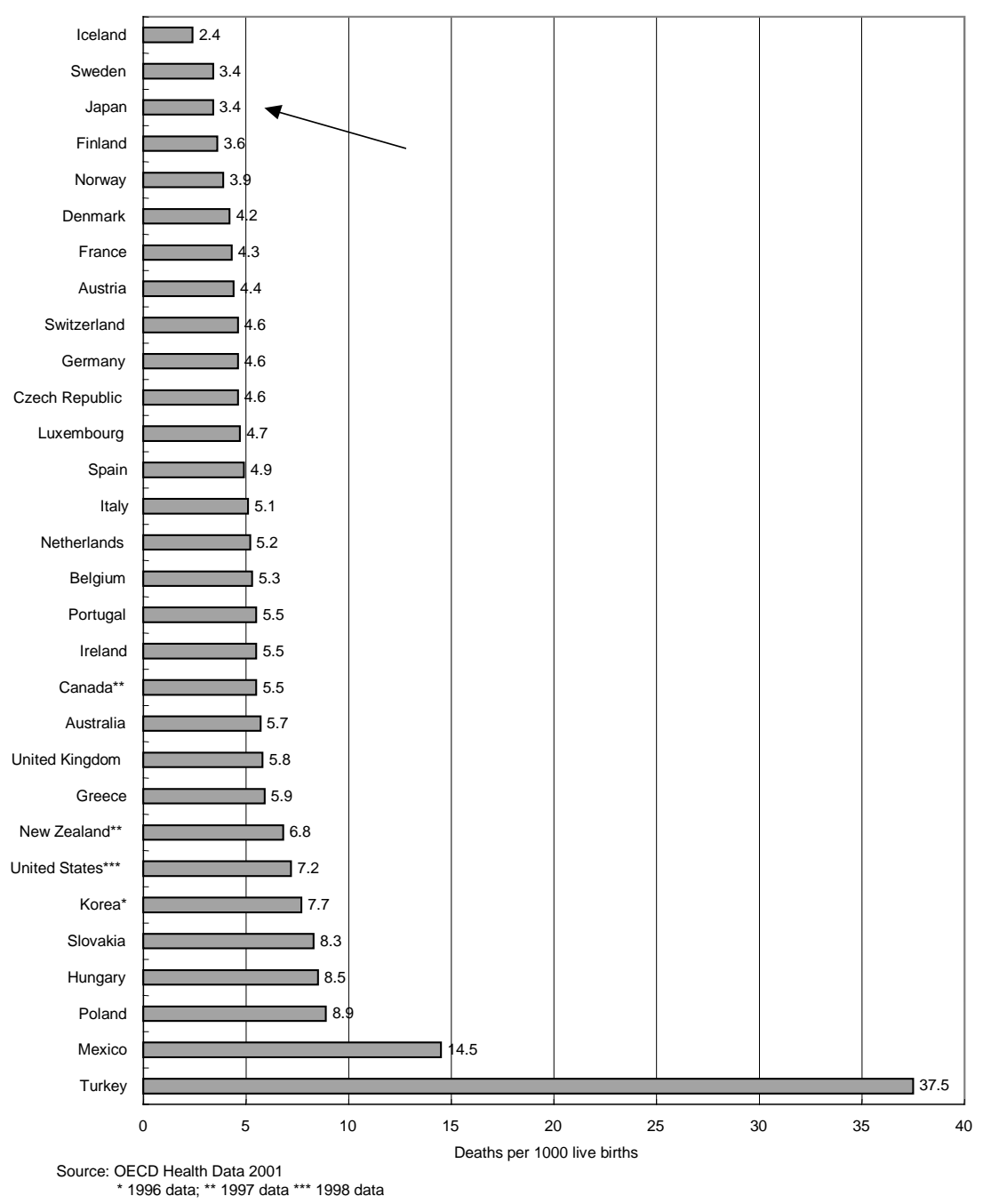

55. Number of live births weighing less than 2500 grams as a percentage of total live births. 
DEELSA/ELSA/WD(2001)9

Table 13: Low birthweight* - \% of total live births, 1970-98

\begin{tabular}{|c|c|c|c|c|}
\hline Country & 1970 & 1980 & 1990 & 1998 \\
\hline Australia & & 5.6 & 6.0 & 6.1 \\
\hline Austria & 6.2 & 5.7 & 5.6 & 6.1 \\
\hline Belgium & & 5.6 & 6.1 & 6.1 \\
\hline Canada & 7.8 & 6.0 & 5.4 & 5.9 \\
\hline Czech Republic & 6.1 & 5.9 & 5.5 & 5.9 \\
\hline Denmark & 6.0 & 5.6 & 5.5 & 5.5 \\
\hline Finland & 5.1 & 3.9 & 3.7 & 4.1 \\
\hline France & & 6.5 & 5.3 & 6.3 \\
\hline Germany & 5.8 & 5.5 & 5.7 & 6.2 \\
\hline Greece & 10.7 & 5.9 & 6.0 & 7.4 \\
\hline Hungary & 10.7 & 10.4 & 9.3 & 8.3 \\
\hline Iceland & 4.2 & 3.4 & 3.2 & 5.0 \\
\hline Ireland & & & 4.2 & 4.2 \\
\hline Italy & 7.2 & 5.6 & 5.6 & 6.0 \\
\hline Japan & 5.7 & 5.2 & 6.3 & 8.1 \\
\hline Korea & & & & 3.5 \\
\hline Luxembourg & & 6.3 & 5.4 & 6.8 \\
\hline Mexico & & & 5.6 & 9.4 \\
\hline Netherlands & & 4.0 & 4.8 & 4.8 \\
\hline New Zealand & & 5.8 & 6.2 & 6.3 \\
\hline Norway & 4.5 & 3.8 & 4.6 & 4.7 \\
\hline Poland & 7.3 & 7.6 & 8.1 & 6.2 \\
\hline Portugal & 5.9 & 4.6 & 5.6 & 6.7 \\
\hline Slovakia & 6.2 & 5.9 & 5.8 & 6.5 \\
\hline Spain & & 2.8 & 4.5 & 6.2 \\
\hline Sweden & 4.3 & 4.2 & 4.5 & 4.1 \\
\hline Switzerland & & 5.1 & 5.1 & 6.0 \\
\hline Turkey & & & & 7.9 \\
\hline United Kingdom & 6.8 & 6.7 & 6.8 & 7.5 \\
\hline United States & 7.9 & 6.8 & 7.1 & 7.6 \\
\hline Average of 16 countries & & 5.6 & 5.7 & 6.2 \\
\hline
\end{tabular}


66. Secondly, the combined dialysis and transplant rate, a process-of-care measure, may act as a proxy for outcomes in the case of chronic renal failure. This rate is very high in Japan (Table 14). That is despite the fact that the functioning kidney transplant patient rate appears to be very low in Japan ${ }^{56}$. This is likely to have led to the postponement of more deaths from chronic renal failure in Japan than in some other OECD countries.

Table 14: Combined dialysis and kidney transplant rate, per 100 thousand population

\begin{tabular}{lccc}
\hline \multicolumn{1}{c}{ Country } & Dialysis & Kidney transplant & Total \\
\hline Australia & 31.5 & 26.6 & 58.1 \\
Austria & 35.9 & 33.5 & 69.4 \\
Belgium & 32.9 & 23.4 & 56.3 \\
Canada & 42.2 & 30.1 & 72.3 \\
Czech Republic & 38.6 & 9.2 & 47.8 \\
Denmark & 36.3 & 25.0 & 61.3 \\
Finland & 21.3 & 33.2 & 54.5 \\
France & 37 & 18.4 & 55.4 \\
Germany & 58.5 & 17.9 & 76.4 \\
Greece & 48.2 & 6.5 & 54.7 \\
Hungary & 12.5 & 10.9 & 23.4 \\
Iceland & 12.6 & 22.0 & 34.6 \\
Ireland & 9.9 & 7.8 & 17.7 \\
Italy & 31.6 & 12.3 & 43.9 \\
Japan & $\mathbf{1 5 5 . 7}$ & $\mathbf{N . A .}$ & $\mathbf{1 5 5 . 7 + \boldsymbol { \alpha }}$ \\
Luxembourg & 60.1 & 23.3 & 83.4 \\
Mexico & 28.8 & 1.2 & 30.0 \\
Netherlands & 26.4 & 26.8 & 53.2 \\
Norway & 6.1 & 37.3 & 43.4 \\
Portugal & 30.3 & 16.8 & 47.1 \\
Spain & 43.7 & 34.3 & 78.0 \\
Sweden & 25.4 & 36.3 & 61.7 \\
Switzerland & 26.5 & 18.3 & 44.8 \\
Turkey & 23.4 & 0.6 & 24.0 \\
United Kingdom & 27 & 26.9 & 53.9 \\
United States & 86.5 & 30.7 & 117.2 \\
\hline Average (except Japan) & $\mathbf{3 3 . 3}$ & $\mathbf{2 1 . 2}$ & $\mathbf{5 4 . 5}$ \\
\hline Source: OECD Health Data 2001 & & & \\
\multicolumn{1}{c}{ Data of the latest year in the 1990s a used } & &
\end{tabular}

67. Thirdly, standards of nursing seemed to be higher in a sample of Japanese nursing home than in samples in other countries, as a comparative study of nursing homes in 5 countries suggests (Carpenter, G.I., et al., 1999). However, this was a small study and the data may not be representative.

56 Organ transplants have not been popular in Japan. "Brain death" was not admitted legally until 1997. 


\subsubsection{Responsiveness}

68. Measures of the responsiveness of health systems to consumers can be classified into measures of patient satisfaction and measures of patient experience known to be valued by patients. The former depends on expectations as well as experience and the latter seeks to describe objective characteristics of health service delivery. In relation to patient's satisfaction with health care, the main complaints by the Japanese include long waiting in outpatient departments; short consultation times with doctors; shortcomings in doctor's explanations and in medical information provided to the patients; and low quality of facilities in hospitals (The Survey on Patient's Behaviour and Satisfaction 1999; hereafter, shortly Behaviour Survey 1999), as shown in Chart 20. However, patient's experiences with health care do not necessarily coincide with their satisfaction or complaints.

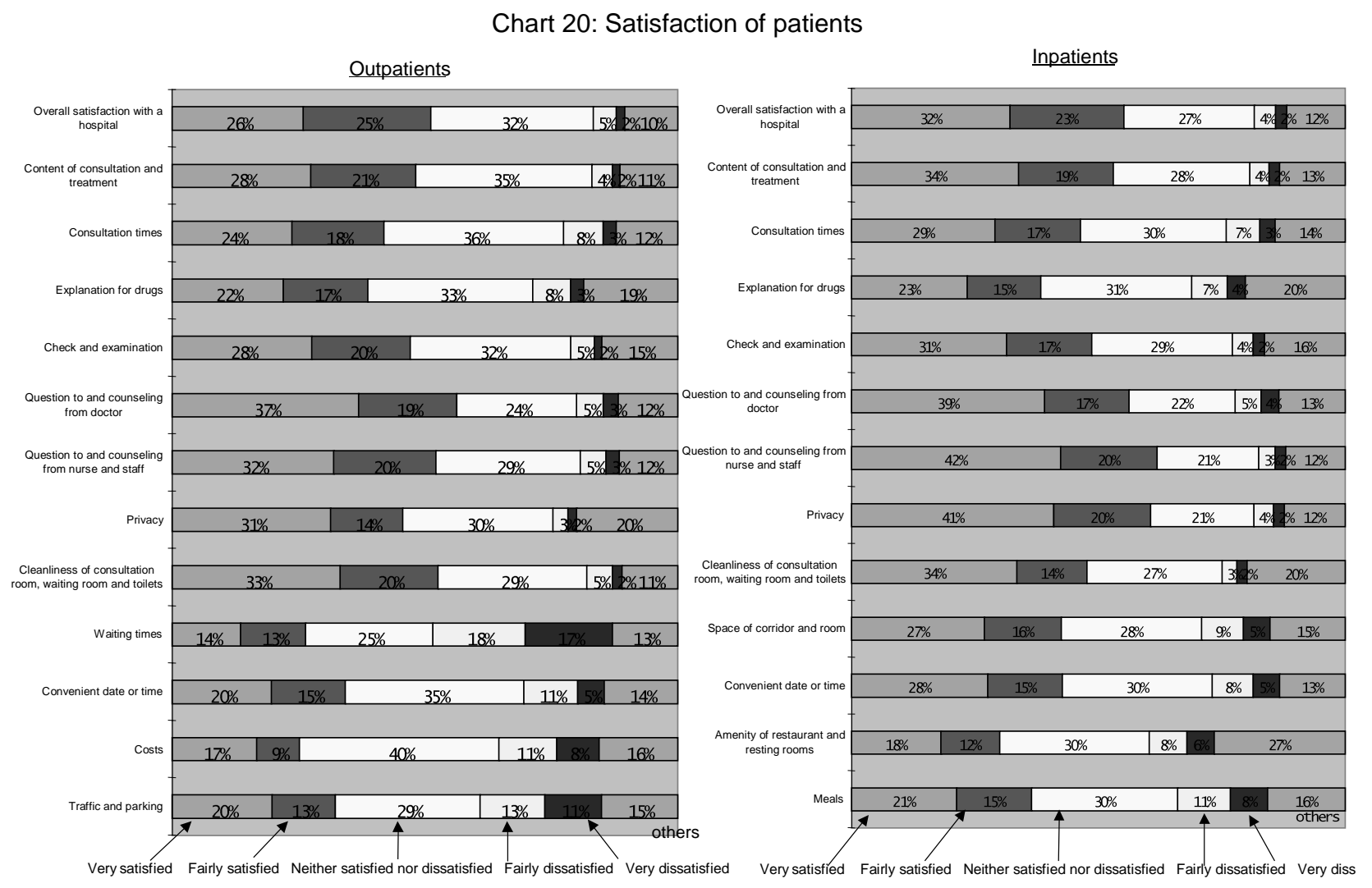

Source: Survey on Patient'sehaviour and Satisfaction 1999 


\subsubsection{Waiting Times}

69. Long waiting times for treatment in outpatient departments followed by short consultations has long been one of the most frequent targets for complaint by Japanese patients, as summed up in the catchphrase "waiting for three hours to be seen for three minutes". That is confirmed by the fact that waiting times by hospital outpatients are the number one item of their dissatisfaction in the Behaviour Survey 1999 (Chart 20). However, patient experience of long waits and queuing are usually limited to large hospitals in the big cities, which enjoy a high reputation among patients who presumably choose the facility that they feel best fit their needs (Chart 21). According to the Survey, 47\% of outpatients who visited small hospitals with less than 100 beds waited for less than half an hour before the consultation and $15 \%$ for more than one hour. Whereas, $30 \%$ of outpatients who visited big hospitals with 500 beds and over waited for less than half an hour and $29 \%$ for more than one hour. It was only $2 \%$ of the surveyed patients that waited for more than three hours as expressed by the catch-phrase. Although Japanese hospitals have appointment systems, they also tend to see ambulatory care patients who turn up without appointments. This causes delays. According to the Behaviour Survey 1996, only 55\% of hospital outpatients made appointments for ambulatory care. In addition to waiting to see the doctor, there is often waiting to receive prescribed medications and waiting to make an on-the-spot payment in hospitals and doctor's clinics.

\section{Chart 21: Waiting times of outpatients by type of hospitals}

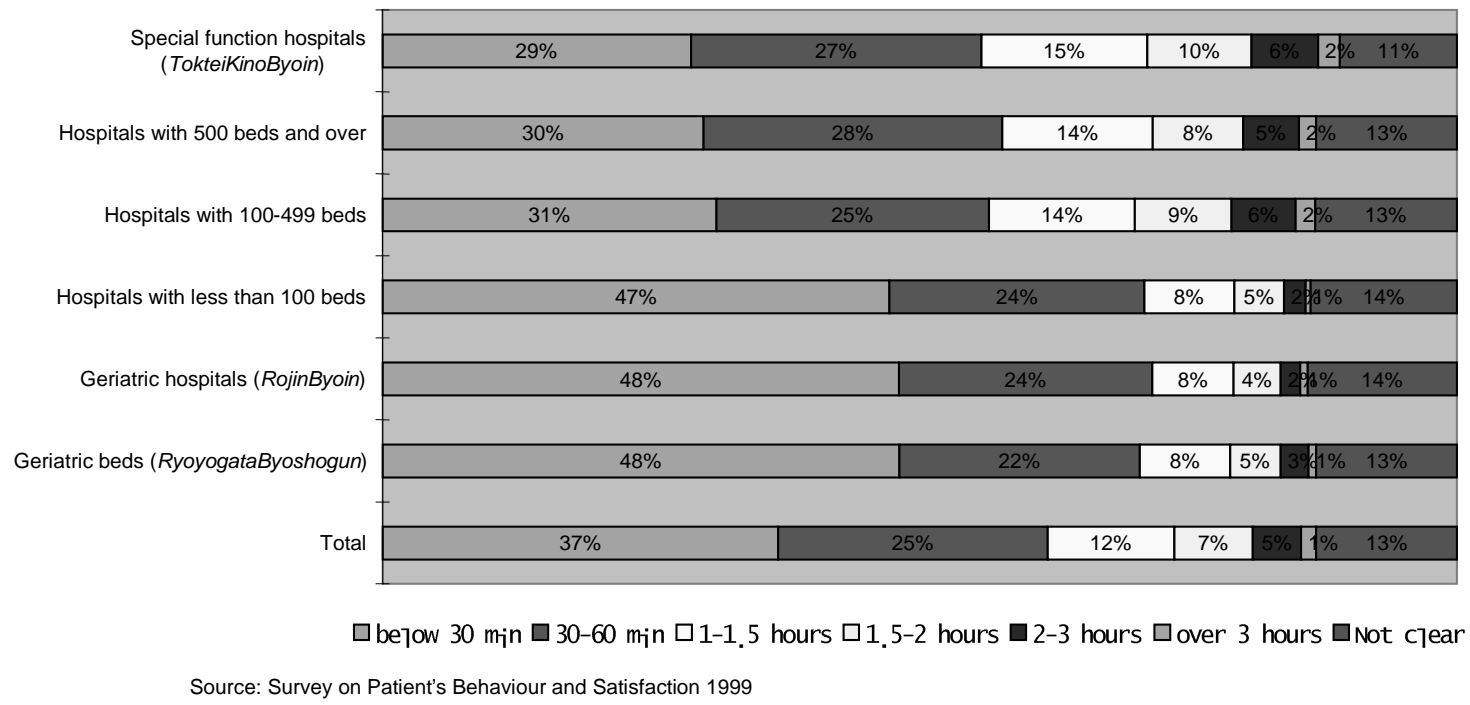

70. Waiting for inpatient surgery on hospital waiting lists is less of a problem compared with some European countries. There is some shortage in the bigger, public hospitals, but it is supplemented by a general surplus of beds for the smaller, private hospitals, which are equally accessible under health insurance. For patients who choose not to be too selective and go to the less prestigious hospitals, there are hardly any waiting lists. 


\subsubsection{Consultation Times}

71. Despite the aforementioned catch-phrase, $42 \%$ of Japanese patients in the Behaviour Survey 1999 showed their satisfaction with their consultation times in the outpatient department of hospitals and only $10 \%$ dissatisfaction (Chart 20). In terms of patient's experience, however, two thirds of those surveyed experienced less than 10 minutes of consultation, and $18 \%$ less than 3 minutes (Chart 22). Consultation times do not vary significantly across the various types of hospital. Concerns about short consultation times have been highlighted by the goal set in a quasi-governmental report of reducing the number of consultations a doctor can see in a day to 42 , since this goal is said to secure 10 minutes on average per visit (Review Committee on Supply and Demand of Doctors, 1998). Under ten minutes does not appear to be enough time to discuss, say, options for treatment or side-effects of drugs, especially if it includes time for administration such as writing medical records.

\section{Chart 22: Consultation times of outpatients by type of hospitals}

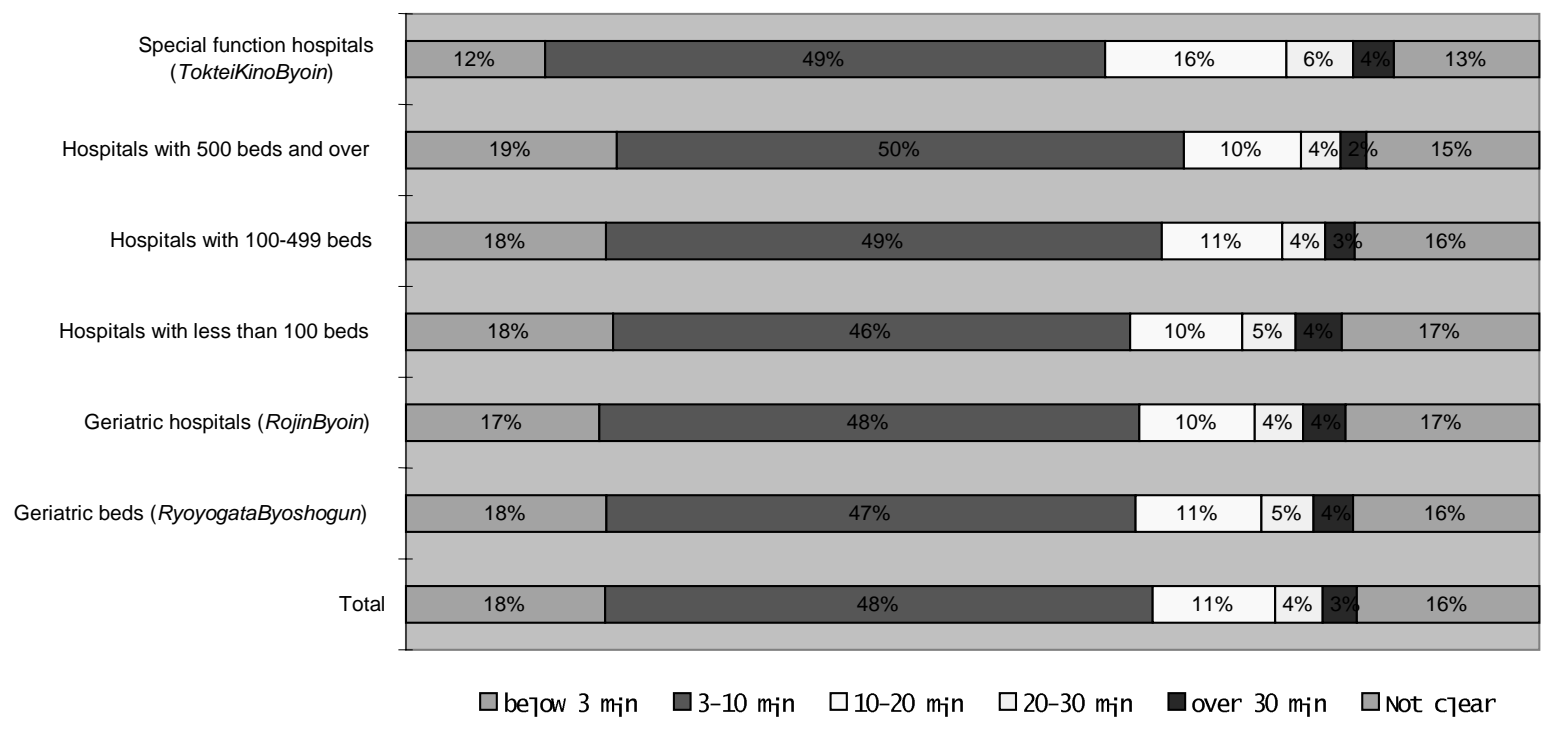

Source: Survey on Patient's Behaviour and Satisfaction 1999 


\subsubsection{Doctor's Explanation and Medical Information for the Patient}

72. Lack of doctors' explanations and lack of medical information have also featured among patients' complaints. In terms of patient's satisfation, 39\% of the surveyed outpatients and $38 \%$ of the inpatients expressed satisfaction with the explanation for the drugs given to them, whereas $10 \%$ and $8 \%$ expressed dissatisfaction, according to the Behaviour Survey 1999. In addition, 56\% of the surveyed outpatients and $56 \%$ of the inpatients expressed satisfaction with receiving answers to their questions from doctors, whereas $8 \%$ and $9 \%$ expressed dissatisfaction (Chart 20). In terms of patient's experience, about half of outpatients and more than half of inpatients received detailed explanation of their disease and drugs from doctors. In particular, inpatients in bigger hospitals experienced more explanation by doctors (Chart 23).

\section{Chart 23: Explanations to patients}
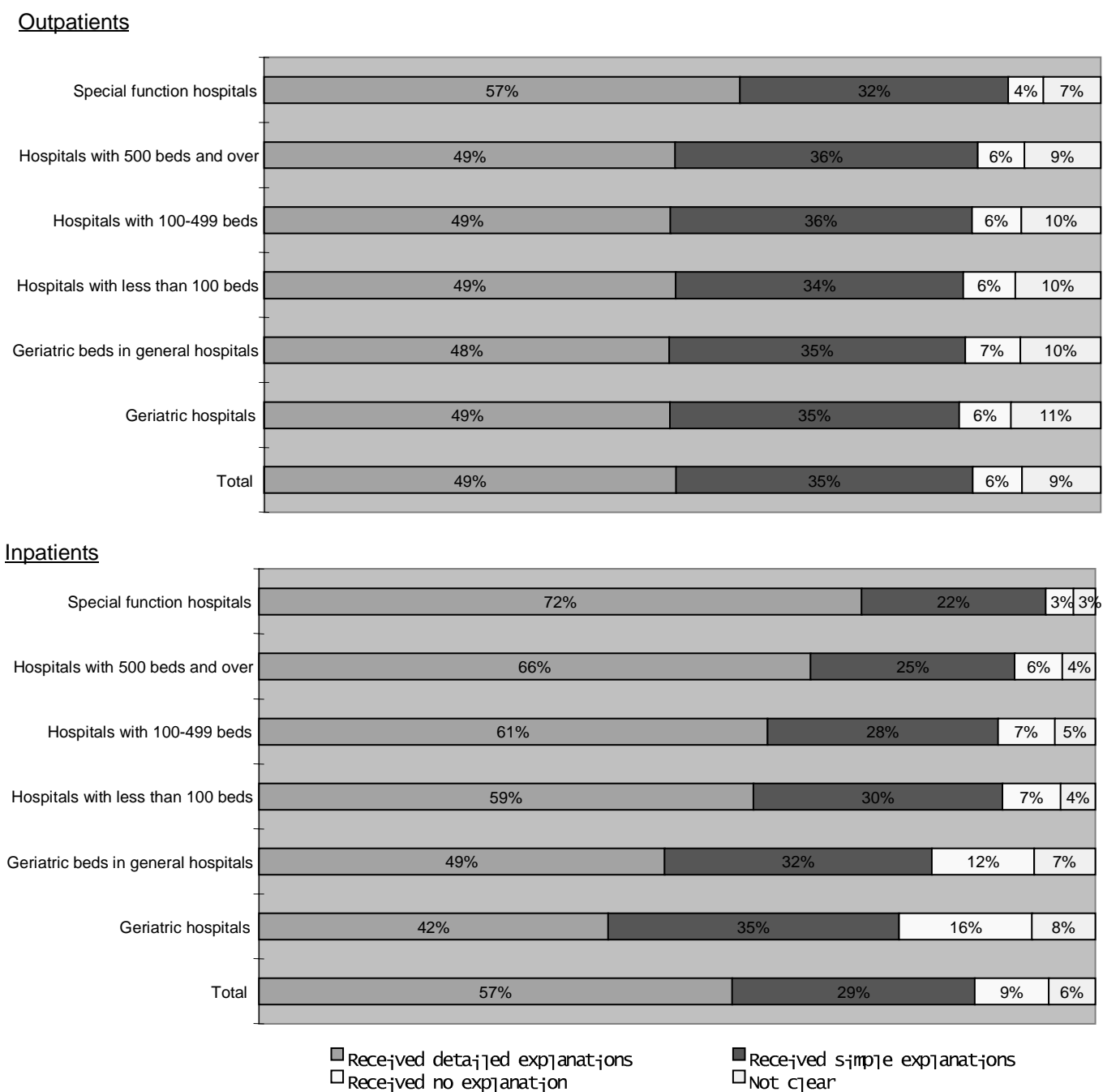

Source: Survey on Patient's Behaviour and Satisfaction 1999

73. Second, the Behaviour Survey 1999 shows that the speciality of doctors is one of the pieces of information that the patients want to know most and that $64 \%$ of the surveyed outpatients and $55 \%$ of the surveyed inpatients hoped to see their medical record. 


\subsubsection{Quality of 'Hotel' Care and Technology in Hospitals}

74. Insufficiency in physical and human resources is often blamed as contributing towards a poor quality of 'hotel' services in the hospital and a lack of high technology facilities. Floor space per bed in Japan was well under one-third the space in the US, according to a study that compared university hospitals in Japan and in the USA (Kawabuchi K., 1996). Tangible fixed assets per bed in Japan were also just under half the amount of the US. The level of staff (per bed) in Japan was also about a third, although this is not surprising if Japanese hospitals were used partly for elderly care. The difference is still greater for private hospitals with no government subsidies ${ }^{57}$. These comparisons may result primarily from the different way that hospitals are used in Japan and the USA. Unfortunately comparisons with European hospitals -which may be more comparable with Japanese hospitals than are US hospitals - do not appear to be available.

75. Meanwhile, part of the explanation for the Japanse/US differences may lie in the limited scope allowed in the Japanese Fee Schedule for plentiful space and leading edge or high technology equipment in hospitals. The fee-for-service system is said, in a theoretical sense, to encourage provision of the services that are most suitable for each patient, and to allow the prompt adoption of newly developed medical technology. But in relation to the latter, an incremental policy has been adopted in Japan in the adjustment of the Fee Schedule, which tends to maintain the pre-existing relative share of total fees among providers with the aim of minimising conflict. This has introduced rigidity in accommodating the changing relative importance of both long-term care and high-technology care. Capital costs are not reimbursed separately in the Fee Schedule. The prices set in the Fee Schedule are usually insufficient to cover the cost of buying new high technology machinery or upgrading facilities. Investment funds are often raised by loans from commercial banks as well as by loans from the Social Welfare and Medical Corporation, which is a semigovernmental financial organisation. However, technological improvements have been limited mainly to universities or to public hospitals, which have had access to additional subsidies from a university or the government.

57 Both floor space and tangible fixed assets per bed in private hospitals are half those in the public hospitals, and the staffing level is 20 percent less in Japan. 


\subsection{Efficiency}

76. Two concepts of efficiency will be addressed: macroeconomic efficiency and microeconomic efficiency. 'Macroeconomic efficiency' involves assessing whether health expenditure is at the desired level compared with expenditure on other goods and services. 'Microeconomic efficiency' involves comparing the activities (or, better, the outcomes of a health system, that is, health improvement and responsiveness) with the resources made available to the system.

\subsubsection{Macroeconomic efficiency}

77. It is not possible to observe or assess macroeconomic efficiency directly. The right level of expenditure on health care compared with expenditure on other goods and services in Japan is a matter for the judgement of the Japanese government and people. However, it may help to inform such a judgement to point out that Japan's per capita health expenditure (1,822 US\$ PPPs in 1998) is below the level expected (2,045 US\$ PPPs in 1998) for a country with Japan's standard of living. The expected level is set by a regression line fitted to observations of per capita health expenditure and per capita income for OECD countries (Chart 24). The expected level does not necessarily represent the desired level. For example, a country's level of health expenditure per capita might lie below the line because its health system is more efficient (in a micro sense) than those of other OECD countries. Alternatively, it might be below the line because its government (in respect of public expenditure on health) and its consumers (in respect of private expenditure on health) have attached lower relative priority to health care than have governments or consumers in other OECD countries.

Chart 24: Health expenditure per capita and GDP per capita, 1998

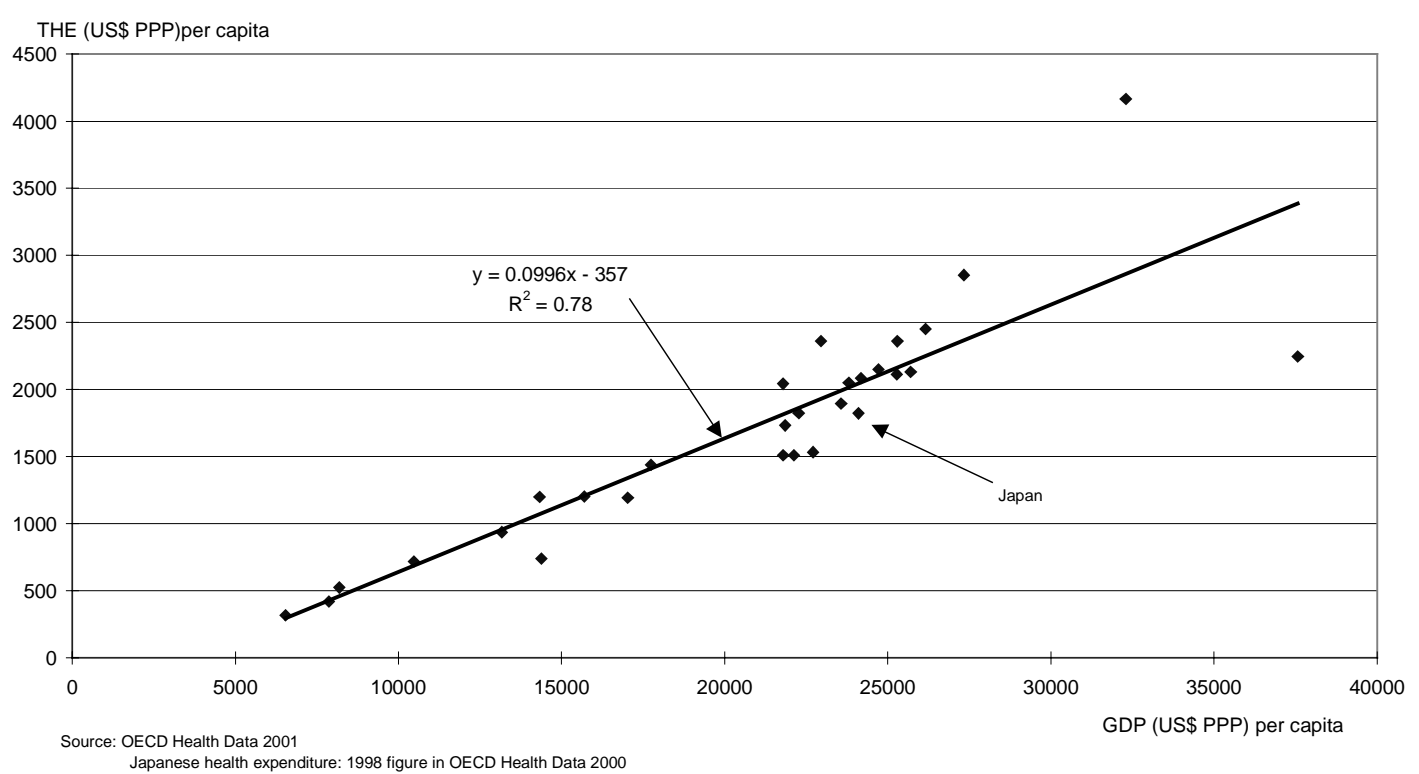

78. It was shown in section 3.1. Monetary Flows and Chart 4 that Japan succeeded in constraining health spending in the 1980s, but that Japanese health expenditure grew faster than GDP and faster than health expenditure in other OECD countries in the 1990s. The Japanese achievement in constraining spending in 1980s was impressive, but was not unique. Other major countries like UK, France and Germany also kept health expenditure at a roughly constant share of GDP in the 1980s. It is worth noting, 
however, that in these nations the proportion of older people in the population stayed roughly constant in the 1980s, while in Japan it was rising rapidly. In Japan, health expenditure in the 1990s could be allowed to increase, to some extent for counter-cyclical purposes, following the collapse of the financial bubble in the early 1990s.

79. Some of the means by which health expenditure has been controlled in Japan are fairly clear. An explicit global budget has not been introduced, but there is what appears to be an "implicit" cap on health expenditure. The Japanese government has long tried to contain the growth rate of NME (National Medical Expenditure) within that of GDP.

80. First, success in that policy has been ensured partly by the public sector using its monopsony power. Payments to providers nearly all flow through a single and universal Fee Schedule. The government has tried to contain health expenditure growth through judicious adjustment of fees (Campbell and Ikegami, 1998). The Fee Schedule has been used firstly to constrain the rate of growth of health care prices over time and secondly to influence the mix of services in such a way that those which are believed the most cost-effective are favoured. On the first, the government has fairly successfully tried to keep the overall growth in fees as low as possible ${ }^{58}$. Out of the nominal annual growth rate in per capita health expenditure, which was $4.8 \%$ between 1980 and 1997, the part due to the relative price increase was only 0.6 percentage points (Chart 25). That together with 1.3 percentage point of general price increase adds up to 2.0 percentage points of total health care price increase. The remaining 2.8 percentage points, approximately $60 \%$, of the annual growth rate was due to the increase in "volume consumed" 59 . On the second, the government has used the Fee Schedule to promote primary care in relation to acute hospital care. As a result, the share of total provider payments devoted to the traditional ambulatory services, mainly in the field of primary care, has remained high compared to the share devoted to inpatient services and high-technology medicine. That has almost certainly helped to keep overall expenditure low.

Chart 25: Volume and price increase of health expenditure per capita in Japan

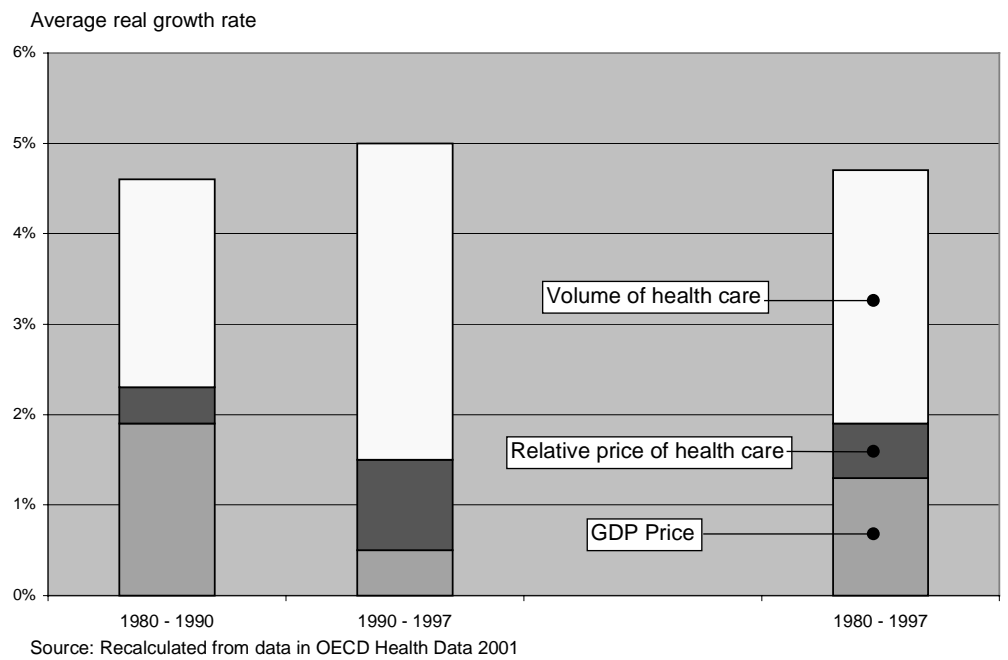

\footnotetext{
58 The government subsidies to both $N H I$ and GMHI are determined by their total outlays multiplied by the legally fixed percentage for the subsidy, which is therefore not easily altered. Thus, the revision of Fee Schedule is directly linked to the scale of subsidy. This is why the scale of subsidy must be approved before each revision of the Fee Schedule by the Ministry of Finance, which is in charge of the general budget. This in turn limits increases in the Fee Schedule.

59. However, volume increase has been limited by restraint on the number of doctors per capita as explained later.
} 
81. Second, increase in co-payment rates has dampened down demand. Three reforms had some success in tempering the speed of expenditure growth in 1980s: the policy in 1983 introducing a certain amount of co-payment by the elderly, the policy in 1984 introducing co-payments by the enrolees in the $E H I$, and the policy in 1986 augmenting the co-payment of the elderly. Augmented co-payments both by EHI enrolees and by the elderly in 1997 may also have contributed to containing the growth of health expenditure. (see Chart 4 in section 3.1. Monetary Flows)

82. Finally, supply-side controls have played a crucial role. The control of intake of students to medical schools has certainly contributed to containing health expenditure. It has helped to provide a constraint on the volume of medical services which the government would otherwise find difficult to control. Control of hospital bed numbers since mid-1980s may also have assisted in limiting the volume of acute and long-term hospital care over time.

\subsubsection{Microeconomic efficiency}

83. Conceptually, microeconomic efficiency could be measured as the ratio of a weighted combination of health improvement and responsiveness to real health expenditure or staff per capita. Given that we have only scraps of evidence about health outcomes and only scanty evidence about responsiveness, it is not possible to make a complete assessment of microeconomic efficiency here. We look first at "process" measures of outputs before looking at outcomes.

84. The number of consultations per Japanese doctor per year, at 8.9 thousand per year, is outstandingly high among OECD countries whose average is 2.6 thousand per year (OECD Health Data). That suggests that Japanese doctors are highly productive at least in terms of volume of consultations. It should be noted, however, that the fact that Japanese doctors dispense as well as prescribe drugs may mean that some of these consultations are less medically intensive than are consultations in other countries. Also, the hospital admission rate is low in Japan. Nevertheless, it would require a very high weighting on the admission rate to reach the conclusion that the productivity of doctors in Japan is not significantly higher than that of doctors in other OECD countries. In addition, it seems likely that high physician productivity is a contributory factor to the low total health expenditure in Japan, as shown in section 4.2.1. Macroeconomic efficiency. 
85. High volume of care is almost certainly the result of the fee-for-service payment system ${ }^{60}$, which pays little per visit but does not regulate the length or frequency of the visit. Doctors have the incentive to see as many patients as possible and to give each patient as much treatment as possible in the shortest time possible. In a sense, Japanese doctors have achieved high volume of care by utilising their working time intensively. The limited supply of doctors, together with the very loose appointment system, makes many patients wait for their turn at the same time, and this encourages doctors to work to their physical capacity limit and patients to accept short consultation times because they can see others waiting. Inverse relationship of consultations per doctor per day with doctor density appears more clearly in Japanese domestic setting as shown in Chart $26^{61}$. There is a general tendency for doctors to prefer working in urban rather than in rural areas. This leads to higher doctor density in urban than in rural areas. Under the fee-forservice system, doctors in lower doctor density areas can be compensated for their higher workloads by higher incomes.

\section{Chart 26: Doctors per 1000 population and Consultations per doctor per day across prefectures}

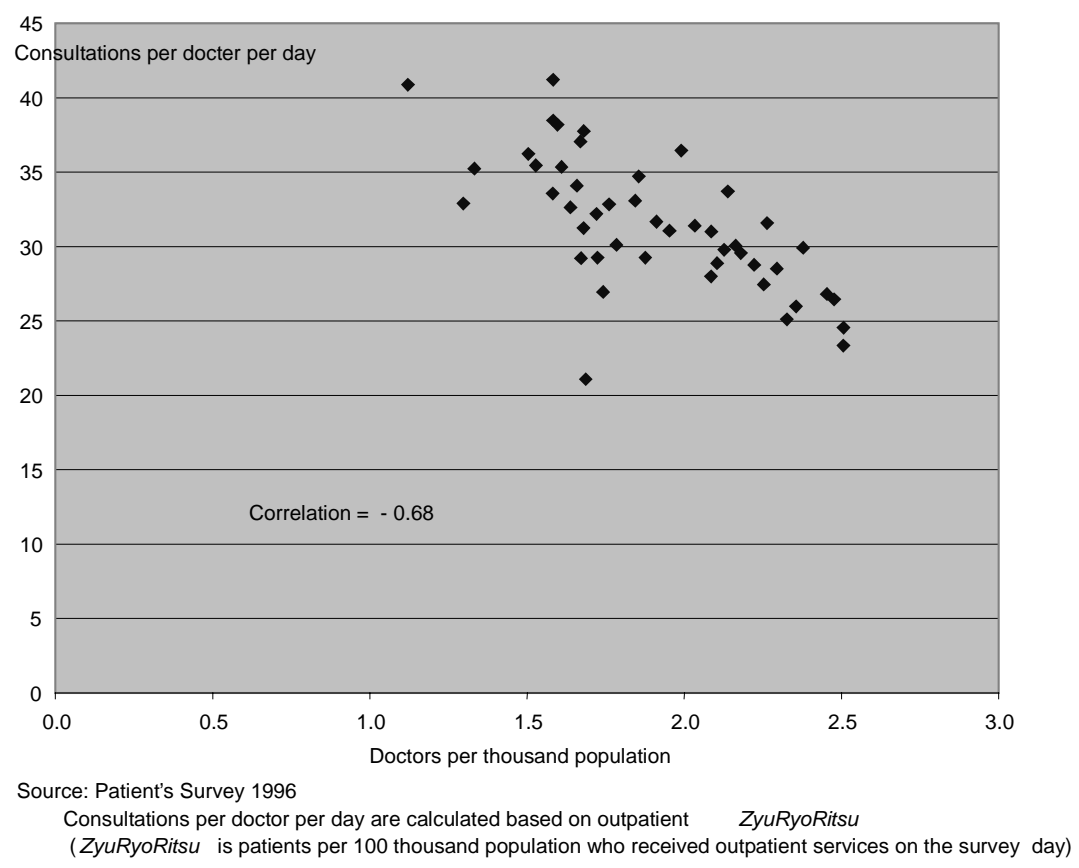

86. Frequent but short consultations may be welcomed particularly in treating elderly patients with chronic conditions, who want to meet doctors at least on the same day that they choose to visit, regardless of the waiting time at hospital or clinic. However, quality can be sacrificed as Japanese doctors pursue quantity. But more generally, they may also represent a relative lack of policy emphasis on promoting patients' right (Campbell and Ikegami, 1998). Certain failures in responding to or satisfying the desire of the patients seem to be the side effects of the effective spending control mechanism that operates through price fixing by the government.

\section{$60 \quad$ Dekidakabarai}

61 It could be argued that this relationship is due to variations in household income. Standards of living will be higher in urban areas. That might lead to better health and hence less need for consultations. However, multivariate statistical analysis across prefectures suggests that there is no significant relationship between consultations per doctor and household expenditure, after allowing for the negative relationship between consultations per doctor and doctor per 100 thousand population. 
87. Turning to health improvement, which is changes in health status attributable to medical care, we have seen in section 4.1.1.2. Health Outcomes Attributable to Health Care System that there are at best only a few scraps of circumstantial evidence that health outcome (in the sense of medical effectiveness) is higher in Japan than in other OECD countries. The evidence on responsiveness is also rather scanty and provides rather a mixed picture. Meanwhile, as we have seen, health expenditure per capita is quite modest for a country with Japan's standard of living. More work is needed, especially, to understand the role, if any, that Japan's high volume of primary care and pharmaceutical consumption play in determining her very high health status.

\subsection{Equity}

88. Three concepts of equity can be monitored across population groups; equity of health, equity of finance and equity of access. The last two concepts are addressed in this section. 'Equity of finance' involves identifying the financial distribution in the burden of paying for health care. 'Equity of access' involves identifying the distribution in the resources and utilisation according to need. Various population groups can be identified across which disparities in financing or access to care might be monitored; such as age, gender, ethnic group, geography and income. In the case of Japan, evidence about disparities across gender and ethnic groups is hard to find. Evidence on variations across income, geographical and age groups will be looked at in this section. 


\subsubsection{Equity of Finance}

89. In the final analysis, what is 'fair' financing for health care is a matter for the political judgement of the Japanese people and their government. However, it has become conventional to inform such judgements by estimating whether payment for health care according to all sources of finance is proportional to income, progressive or regressive ${ }^{62}$ (see Van Doorslaer, 1993). The implied judgement is that payment for health care that is proportional to income would be "payment in accordance with ability to pay". In the case of Japan (Chart 27), the evidence suggests that payment for health care from all sources of finance (health insurance contributions, general taxation and patient's co-payments) is regressive ranging from $165.5 \%$ of income for households with income less than $¥ 1$ million per year to $8.7 \%$ of income for households with income more than $¥ 10$ million. In particular, both insurance contributions and co-payments were more regressive than tax. Households with income below $¥ 1$ million paid more absolutely for health care ( $¥ 298$ thousands on average) than households with income between $¥ 1$ million and $¥ 2$ million pay ( $¥ 275$ thousands on average). Regressive payment, however, are normal across OECD countries. Further work needs to be done to provide precise estimates of the regressivity of payment for health care in Japan compared with that in other OECD countries. [Using, for example, Kagwati or Suits index of progressivity, as used in Wagstaff (1999)]

Chart 27: Finance for health care across income groups

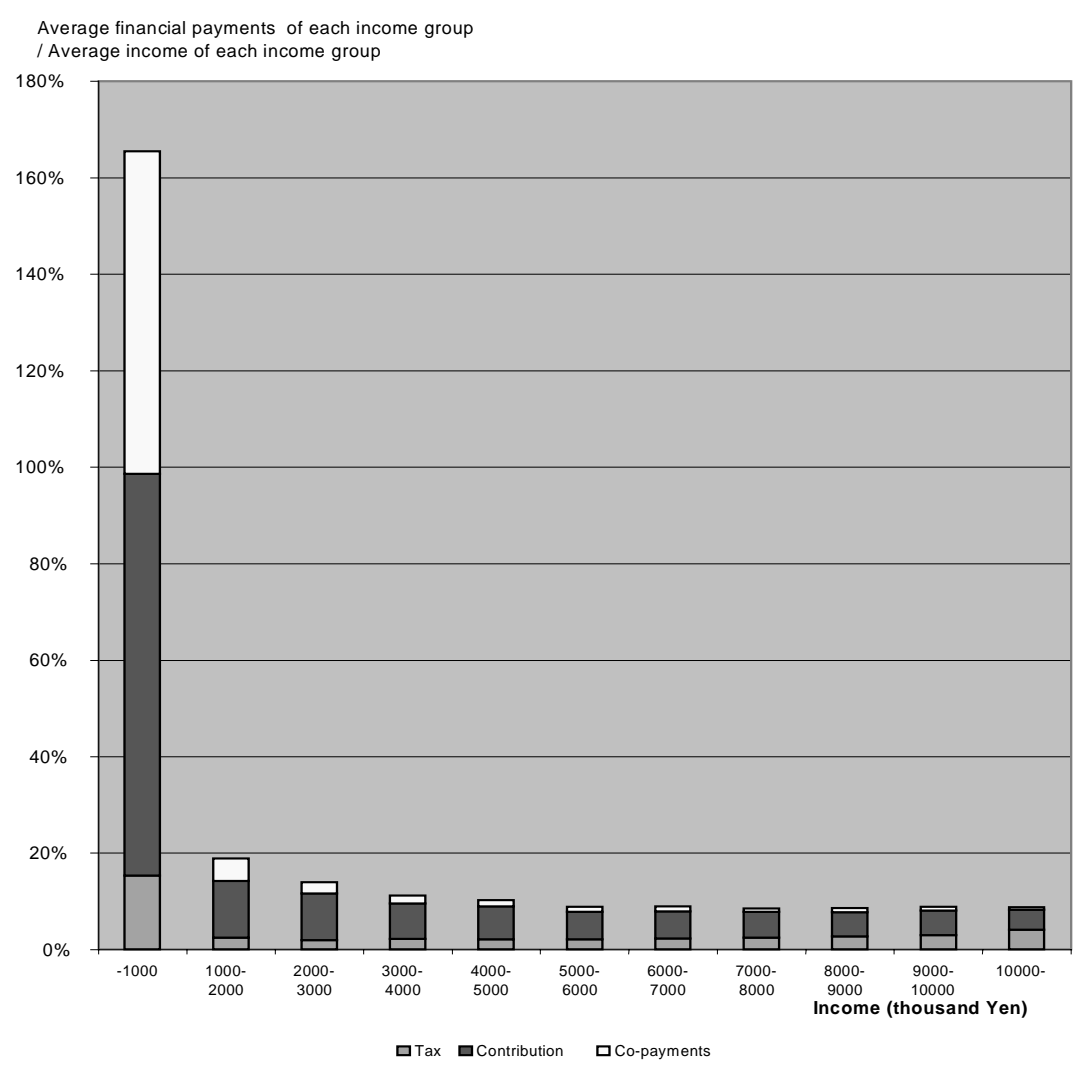

Source: Calculated based on data from Survey on Income Re-distribution 1996 and National Medical Expenditure

62. A progressive system is one in which health care payments rise as a proportion of income as income rises, whereas a regressive system is one in which payments fall as a proportion of income as income rises. 
90. Apart from the vertical equity of finance, some questions about horizontal equity remain across the Japanese health insurance schemes ${ }^{63}$. First, there is variation in the contribution rates across the main health insurance schemes, such as $S M H I$ and $N H I$, as well as variation between health insurers within each scheme. Annual average per capita contribution of NHI societies was $¥ 110$ thousand in 1997, whereas average per capita contribution of NHI municipalities was $¥ 77$ thousand. Meanwhile, among societies of SMHI the contribution rate varies from $6 \%$ to $9 \%$ of wages, and the employer's share of this varies from $50 \%$ to $80 \%$ (Table 15). This difference is closely related to the average age or the wage level of the employees. Second, some gaps exist in terms of co-payment rates. Patients make co-payments ranging from $20 \%$ to $30 \%$ towards their treatment, depending upon which health insurers they belong to and according to whether they are the enrolees (affiliates) or dependants. The effective co-payment of the elderly under the HSSE was less than 7\% in 1999 whereas it averaged around 19\% for the non-elderly. This means that a large portion of the health expenditure for the elderly is now financed by the working generation, whose financial capabilities are not significantly superior to those of their elders [Basic Survey on People's Life 1998, Survey on Saving Trends 1998, and Reforms for an ageing society (OECD, 2000)]. However, inequities in co-payment rates among health insurers are capped by the provision of a ceiling for the monthly co-payment amount. Finally, there is variation in government subsidies (financed by tax) to the main health insurance schemes. The subsidy to the GMHI was $13 \%$ and to the $N H I$ municipalities was $50 \%$ of insurance benefit expenditure in 1999, whereas almost no subsidy was made to SMHI and civil servant scheme.

Table 15: Contribution rates and employer's share across societies of SMHI, 1998

\begin{tabular}{ccc}
\hline & Category & $\begin{array}{c}\text { Share of corresponding societies } \\
\text { in all SMHI societies }\end{array}$ \\
\hline & $6.0 \%-6.9 \%$ & $1.6 \%$ \\
Contribution rates & $7.0 \%-7.9 \%$ & $16.1 \%$ \\
& $8.0 \%-8.9 \%$ & $55.6 \%$ \\
& $9.0 \%-9.4 \%$ & $24.9 \%$ \\
& $9.5 \%-$ & $1.9 \%$ \\
\hline Employer's share & $50 \%-59 \%$ & $71.4 \%$ \\
in contribution & $60 \%-69 \%$ & $25.1 \%$ \\
& $70 \%-79 \%$ & $3.4 \%$ \\
& $80 \%-$ & $0.1 \%$ \\
\hline
\end{tabular}

Source: Ministry of Health, Labour and Welfare (1999 a), Trends in Insurance and Pension, etc.

91. Considering all sources of finance, financing of health care is regressive in Japan mainly because the contributions of the self-employed and inactive are not proportional to their income. Also, there is a contribution ceiling for employees. Moreover, there is horizontal inequity of finance that has its origin in the evolutionary development of the Japanese health insurance system. Different contributions among health insurers are attributable to long-standing fragmentation of the scheme. Workers in declining industries such as coal mining, which have an older work force, have to pay a higher contribution. Workers in industries where the average wage is low, such as textiles, are also facing a high contribution rate, although the absolute contribution amount is low. Differentiation between the insured employees and their dependants has its historical background as well. Health insurance was in its first stage provided to improve the work force by protecting their health, not their dependants' health.

63. According to Dooslaer, E.V. (1993, p. 15), vertical equity of finance means the requirement that persons or families of unequal ability to pay make appropriately dissimilar payments for health care, and horizontal equity of finance means the requirement that persons or families of the same ability to pay make the same contributions. 


\subsubsection{Equity of Access}

\subsubsection{Across Income Groups}

92. 'Fair' access is usually taken to mean treatment in accordance with need - but it is not easy to measure 'need' (Wagstaff, A. et al, 1993). The level in health insurance benefits across income groups in Chart 28 shows that health care utilisation by households is weakly negatively correlated with their income level $(r=-0.19)$. Households with income below $¥ 0.5$ million received health care worth almost 1.7 times that received by average household. That suggests that the health insurance scheme is re-distributive. However, evidence of the variation of health status across income groups would be needed to judge whether utilisation of health care is distributed in accordance with need.

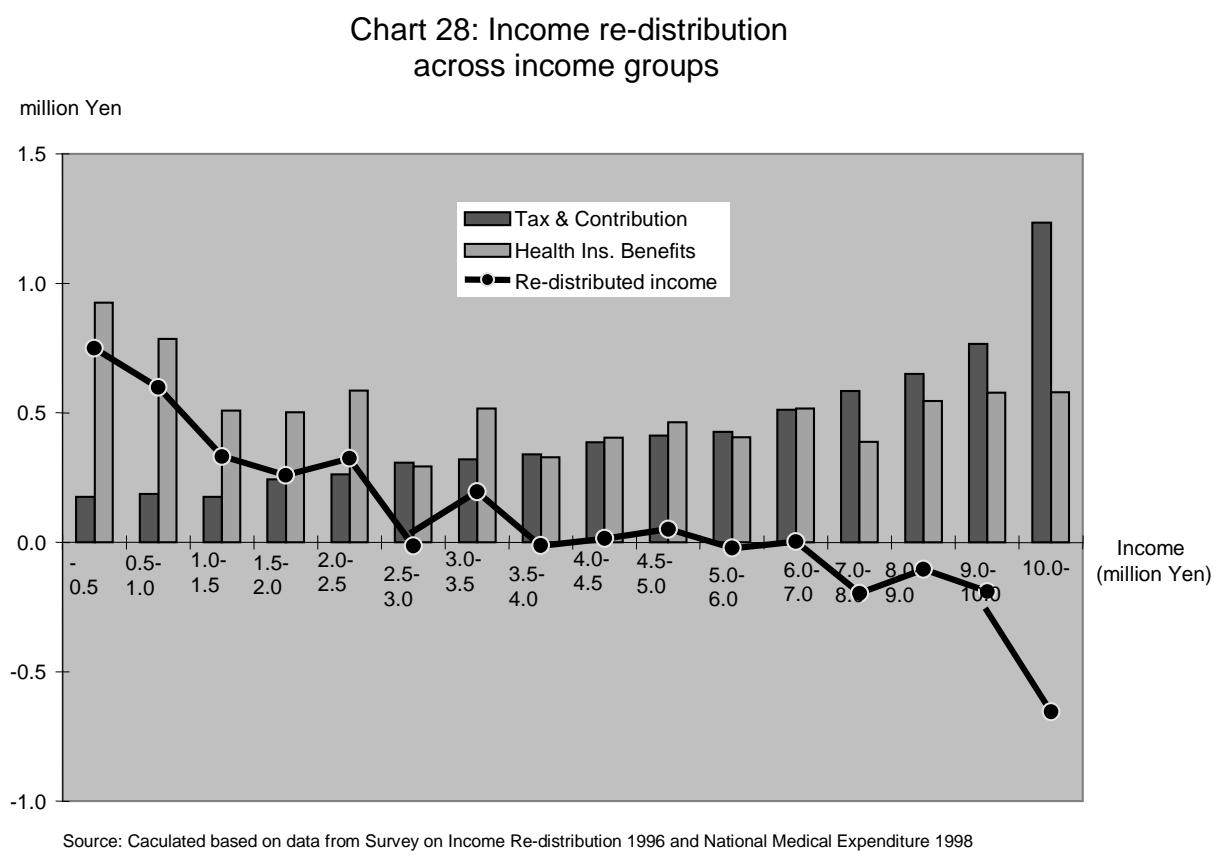

93. The continuous line in Chart 28 shows how income (in the form of health expenditure benefits) was re-distributed across income groups in 1996 by the health insurance system. Households with low income gained most. The re-distribution coefficient, which is defined as the income gain divided by the original income, amounted to $1500 \%$ for households with income below $¥ 0.5$ million. The re-distribution coefficient of households with income above $¥ 10$ million was minus $4.4 \%$.

94. There is re-distribution across income groups that is caused more by equity of access than by equity of finance. Equity of access has been brought about by a combination of universal public health insurance and its comprehensive benefits, both of which derive from a strong spirit of egalitarianism in Japan. The whole population receives the benefit package of the public health insurance covering nearly all regular health care services with only relatively moderate co-payments. There is no difference in benefits among patients according to their income or contribution. Providers and insurers are not allowed the freedom to negotiate with each other for more favourable conditions. Main benefits cannot be negotiated, and are strictly controlled by the uniform Fee Schedule. 


\section{DEELSA/ELSA/WD(2001)9}

\subsubsection{Across Age Groups}

95. According to National Medical Expenditure 1998 (MHLW), health expenditure per capita was the lowest in the age group 15-19 and then increased with age. Health expenditure per capita for the Japanese 65 or older was five times the average of the younger age population. Again, evidence on health status across age groups would be needed to check whether these variations match need.

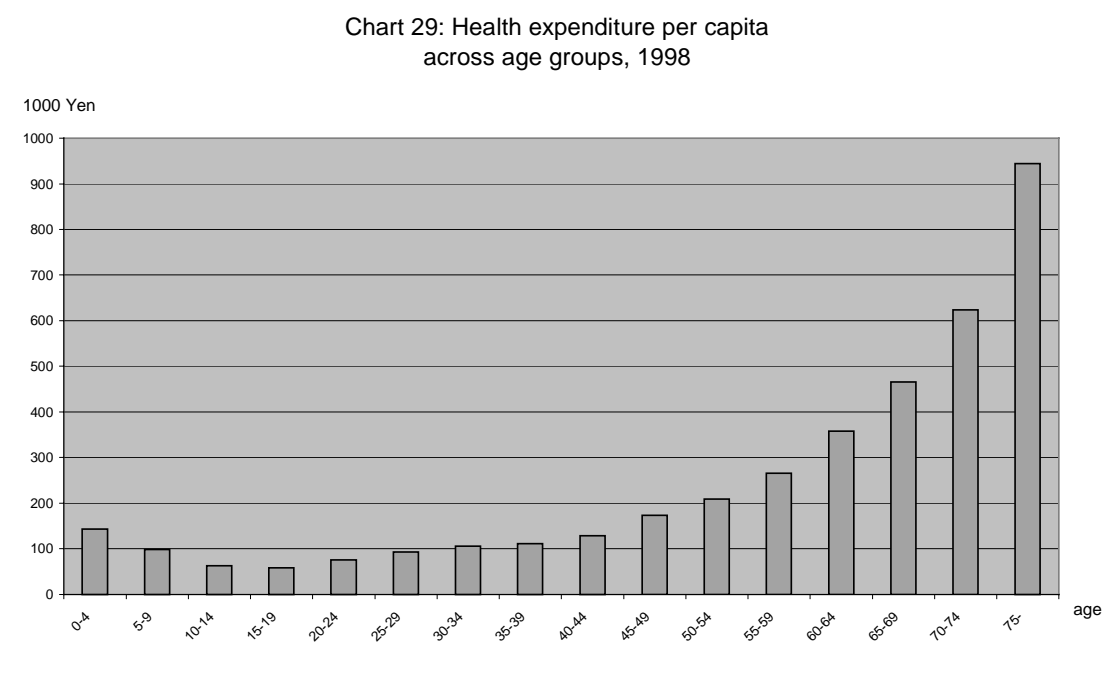

Source: National Medical Expenditure 2000

\subsubsection{Across Geographical Area (Equity of geographical access)}

96. At first glance, medical personnel and facilities are not very evenly distributed geographically across Japan. Rural areas are not as well supplied as big cities ${ }^{64}$. Service utilisation rates are also unevenly distributed $^{65}$. However, what really matters is how those resources and utilisation are distributed according to need. Here, the crude mortality rate of each prefecture can be used as a proxy for need. The assumption, here, is that there is an indirect link between death and the need for health care, in that communities with relatively high mortality will also have high morbidity. Chart 30 shows that there are good correlations between mortality and access rates across prefectures in Japan ${ }^{66}$. Access rates are measured by doctors and beds per capita, consultations and admissions per capita, and health expenditure per capita. To a large extent, the uneven geographical distribution of resources and treatments seems to reflect different needs in different prefectures ${ }^{67}$. There is a higher correlation between doctors' consultation rates and the mortality rate $(0.61)$ than there is between doctor's numbers and the mortality rate $(0.44)$. This confirms the inverse relationship of doctors' productivity with their density per capita (see section 3.2.2.2. Activities and Utilisation).

64. At the municipality level, the number of practising doctors per 1000 population in the small municipalities with less than 10 thousand population was less than 1.0, whereas it reached 2.5 in the big municipalities with more than one million population in 1998. Specialists such as ophthalmologists and otorhinolaryngologists are needed in many remote areas.

65. The number of beds per 1000 population ranged from 6.7 in Saitama Prefecture to 19.9 in Kochi Prefecture in 1998. Kochi prefecture, which has the highest number of beds, the highest admission rate and the longest ALOS, has beddays more than three times as large that in Saitama prefecture, which has both the lowest number of beds and the lowest admission rate.

66 It has been suggested that an equitable distribution of health care is one in which the amount of health care received correlates highly with indicators of need (Anderson).

67 Multivariate analysis shows that there is a statistically significant negative relationship between the mortality rate and these resource and activity variables, even after allowing for the income level. 
Chart 30: Mortality rate and access rate across prefectures

Mortality Rate and Doctors

Doctors per 100 thousand population

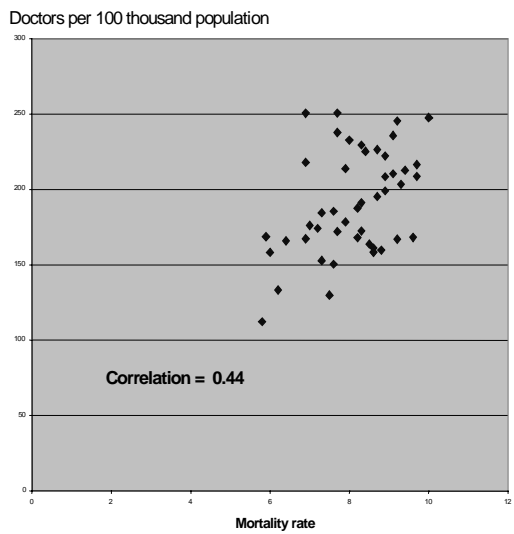

ource: Vital Statistics of Japan 1998
Survey of Phisicians, Dentists and Pharmacists 1998

Mortality Rate and Consultations

Consultations per 100 thousand population*

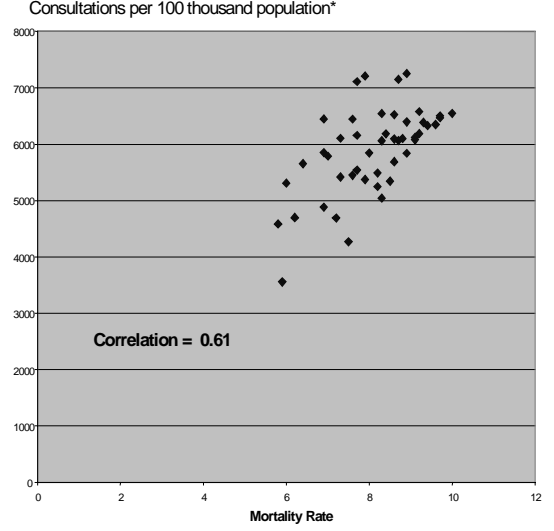

Source: Vital Statistics of Japan 1998
Patient Survey 1996

- Number of patients who received outpatient services on the survey date
Mortality Rate and Beds

Beds per 100 thousand population

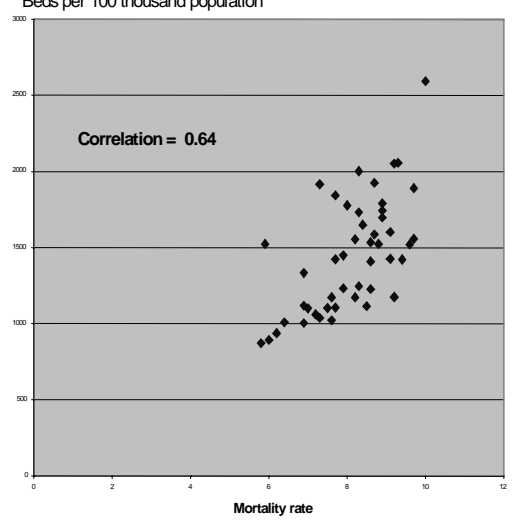

Source: Vital Statistics of Japan 1998
Survey of Medical Institutions 1999

Mortality Rate and Bed days

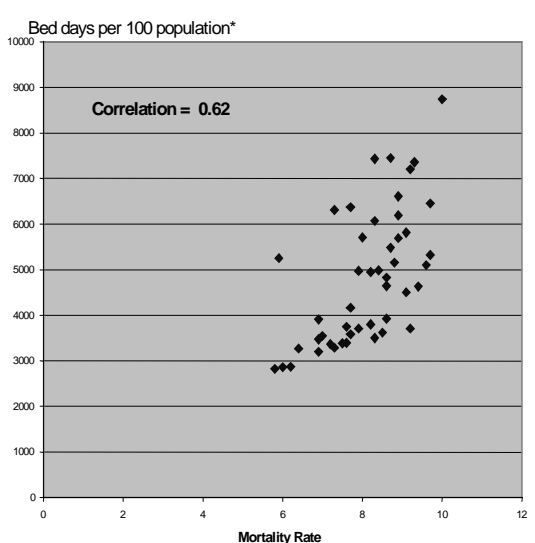

Source: Vital Statistics of Japan 1998

Patient Survey 1996

Mortality Rate and Health Expenditure per capita

Thousand Yen per capita

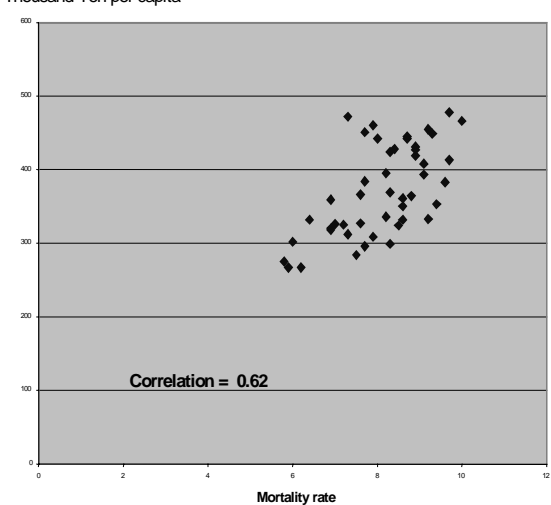

Source: Vital Statistics of Japan 1998

and MHLW, Map on Medical Expenditure of National Health Insurance 1998 
97. Equity of geographical access to health care in Japan is a result mainly of its universal health insurance. However, the functioning of the health insurance system has been reinforced in this respect by the regional medical care plans drawn up by the prefecture governors to rectify the geographical differences in medical resources since 1985, and the Plan for Health and Medical Care for Remote Areas formulated and revised nine times since $1956^{68}$.

68 These plans include comprehensive measures to provide clinics and doctors in remote and rural areas. One example is the measures establishing medical schools in every prefecture and securing living quarters for doctors. 
DEELSA/ELSA/WD(2001)9

\section{CONCLUSIONS AND SOME IDEAS ABOUT FUTURE REFORMS}

98. This paper set out to describe the Japanese health care system and to review its performance in terms of its efficiency and equity.

99. It has been confirmed that Japanese health expenditure is below the expected level for a country with Japan's standard of living. Also, Japan manages with fewer physicians per capita than most OECD countries. Although the health expenditure share of GDP rose quite sharply in the 1990s, that was due mainly to a fall in the historic rate of growth of GDP per capita rather than to a rise in the historic rate of growth of health expenditure per capita. Most of the real rise in health expenditure per capita in the past two decades has been due to a rise in the volume of health care per capita, above that needed to keep pace with the ageing of the population. The relative price of health care has been rather stable. This mix of cost containment and volume growth appears to have been brought about by a combination of: "implicit" global budgeting of public expenditure on health; fee for service incentives for physicians; and strong fee controls.

100. In terms of health care activity, the Japanese health systems displays high levels of consultations with physicians, high levels of prescribing but relatively low admission rates. Consultations per doctor are among the highest in the OECD area. This may be explained by a combination of fee for service payments and relative few doctors per capita. In addition consultations per doctor may be boosted by the fact that doctors dispense as well as prescribe and by the low admission rate.

101. In terms of outcomes, Japanese expectation of life is the highest in the World. However, it is difficult to say to what extent the high and growing volume of health care has been responsible for high health status, as opposed to, say, lifestyle, social and environmental factors. The scraps of evidence gathered for this study do support the idea that health care has played a significant role in bringing about high health status in Japan.

102. The responsiveness to patients of the Japanese health care system may be one of its weaker features. Surveys of patient experience suggest that there is often much waiting for consultations with doctors at big hospitals and that consultations are often brief and uninformative for the patient. Also, there are some reports of low standards of hotel care in hospitals. Nevertheless, Japanese patients seem to be quite satisfied with the care they receive.

103. Turning to equity, the evidence suggests that payment for health care in Japan is slightly regressive, as in many other OECD countries. Meanwhile, treatment appears to be broadly in line with need, at least judging by the geographical distribution of health care.

104. With a rapidly ageing population, reforms in recent years have focused on improving access to health and long term care services by the elderly and on shifting the balance of long term care away from hospitals towards nursing homes and domiciliary settings. These reforms seem to be a highly appropriate response to the challenge of ageing and are already showing signs of success, such as the beginning of a decline in length of stay in general hospitals. 
105. Nevertheless, there appears to be scope for further action to improve the system. Some suggestions follow.

a) Merging existing insurers into larger units

Consideration could be given to merging some of the over 5000 insurers both on grounds of administrative efficiency and on grounds of equity. Each of the insurers maintains an administrative staff that increases costs. Also, the small size of the risk pools introduces inequities in contributions and the need for transfers to prevent deficits arising in funds whose beneficiaries experience greater than average risks. In addition, larger and stronger insurers should be able to play a more effective role as purchasers on behalf of the insured.

b) Rearranging of the co-payment rates

Equity considerations raise questions about the relatively low level of co-payments by the elderly under the Health Service System for the Elderly (the share of co-payments in Health Expenditure for the Elderly was $6.5 \%$ in 1999 , whereas the average level of co-payment share among the non-elderly in the $N M E$ was around 19\%.). Incomes of the elderly have improved since the 1970s when free access to medical care was introduced for the elderly and since the 1980s when the Health Service System for the Elderly (HSSE) started. In addition, there is horizontal inequity in co-payments between insured employees and their dependants that has its origin in the evolutionary development of the Japanese health insurance system. These differentiations have gradually lost their justification.

c) Promoting patient's rights and disseminating information by health service providers

Consideration could be given to promoting patients rights and the dissemination of information by health service providers. Objective evaluation of hospital and nursing home performance by an independent agency should be encouraged and the results made public - for example, made available on the Web. Improved information about the quality of services offered gives a better basis for patients' choice of service providers, thereby promoting competition and functional specialisation among them. In addition, Japanese doctors should be allowed to make public more information on themselves and encouraged to provide more choice between therapies and more explanation to patients.

d) Re-arranging of the policy for doctor provision and remuneration

Consideration could be given to limited relaxation of the control of doctor's numbers with a view to increasing consultation times and raising the quality of patient/doctor interactions. Countries like France, which have public health insurance and doctors paid mainly by fee-for-service seem to achieve longer consultation times by having more doctors per capita than Japan. Such countries also have higher costs. To maintain control of costs, it would probably be necessary to introduce at the same time an element of capitation payments in doctors' remuneration packages, to dampen unwanted volume effects. In any case, experimentation with mixed capitation/bundling/fee-for-service might provide useful insights for policy makers, particularly in terms of care for the elderly.

e) Keeping overall control of public spending on health

It will presumably remain policy to control the rate of growth of health expenditure in Japan, as a longterm objective. Some recent relaxation of payment obligations has had a counter-cyclical role, which 
implies that they should be reversed when (and if) a cyclical recovery occurs ${ }^{69}$. It might be desirable to make the policy of cost containment clearer by adopting an explicit plan, or budget, for public spending on health care.

69 Co-payments by elderly outpatients for drugs medicated by doctors were removed in July 1999, because it was judged that counter-cyclical expenditure was needed (MHLW, 1999 a). 


\section{ANNEX: FURTHER WORK}

This Annex contains suggestions about further work that might be undertaken in Japan and at the OECD to increase our understanding of the performance of the Japanese health system and the reasons for its performing as it does.

a) The most important requirement is to obtain a better understanding of the causes of Japan's high health status and, in particular, the role that health care plays in achieving that. More specially, a better understanding is required of the rate that abundant primary care and relatively low surgery rates play in generating better health.

b) It would be helpful to have data on survival rates following a diagnosis of cancer or survival following a stroke or heart attack.

c) It would be useful to have more information on the morbidity of the Japanese population - to supplement the existing data on mortality. Is it really the case that the health of Japanese people is quite poor compared with some other OECD countries, as responses to the Japanese health interview survey seem to suggest? (MHLW, Basic survey on people's life 1998)

d) It would be useful to know what happens to Japanese people who in other OECD countries would be recommended for non-emergency surgery for common conditions such as cataract and osteoarthritis of the hip?

e) It would be helpful to have evidence of rates of 'adverse events ' (such as serious medication errors leading to the deaths of patients) in Japan.

f) It would be useful to have more information on the responsiveness of the Japanese health system and patient's attitudes towards it. For example, what are the waiting times for non-emergency surgery?

g) It would be useful to have better measures of the productivity of the Japanese health systems in terms of aggregate cost-weighted activity. What is wanted is the ability to construct through time a costweighted index of the major types of activity in the Japanese health system - such as consultations with doctors, admissions to hospitals and long-term bed days. This requires time series data on such activities together with appropriate prices or cost weights. Such an index would be compared with an index of real expenditure or an index of staff employed in producing such activity to yield an index of productivity. If similar work is done across other OECD countries, it will be possible to make rough international comparisons of health system productivity.

h) It would be helpful to have more work on various aspects of the equity of the Japanese health system, especially the fairness of financing of the system and the equity of access to care. For the first, what is needed is better data on the distribution of the main sources of financing across income groups and the calculation of appropriate statistics of equity that would allow equity of financing in Japan to be compared with that in other countries. For the latter, what is needed is more data on the distribution of health services activities across income, gender, age and perhaps ethnic groups. At the same time, 
DEELSA/ELSA/WD(2001)9

evidence on the health status of these groups is required. This would link with the suggestion above about collecting better morbidity data. 


\section{BIBLIOGRAPHY}

\section{$\underline{\text { ENGLISH }}$}

Anderson (1975), Health service distribution and equity, Equity in Health Services, (ed.) Andersen, R. et al., Ballinger, Cambridge Mass.

Campbell, J.C. and Ikegami (1998), N., The art of balance in health policy: Maintaining Japan's low-cost, egalitarian system, Cambridge University.

Carpenter, G.I. (1999), et al., Targeting and quality of nursing home care: a five-nation study, Aging Clin. Exp. Res. 11, 83-89.

Eddy, D.M. (1998), Performance Measurement: Problems and Solutions, Health Affairs,17(4), 7-25.

Elola J., Daponte A., Navarro V. (1995), Health indicators and the organisation of health-care systems in Western Europe, American Journal of Public Health, 85(10); 1397-1405.

Epstein, A. (1995), Performance Reports on Quality - Prototypes, Problems, and Prospects, The New England Journal of Medicine, 333(1), 57-61.

Jeong, H.S. and Gunji, A. (1994), The influence of system factors upon the macro-economic efficiency of health care: implications for the health policies of developing and developed countries, Health Policy, 27.

Grubaugh S.G., Santerre R.E. (1994), Comparing the performance of health-care systems: An alternative approach, Southern Economic Journal, 60(4), 1030-42.

Jacobzone, S. (2000), Pharmaceutical policies in OECD countries: reconciling social and industrial goals, Labour Market and Social Policy Occasional Papers, No. 40, OECD, Paris.

Kawabuchi, K. (1996), Comparison of capital costs in health care between Japan and the united states, Containing Health Care Costs in Japan edited by Ikegami, N. and Campbell, J.C., University of Michigan Press, 73-79.

Murray, C.J.L. and J. Frenk (2000), A framework for assessing the performance of health systems, Bulletin of the World Health Organisation, 78(6).

OECD (1992), The reform of health care: a comparative analysis of seven OECD countries, Health Policy Studies, No.2, Paris.

OECD (1994), Health care reform controlling spending and increasing efficiency, Economics Department Working Papers, No.149, Paris, OECD.

OECD (1995), New directions in health care policy, Health Policy Studies, No.7, Paris. 
OECD (2000), A system of health accounts, Paris.

OECD (2000), Reforms for an ageing society, Paris.

OECD (2000), Performance measurement and performance management in OECD health system, DEELSA/ELSA/WP1(2000)4.

OECD (2000), Development of health status indicators; Self-rated general health in OECD countries, DEELSA/ELSA/WP1(2000)3/ANN1

OECD (2001), Economic Survey of Japan

Or Z. (2000), Determinants of health outcomes in industrialised countries: A pooled, cross-country, timeseries analysis, OECD Economic Studies, no. 30, 2000/1, Paris.

Van Doorslaer, E., et al. (1997), Income-related inequalities in health: some international comparisons, Journal of Health Economics, 16(1), 93-112.

Van Doorslaer, E., Wagstaff, A., et al. (2000), Equity in the delivery in Europe and the US, Journal of Health Economics, 19, 553-583.

Wagstaff, A., Van Doorslaer, E., et al. (1993), Equity in the finance and delivery of health care: an international perspective, Commission of the European Communities, Oxford University Press.

Wagstaff, A., Van Doorslaer, E., et al. (1999), Equity in the finance of health care: some further international comparisons, Journal of Health Economics, 18, 263-290.

WHO (2000), The World Health Report 2000, Health Systems: Improving Performance, Geneva.

\section{JAPANESE}

Endo, H. and Komamura, K. (1999), Equity in the finance of Japanese public medical insurance, The Quarterly of Social Security Research, 35(2), 141-148.

Fukuda, M. (2000), Long-term care as personal social service compared with health care, The Quarterly of Social Security Research, 36(2), 210-223.

Ichizyo, K. (1989), Japanese hospitals, Nihonhyoronsha

Ikeda, S. (2000), Principle of subsidiarity of long-term care insurance, The Quarterly of Social Security Research, 36(2), 200-209.

Jeong, H.S., (1995), Relationship between supply factors of medical care and use of bed, Korean Journal of Policy and Administration, 5(2), 18-34. (in Korean)

Japanese Nurse Association (1997), Report of a survey on long stay in general beds.

Koyama, H. (2000), Fee schedules of the long-term care insurance system, The Quarterly of Social Security Research, 36(2), 224-234. 


\section{DEELSA/ELSA/WD(2001)9}

Ministry of Health, Labour and Welfare (1999 a), Trends in Insurance and Pension (Hokento Nenkinno Doko).

Ministry of Health, Labour and Welfare (1999 b), Trends in People's Health (KokuminEiseino Doko).

Ministry of Health, Labour and Welfare, (1999), Trends in People's Welfare (KokuminnoHukushino Doko).

Ministry of Health, Labour and Welfare, Survey on Income Re-distribution 1996

Ministry of Health, Labour and Welfare, Patient's Survey 1996

Ministry of Health, Labour and Welfare, Patient's Survey 1999

Ministry of Health, Labour and Welfare, Survey on Patient's Behaviour and Satisfaction 1996 (JyuryoKodoChosa)

Ministry of Health, Labour and Welfare, Survey on Patient's Behaviour and Satisfaction 1999 (JyuryoKodoChosa)

Ministry of Health, Labour and Welfare, Survey on Physicians, Dentists and Pharmacists 1998

Ministry of Health, Labour and Welfare, Vital Statistics of Japan 1998

Ministry of Health, Labour and Welfare, Comprehensive Survey of Living Conditions of the People on Health and Welfare 1998

Ministry of Health, Labour and Welfare, Survey on Saving Trends 1998

Ministry of Health, Labour and Welfare, Survey of Medical Institutions 1999

Ministry of Health, Labour and Welfare, Hospital Report 1999

Ministry of Health, Labour and Welfare (2000), National Medical Expenditure 1998

Ministry of Health, Labour and Welfare (2000), Map on Medical Expenditure of National Health Insurance 1998

Ministry of Health, Labour and Welfare, Survey on Health Service Facilities for the Aged (Intermediate Nursing Facilities) 1999 (RojinHokenShisetsuChosa)

Ministry of Health, Labour and Welfare (2000), The current status of long-term insurance scheme in Japan, Room Document submitted to OECD Working Party on Social Policy (October 2000)

Review Committee on Supply and Demand of Doctors (1998.5), The Report on the demand and supply for doctors

Tsugane, S. (1992), Human ecological and epidemiological studies of Japanese immigrants and their descendants in South America, The Journal of Japanese Hygiene (Nippon Eiseigaku Zasshi) 47(4), $775-84$. 